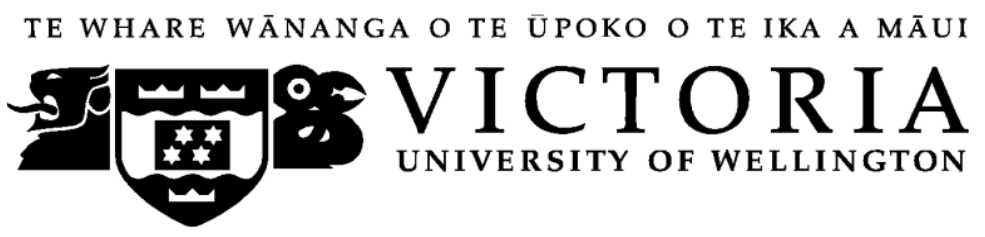

\title{
Managing Consumerization of Personal Cloud Storage: A New Zealand Perspective
}

\author{
MMIM 592 Research Project
}

By

Soklay Ky

Student ID: 300279664

Supervisor: Dr. David Mason

Submitted to the School of Information Management,

Victoria University of Wellington

in partial fulfillment of the requirements for the degree of

Master of Information Management

$6^{\text {th }}$ June 2014 


\section{Preface}

This Report is not confidential.

I would like to acknowledge and express my sincere thanks and gratitude to the following people for their support and guidance that made this research project possible.

- My parents for their upbringing, support and encouragement throughout my life and academic endeavor.

- My beloved wife and daughter for their patience and time for conducting the research and writing up this report.

- My supervisor Dr. David Mason who truly inspired me to embark on this research, and has been very kind, caring and motivating to me throughout the whole project.

- MIM program director Tony Hooper and MIM program administrator Usha Varatharaju for their helpful advice and kind support in facilitating the survey distribution to MIM alumni.

- All the survey respondents and participants in the online focus group for their kindness, valuable time and effort for participating in this research process.

- Last but not least, the New Zealand Government and Tax Payers for funding and offering me an opportunity to pursue this master program under the NZ ASA Scholarship Program (NZ Aid).

I certify that except as noted above, the Report is my own work and all references are accurately reported.

Signature Date 06/06/2014

Soklay Ky 


\begin{abstract}
Employees' behavior of using personal cloud storage at the workplace might put corporates at risk. This trend has been happening globally and known as consumerization of personal cloud storage. This research reports on the state of this trend in New Zealand corporates. A mixed methods approach was employed with data collection through online anonymous surveys and an online focus group. It was found that personal cloud storage prevails widely throughout the corporates involved in the study. In light of earlier studies in IT consumerization and recent market researches on personal cloud storage, this study identifies many drivers, benefits and challenges of IT consumerization which remain significant in personal cloud storage consumerization, and additionally divulges new factors not previously surfaced in prior literature and publications. The results reveals that its challenges far outweigh its benefits and that the driving forces born within organizations are as considerably significant as those in the external environment. Resulting corporate risks such as security, support, regulatory obligations, data governance and policies are top-critical amongst other challenges with which corporates have to confront. Regardless of those challenges, corporates might gain several benefits, namely employee engagement, productivity, business agility and cost benefits to some extent.
\end{abstract}

Keywords: Consumerization, Personal Cloud Storage, Cloud Computing, Information Technology, BYOC 
Table of Contents

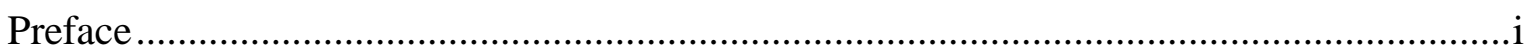

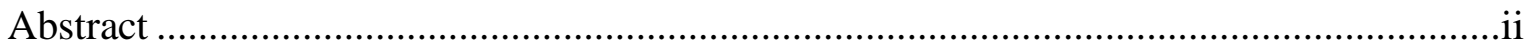

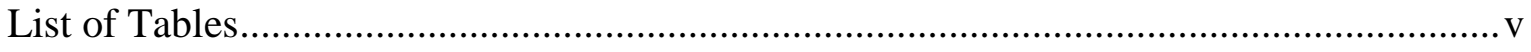

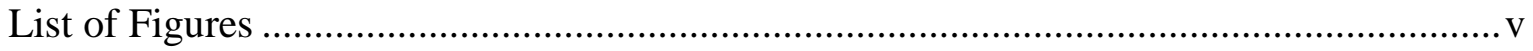

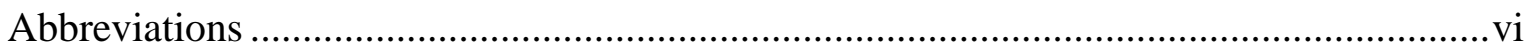

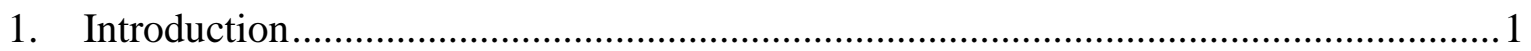

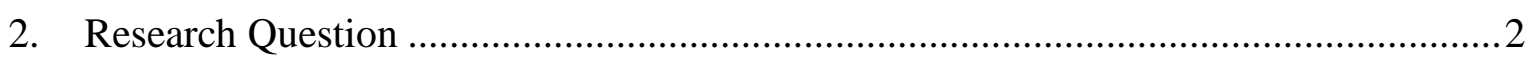

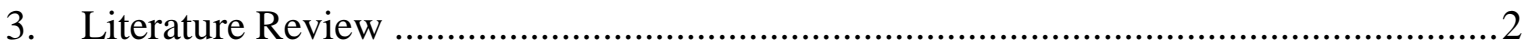

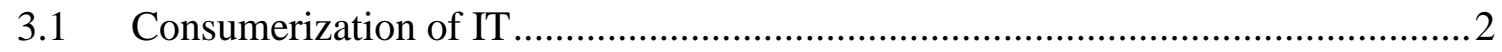

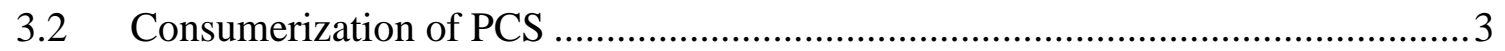

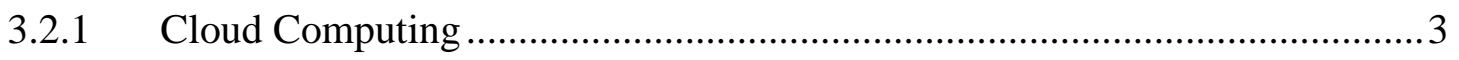

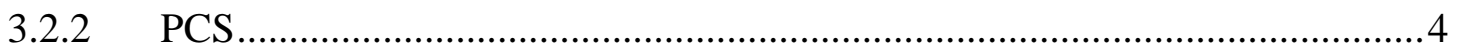

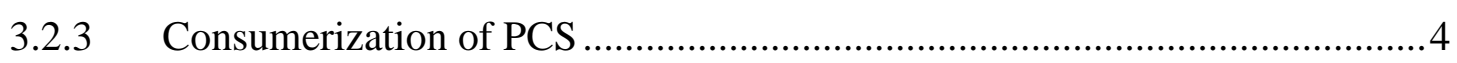

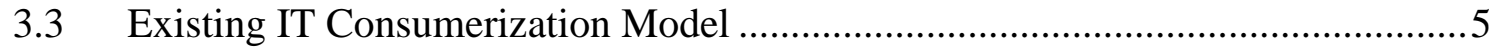

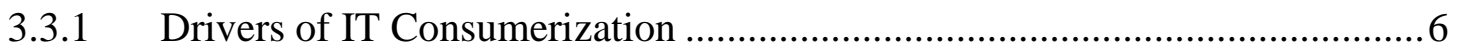

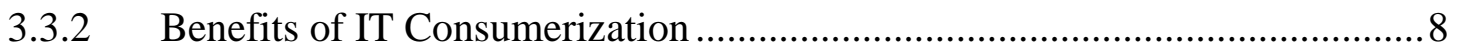

3.3.3 Challenges of IT Consumerization..........................................................

3.4 Extending IT Consumerization Model for PCS ................................................ 10

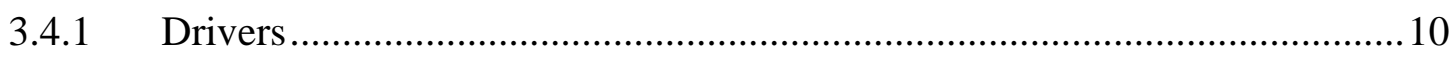

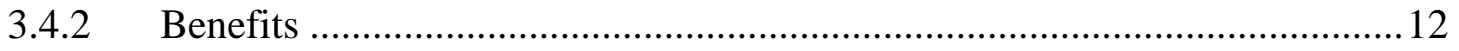

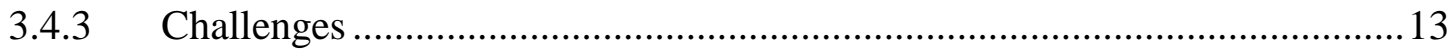

3.4.4 The Conceptual Model of Consumerization of PCS .................................... 15

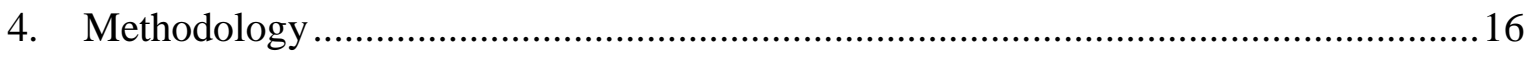

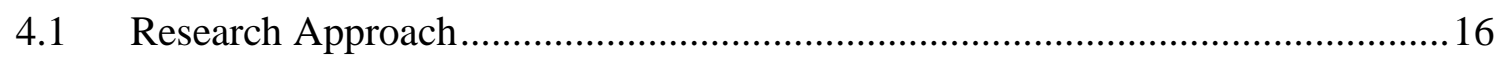

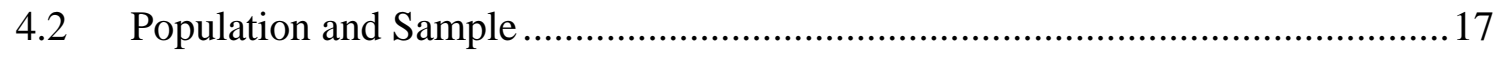

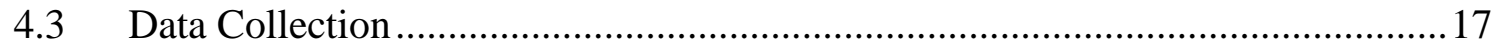

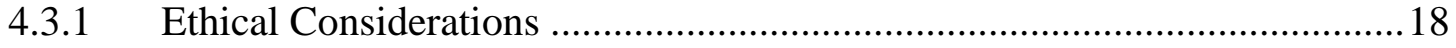

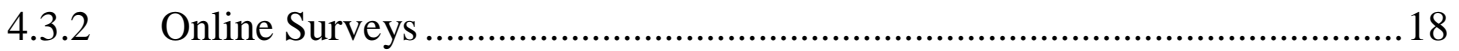

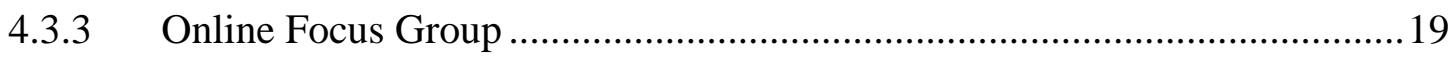




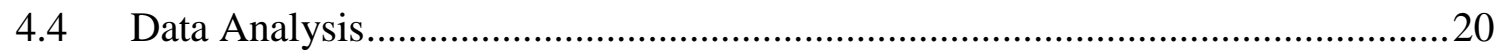

4.4.1 Quantitative Analysis of Survey Data........................................................220

4.4.2 Qualitative Analysis of Focus Group Data ...............................................20

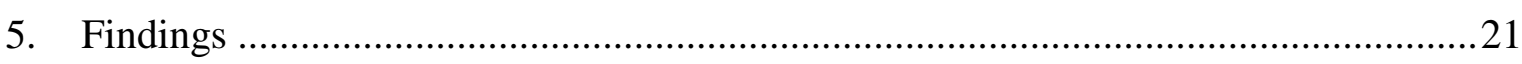

$5.1 \quad$ State of PCS Consumerization in NZ Corporates …........................................22

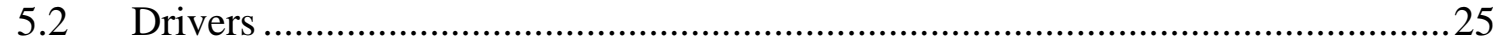

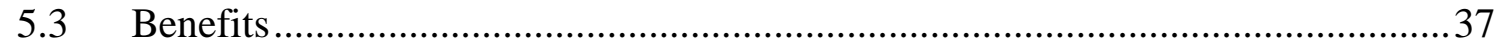

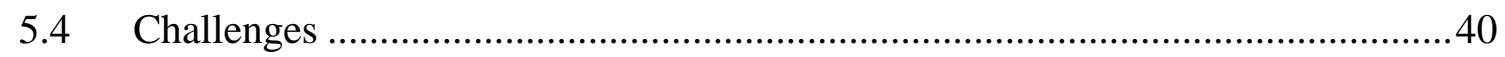

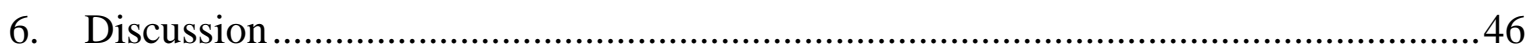

6.1 A Glance at Consumerization of PCS in NZ Corporates ...................................46

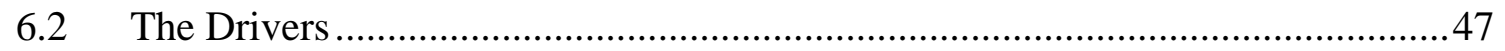

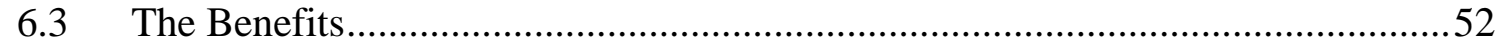

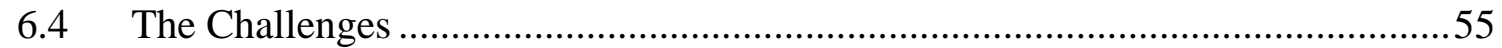

7. Limitations and Implications for Future Research ..................................................59

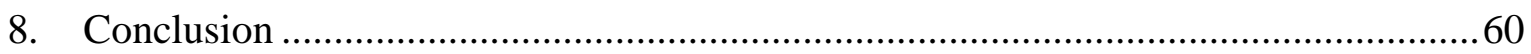

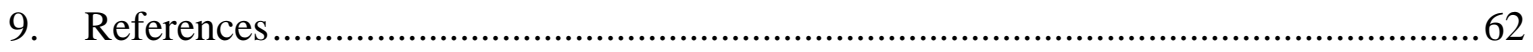

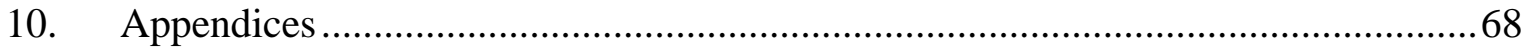

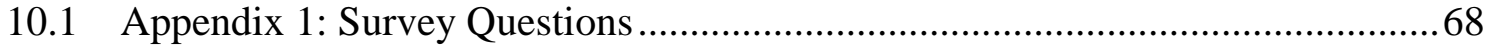

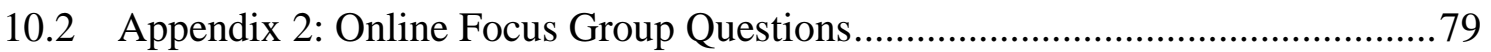

10.3 Appendix 3: Mappings of the Conceptual Model and Survey Questions .............80

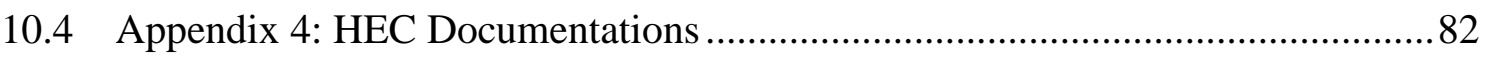

10.5 Appendix 5: Detailed Table of Comparison of Findings and the Literature .........84

10.6 Appendix 6: Summary Table of Comparison of Findings and the Literature .......89 


\section{List of Tables}

Table 3-1: Drivers of IT consumerization (Sen, 2012) 8

Table 3-2: Benefits of IT consumerization (Sen, 2012) 8

Table 3-3: Challenges of IT consumerization (Sen, 2012) 9

Table 3-4 Functionality of PSC 11

Table 3-5: Drivers identified in PCS Consumerization 15

Table 3-6: Benefits identified in PCS Consumerization 15

Table 3-7: Challenges identified in PCS Consumerization 16

Table 4-1 Focus Group Participants 20

Table 5-1: Position demography of respondents in the three surveys 22

Table 5-2: Demography of business size in the three surveys 22

Table 5-3 How did you become aware of the trend for employees to use personal cloud storage for both corporate and private data? 24

Table 5-4 Does your organization have any security training/awareness program about personal cloud storage? $\quad 25$

Table 5-5 Drivers identified from the findings 26

Table 5-6 Corporate benefits identified from the findings 37

Table 5-7 Corporate challenges identified from the findings 41

Table 6-1 Significant Drivers: Comparison of the findings with literature 52

Table 6-2 Significant benefits: Comparison of the findings with literature 55

Table 6-3 Significant challenges: Comparison of the findings with literature 59

\section{List of Figures}

Figure 5-1 Do you use personal cloud storage (e.g. DropBox, iCloud, GoogleDrive, etc.)?

Figure 5-2 How many employees use personal cloud storage (e.g. DropBox, iCloud, GoogleDrive, etc.) in your organization? 23

Figure 5-3 What purposes might your consumers use personal cloud storage for? 23

Figure 5-4 Does your organization have a policy related to personal cloud storage? 25 Figure 5-5 What industry-related factors do you think are driving Personal Cloud Storage in the Workplace?

Figure 5-6 What device factors do you think are driving Personal Cloud Storage in the workplace?

Figure 5-7 What application factors do you think are driving Personal Cloud Storage in the workplace?

Figure 5-8 What behavioral factors do you think are driving Personal Cloud Storage in the workplace?

Figure 5-9 What industry-related factors do you think are driving Personal Cloud Storage in the Workplace?

Figure 5-10 What Benefits can Personal Cloud Storage in the workplace bring to organizations?

Figure 5-11 What Challenges can Personal Cloud Storage in the workplace pose to organizations? 


$\begin{array}{lll}\text { Abbreviations } & \\ \text { CIO } & - & \text { Chief Information Officer } \\ \text { CISO } & - & \text { Chief Information Security Officers } \\ \text { COO } & - & \text { Chief Operational Officers } \\ \text { CTO } & - & \text { Chief Technology Officer } \\ \text { EMP } & - & \text { The Employee Survey } \\ \text { FOC } & - & \text { The Online Focus Group } \\ \text { HEC } & - & \text { Victoria University Human Ethics Committee } \\ \text { InfoSec } & - & \text { Information Security } \\ \text { IP } & - & \text { Intellectual properties } \\ \text { IS } & - & \text { Information system } \\ \text { IT } & - & \text { Information technology } \\ \text { MAN } & - & \text { The Employer Survey } \\ \text { MIM } & - & \text { Master of Information Management Programme, } \\ & - & \text { Victoria University of Wellington } \\ \text { NZ } & - & \text { New Zealand } \\ \text { PCS } & - & \text { Personal cloud storage } \\ \text { PRO } & - & \text { The Cloud Provider Survey }\end{array}$




\section{Introduction}

Personal cloud storage intrudes into the workplace through employees' increasing adoption of personal cloud storage (e.g. DropBox, iCloud and GoogleDrive) for storing and handling their private and corporate data. Approximately three-thirds of the US office workers used personal cloud storage and personal email for storing work data (Stroz Friedberg, 2013). Senior managers commonly fall into this conduct. SafeNet's global study (Seagate, 2013) reported about three out of five global business executives use personal cloud storage to store their private and business data. This proliferation of personal cloud storage in the corporate network might pose severe risks to corporates. Kennada (2013) argues that the real challenge for corporates is not about consumer devices or just tools, but rather it is obviously the corporate data that matters. Gartner predicted that consumers will be storing one third of their digital content in cloud by 2016 (Gartner, 2012); while numerous studies indicated that employees currently store both personal and corporate data in their personal cloud storage and other unregulated consumer devices (Bless, Alanson, \& Noble, 2010; Mullevey, 2013).

This trend of using personal cloud storage by employees at the workplace is called consumerization of personal cloud storage, sometimes known as Bring Your Own Cloud (BYOC) (Conley, 2013; Mitchell, 2013). It is a software form of IT consumerization (the shifting pattern of technology deployment at the workplace away from traditional central control under corporate strategy and policy to bottom-up decision power based on employee choice of technology (Moschella, 2011)). Personal cloud consumerization is a new outbreak of 2013 (Mitchell, 2013), following the well-known IT consumerization of 2012 top-ten IT issues (Grajek \& Pirani, 2012). Although this consumerization issue has been widespread, there has been little attention from corporate executives on it. IDC study pointed out that only $27 \%$ of executives have begun to address IT consumerization issues (Burrus, 2013).This paper describes what consumerization of personal cloud storage is, and reports on the state of consumerization of personal cloud storage in New Zealand corporates. Since consumerization of personal cloud storage is a software form of IT consumerization, this study proposes a new conceptual model based on existing works in IT consumerization and recent literature in personal cloud storage for investigating the significant drivers, benefits and challenges inherent in personal cloud storage consumerization. Hereafter, personal cloud storage will be referred to as PCS. 


\section{Research Question}

There are underlying causes and potential good and bad effects brought by PCS consumerization to New Zealand corporates, of which business executives should beware. Accordingly, this research set out to identify the factors that drive consumerization of PCS, and the resulting benefits and challenges. The main question that this research attempts to answer is "What are the drivers, benefits and challenges of 'Consumerization of Personal Cloud Storage' with respect to New Zealand corporates?"

The question is structured into the following underlying questions.

- What is 'Consumerization of Personal Cloud Storage'?

- What drives it?

- What are its benefits and challenges for corporates?

\section{Literature Review}

\subsection{Consumerization of IT}

From a consumer perspective, IT consumerization is the trend where new information technology both hardware and software first emerges and is privately owned by consumers in the market, and then spreads into business environments (ENISA, 2012). From a corporate perspective, it refers to a changing attitude where employees now make the ultimate decision on choosing the devices, applications and services they use for doing their jobs (Microsoft, 2011). IT consumerization, from a tech-savvy perspective, is a revolution where workers are now self-empowered, capable and willing to invest their own resources to buy, learn and use cutting-edge consumer technologies and application tools to accomplish their work in the workplace (Unisys, 2010). Consumerization of IT is a worldwide trend (van Zant, 2009). Though IT consumerization has been a hot IT issue in the business over the recent years, it has its traditional form manifest over two decades ago (Finnie, as cited in Clevengar, 2011). Traditional IT consumerization began with the introduction of the first personal computers bought by the staff to get around time-shared access to the central system (Madden, 2011). The advent of technology and adoption of consumer technology including smartphones, tablets and internet-based applications into the workplace marked the contemporary IT consumerization (D'Archy, 2011). 
Consumerization of IT is much more than such initiatives as BYOD ("Bring Your Own Device”) or BYOT (“Bring Your Own Technology”) (Madden, 2011; Sen, 2012). First, it has a consumer root (e.g. Facebook and Twitter) and extends the use of enterprise applications to a wide range of business processes both internal employee-facing and external customer/partner-facing processes (Gens, Levitas, \& Segal, 2011). Second, IT consumerization increases users' control over and interaction with enterprise central IT resources, which creates a new model of "Consumer-driven IT" where users themselves drive IT requirements while IT department surrenders their role of a gatekeeper and becomes more of a business enabler (Blount, 2011, p. 5). Third, IT consumerization is more than just a change for an attractive interface on the same old application or adoption of an easy-to-use SaaS application; rather, it recognizes the increasingly permeable boundary between the workplace and the outside world, and meanwhile promotes more direct end-user engagement with the enterprise systems transforming business relationships (Golden, 2011). In addition, IT consumerization is about an influx of consumer-oriented technology and behaviors into the realm of enterprise IT, which will potentially redefine the workplace technology deployment (van Zant, 2009). With their changed expectations on enterprise IT, employees now are bold in justifying their use of consumer technology for work. In other words, they would no longer bear the long approval cycles, support for merely decade-old devices, and the lack of control imposed by the central IT (Blount, 2011).

\subsection{Consumerization of PCS}

\subsubsection{Cloud Computing}

Cloud Computing is an innovative breakthrough in information technology of the $21^{\text {st }}$ century. It was initially known as On-Demand Computing when the new model of computing technology first emerged in late 2002 (Wladawsky-Berger, 2009). Cloud Computing, or generally referred to as Cloud, is "a model for enabling ubiquitous, convenient, on-demand network access to a shared pool of configurable computing resources, for example, networks, servers, storage, applications, and services that can be rapidly provisioned and released with minimal management effort or service provider interaction", according to the definition by the National Institute of Standards and Technology (NIST) (Mell \& Grance, 2011, p. 2). To put it simply, an end user views Cloud Computing as enabling them to share and access applications and resources from 
anywhere in the world on demand as online services via the Internet rather than offline computer access (Buyya, Yeoa, Venugopala, Broberg, \& Brandic, 2009).

\subsubsection{PCS}

NIST categorizes cloud computing services into three basic types: Software as a Service (SaaS), Platform as a Service (PaaS), and Infrastructure as a Service (IaaS) (Mell \& Grance, 2011). A recent development of another new service model of renting storage infrastructure in the cloud introduces another type known as Storage as a Service (StaaS) (Martini \& Choo, 2013; Shelke, Kulkarni, Belsare, Palwe, \& Shinde, 2013). PCS, as it is currently available for consumers, falls into the StaaS type. PCS is simply a cloud service which provides file storage and management capabilities through a cloud environment where users can access their files via the internet from anywhere (Sosa-Sosa \& Hernandez-Ramirez, 2012).

\subsubsection{Consumerization of PCS}

An earlier instance of consumerization of personal storage could be traced back at the time when portable storage devices began to penetrate into workplaces. Personal USB flash drives, portable hard disks, and other portable storage devices have been widely used by employees for storing and transporting both private and corporate data across computers between workplace and home PCs. This trend was further stimulated by the increasingly inexpensive portable storage devices (Cobb, 2007) and the growing huge storage capacity that can accommodate even an entire workspace environment (Leinwand, 2007). A document security survey conducted by FileTrek (2012) found that 55 percent of the surveyed 2,625 workers in the US admitted using a flash drive to transport business data between workplace, home and remote locations. This particular use of portable storage devices generally threatens corporate security including not only data security due to lost or stolen devices (Faas, 2012) but also network security vulnerability of executable malwares and virus spread (Cobb, 2007).

The contemporary consumerization of personal storage moves from a hardware-based to cloud-based form through cloud storage applications, which provides ease of use and better file management functionalities than ever. A wide range of key functionalities that PCS services currently offer include scalable storage capability; access capability(sharing, collaboration, integration, and on-demand access with any device, anywhere, anytime); 
management capability (classification, search, authentication and control); and security capability in storage and transmission (Egnyte, n.d.; Lelii, 2011).

Despite major concern of both the early and current consumerization of PCS about security vulnerability, there has been a rapid rise in its adoption. Gartner (2012) discovered that as of 2011 there existed $7 \%$ of consumer content stored in cloud and approximately 500 million PCS accounts, and predicted over a third of consumer data in cloud by 2016 (Tejada 2013). According to a global survey conducted by Gemalto in $2012,80 \%$ of the respondents wanted PCS and $60 \%$ were willing to pay extra for such services (Tejada 2013). Moreover, SafeNet's survey found 64\% of global business executives admitted to storing personal and professional data in cloud-based applications (Seagate, 2013). This striking trend of PCS penetration into corporates raises considerable challenges for organizations. While D'Archy (2011) warned about security vulnerability of increasing IT bypass of employees' self-provision of third-party cloud services for storing sensitive corporate data in cloud; Junglas and Harris (2013) suggested the availability of cloud-based data and applications rapidly opens up opportunities for value creation, increasing worker productivity regardless of time and location with minimal investment upfront.

Literature shows the close link between IT consumerization and cloud computing through their mutual effect. For some, cloud computing is an enabler of consumerization of applications, which creates a "Bring Your Own App" movement (Cheston, 2012; Rodrigues, 2013). For others, IT consumerization is precursor to cloud computing which creates the next enterprise wave of PCS consumerization (Kaplan, 2012; Mitchell, 2013). Through this effect relationship, this research extends the IT consumerization model to incorporate PCS as software consumerization. Therefore, a conceptual model of Consumerization of PCS for this study is proposed to incorporate the common drivers, benefits and challenges of existing IT Consumerization Model, mainly a recent work by Sen (2012), and additional factors identified from recent literature in PCS.

\subsection{Existing IT Consumerization Model}

Many literature works investigated the state of IT consumerization, and particularly Sen (2012) focused on New Zealand corporates. This provides a model for subsequent studies in the consumerization trend. While many of the previous publications are from market 
research, an academic approach of Sen (2012) was conducted with a guiding literature review and a qualitative method of investigation. This section briefly reviews the components of IT Consumerization Model: Drivers, Benefits and Challenges.

\subsubsection{Drivers of IT Consumerization}

General Industry Factors: The advent of supportive telecommunication infrastructure, e.g. widely available and reliable Internet of home and mobile broadband has been a core driver of IT consumerization (Bless et al., 2010). This trend was boosted by the price drop of both Internet (Sen, 2012) and consumer devices (smartphones and tablets), which has become more affordable to a wider population of low-end consumers (Clevengar, 2011).

Consumer Device Factors: Consumer devices such as iPads are so disruptive technology that they have made IT consumerization commonplace; for instance, the proliferation of iPhones and tablets in the personal usage space, as well as the fast, vast uptake of enterprise iPads by $80 \%$ of Fortune 100 companies (Clevengar, 2011). Other than this phenomenon, consumer devices are designed to be highly attractive (Clevengar, 2011), super high in processing power (Blount, 2011), rich in functionalities (Golden, 2011), and capable of both information consumption and creation (Clevengar, 2011); which hugely influence the consumerization trend. In addition, IT consumerization is characterized by the fact that smartphones and tablets are always with us without needing to turn off (Sen, 2012), and are eco-friendly due to their smaller footprint compared to desktop PCs (Blount, 2011).

Consumer Application Factors: IT consumerization is considerably driven by the richness and diversity of consumer software, commonly known as mobile apps, which has satisfied the increasing demands of users (Clevengar, 2011). Such demands as work collaboration and interaction with virtual communities are fulfilled by collaborative and social computing apps (D'Archy, 2011; Prete et al., 2011). Importantly, a Freemium model of mobile apps has become an attractive licensing scheme that facilitates the consumerization (Woodward, 2011).

Consumer Behavior Factors: IT consumerization is strongly determined by the blurring work and home lives of workers nowadays (Blount, 2011; D'Archy, 2011), as well as the increasing tendency of mobility of both employees and customers (Gens et al., 2011; Prete et al., 2011); in other words, there is no longer a pre-determined physical place for work. 
Moreover, another driving force is the changing expectations of customers and tech-savvy employees who expect not only more freedom of corporate technology but also modern technology denoting their fashion, status and curiosity (Sen, 2012).

Corporate Factors: IT consumerization is pushed by a significant trend of business externality where corporates exploit such innovative technology as cloud computing to create partner eco-systems as a means for reducing cost by outsourcing non-core functions and for extending business outreach to customers, suppliers, distributors, and other strategic partners (Blount, 2011). Inside corporates, the increasing population of young employees who are digital natives and demanding for innovative new technology is a contributing factor to IT consumerization (Bernnat, Acker, Bieber, \& Johnson, 2011). Moreover, business leaders in an average age are another driving force as they are young and have strong decision power on new technology (Sen, 2012).

Table 3-1 lists the drivers identified in IT consumerization model with recognition levels.

\begin{tabular}{lcc}
\hline \multicolumn{1}{c}{ DRIVERS } & & \\
\hline \multicolumn{1}{c}{ Drivers Identified } & Recognition & Group \\
$\begin{array}{l}\text { Telecommunications-infrastructure and general } \\
\text { affordability }\end{array}$ & High & $\begin{array}{c}\text { General, } \\
\text { Industry-Wide }\end{array}$ \\
\hline $\begin{array}{l}\text { Consumer devices as disruptive technology } \\
\text { Processing power of consumer devices }\end{array}$ & High & $\begin{array}{c}\text { Consumer } \\
\text { Devices }\end{array}$ \\
$\begin{array}{l}\text { Usage factor of consumer devices } \\
\text { Form factor of consumer devices }\end{array}$ & High & \\
$\begin{array}{l}\text { Ecological factor of consumer devices } \\
\text { Always-on feature of consumer devices }\end{array}$ & Medium & \\
\hline Consumer applications driving consumerization & Medium & \\
Attractive licensing models & Medium & \\
Collaboration and social computing tools & Low & Consumer \\
\hline Blurring of work and home & Low & Applications \\
Increasing mobility of customers and employees & High & \\
$\begin{array}{l}\text { Workplace expectation of customers and employees are } \\
\text { changing }\end{array}$ & High & $\begin{array}{l}\text { Consumer } \\
\text { Fehaviour }\end{array}$ \\
\hline Fashion, status and curiosity & Medium & \\
\hline
\end{tabular}


Externalization of businesses, cloud computing and partner eco systems

Employees from younger generation and digital natives

Average age of leadership
Corporate
Medium $\quad$ Factors

Low

High

Table 3-1: Drivers of IT consumerization (Sen, 2012)

\subsubsection{Benefits of IT Consumerization}

IT consumerization might bring several benefits to corporates. Major benefits are derived from acceleration of business growth (Moschella, 2011) and increased employee productivity (Clevengar, 2011). Businesses that accommodate IT consumerization are harnessing such opportunities as innovative information access; fast decision making processes; breakdown of traditional cost, geographical and technological barriers (Moschella, 2011); better trust relationship between employees and employers (Bernnat et al., 2011); new creative behaviors and skills contributed by employees (Sen, 2012); and access to new bottom-up innovative technology initiatives from employees (Clevengar, 2011). In addition to cost reduction through employees' own investment on their devices, Sen (2012) underscored two other benefits: standardization in workplace enforced by consumer vendors; and improved personal learning environments for employees finding new skills through social networking.

Table 3-2 outlines the benefits in IT consumerization model with recognition levels.

\section{BENEFITS}

\section{Benefits Identified}

Accelerates business growth

Productivity through employees bringing in new technology

Employee productivity through trust

Productivity through employees bringing in consumer behaviour and skills

Standardisation enforced by consumer vendors

Finding newer skills through social networking websites

Cost benefits

\section{Recognition}

High

Low

Medium

High

Medium

Low

Low

Table 3-2: Benefits of IT consumerization (Sen, 2012) 


\subsubsection{Challenges of IT Consumerization}

Corporates might face many challenges as a consequence of IT consumerization. Five major challenges include: 1) security issues (data leak, compliance with data and security standards, privacy, system hack, and virus spread) (Bernnat et al., 2011; Blount, 2011); 2) greater workload for IT department in supporting and controlling individual consumer devices (Blount, 2011; D'Archy, 2011); 3) regulatory obligations and liability to organizations resulting from employee violation of copyrights and licenses (Bernnat et al., 2011; Moschella, 2011); 4) immaturity of consumer technologies thanks to no proven incentives for organizations to consumerize those technologies (Sen, 2012); and 5) economic downturn which hinders consumerization initiatives (Sen, 2012).

Additionally, three moderate challenges are: 1) the need for changing corporate policy (Microsoft, 2011); 2) organization-wide relations and expectations (business and IT, technology adoption pattern between industries, consumer and vendors, business and consumers, and employee needs and talent retention) (Blount, 2011; D'Archy, 2011; Moschella, 2011; van Zant, 2009); and 3) cost constraints and uncertainty related to changes in corporate infrastructure and support and maintenance in accommodating consumer devices (Bernnat et al., 2011).

Table 3-3 lists the challenges found in IT consumerization model with recognition levels.

\section{Challenges}

\begin{tabular}{lc}
\hline \multicolumn{1}{c}{ Challenges Identified } & Recognition \\
Immaturity of consumer technologies & High \\
Cost constraints and uncertain cost boundaries & Medium \\
Economic downturn & High \\
Security challenges & High \\
Challenges in support and control & High \\
Challenges around evolving relations and expectations & Low \\
Changing policy needs & Medium \\
Regulatory obligations & High \\
\hline
\end{tabular}

Table 3-3: Challenges of IT consumerization (Sen, 2012) 


\subsection{Extending IT Consumerization Model for PCS}

This section attempts to develop a conceptual model of PCS consumerization for this study by including additional factors from literature in the PCS area into the above model of IT consumerization. Numerous literature works, mainly from recent professional and practitioner sources, shed light on PCS consumerization, unfolding several other drivers, benefits and challenges as follows.

\subsubsection{Drivers}

Superior Application Usability: Many studies found that the usability factor of PCS, which considerably outperforms the legacy enterprise systems significantly, drives PCS consumerization. Based on Technology Acceptant Model (TAM), ease of use and usefulness are key determinants of user behavior to use and continue using technology (Venkatesh \& Bala, 2008). Employees grew their dissatisfaction with internal IT infrastructure and resorted to uncontrollably use private devices and applications (Weiß \& Leimeister, 2012). Modern cloud storage services are easier to learn and more convenient to use and manage data, which is central to user adoption (Junglas \& Harris, 2013; Mitchell, 2013; Sheldon, 2011; Tejada 2013). A variety of functionalities which promotes user uptake of PCS include: infinite access (Mokros, 2013; Rigsby, 2011); document management and collaboration (Mokros, 2013; Sheldon, 2011; Tejada 2013); secured backup (Mokros, 2013; Tejada 2013); and unrestricted usability (Mitchell, 2013). Table 3-4 describes these functionalities in detail. Transparency Market Research's report on the global personal cloud market (2013-2019) pointed out that demand for efficient storage and increased volume and frequency of data sharing and access are two of the major driving forces of PCS adoption (Seagate, 2013). With such convenience and superior functionalities that PCS services currently offer, employees are increasingly motivated, satisfied and enjoyed in leveraging PCS for doing their jobs at the workplace. This factor supersedes the Consumer Applications Driving Consumerization, and will be used in the conceptual model, instead.

\begin{tabular}{lll}
\hline Functionality & Description & Literature \\
\hline Infinite access & $\begin{array}{l}\text { Access with any devices, anywhere and } \\
\text { anytime }\end{array}$ & $\begin{array}{l}\text { (Mokros, 2013; Rigsby, } \\
2011) ;\end{array}$ \\
\hline Document management & File sync, share and collaborative access & (Mokros, 2013; Sheldon, \\
\cline { 2 - 3 }
\end{tabular}




\begin{tabular}{lll}
\hline $\begin{array}{l}\text { and collaboration } \\
\text { Secured backup }\end{array}$ & $\begin{array}{l}\text { Backup protecting from hardware crashes } \\
\text { and theft }\end{array}$ & $\begin{array}{l}\text { (Mokros, 2013; Tejada } \\
\text { 2013) }\end{array}$ \\
\hline Unrestricted usability & $\begin{array}{l}\text { No restriction for transporting huge files } \\
\text { and types of files constrained by general } \\
\text { email systems and internal IT rules }\end{array}$ & (Mitchell, 2013) \\
\hline
\end{tabular}

Table 3-4 Functionality of PSC

Cloud Bundle: The tendency of PCS consumerization is significantly influenced by another popular trend that major consumer-hardware vendors employ a marketing strategy of bundling cloud storage services with devices. AMI Partners' research into the small and medium-size business market found that mobile workers drove demand for bundled cloud storage services (Engebretson, 2011). In 2011, Apple first took a lead in a business model of iCloud storage bundle with Apple devices (Norman, 2011). Deemed to be strategic in capturing market segments, consumer-device vendor Samsung and cloud provider DropBox jointly offered a bundle scheme of Samsung smartphones with free DropBox storage (Steger, 2012). Thereafter, this example was followed by other big players, namely Google (Motorola) and Microsoft (Nokia) (Stanley, 2013). This simply increases PCS adoption as a result of having the service readily embedded within consumer devices.

Plurality of Devices: People's tendency and desire to own many devices apparently contributes to consumerization of PCS. Cloud applications become key to users who own multiple devices (desktops, laptops, smartphones, and tablets) for solving their problems of hardware dependence; device interoperability; and data transport across devices (Douglas \& Katz, 2013). (Unisys, 2010) research revealed that an iWorker owns four devices on average. Another study by Gartner in 2012 looking at general consumers found that users commonly owned many devices with an average of 2.8 devices, and this figure was predicted to grow to 3.3 devices by 2014 (Cheston, 2012). Importantly, the nature of cloud applications that helps get rid of hardware and software dependency is driving the consumerization of PCS (Cheston, 2012).

Network Externality: Network externality posits that network effects influence individuals to adopt new technology (Wattal, Rachera, \& Mandviwalla, 2010). For instance, an individual chooses to use DropBox because her network, group or peers are using it, too. Rodrigues (2012) regarded network effects as de facto standards and argued that the adoption of cloud services or tools is no different from its predecessors of widely 
used social networks (e.g. Facebook) and traditional software (e.g. Microsoft Windows) in a way that because everyone knows it and so many people use it. It is therefore an effect of network externality that triggers employee behavior in following the adoption and usage pattern of PCS within their everyday and work environments.

\subsubsection{Benefits}

Three additional benefits were discussed in PCS consumerization in enterprises. Those benefits are employee engagement and retention; innovation; and competitive advantage and agility.

Employee Engagement and Retention: To top-performing organizations, employee engagement is a core corporate strategy contributing to business outcomes (Gallup, 2010). Schmidt et al. (1993) regarded employee engagement as a modernization of employee satisfaction, defining it as "an employee's involvement with, commitment to, and satisfaction with work. Employee engagement is a part of employee retention." (as quoted in Swarnalatha \& Prasanna, 2013, p. 53). Gallup's 2010 research estimated an annual cost of $\$ 370$ billion to productivity loss in the US economy resulting from disengaged employees (McGrath \& Freed, 2012). Numerous literature works supported that employee satisfaction increases considerably with provisions for them of devices and tools they want (Burrus, 2013; Caldwell, Zeltmann, \& Griffin, 2012; Junglas \& Harris, 2013), and that tech-savvy employees feel empowered when using state-of-the-art devices and applications which offer a user-experience breakthrough and fulfill their expectations about corporate IT (Burrus, 2013; Conley, 2013; Unisys, 2010). Intel's study found 83\% of tech-savvy workers feel being a more valuable employee when knowing a wide range of technologies (Bless et al., 2010). While Unisys (2010) agreed that consumer-powered IT may unleash a potential for more workforce engagement and productivity; Bless et al. (2010), Cheston (2012), Junglas and Harris (2013) supported that it makes employees more satisfied, constantly engages them with their jobs, attracts top talent; or otherwise failure to fulfill such needs means risking alienation and loss of valuable employees and finally upsetting business success. Therefore, PCS consumerization, as a form of software consumerization, has a key role in helping organizations constantly engage and effective retain valuable employees. 
Innovation: PCS consumerization may channel external innovation through employees into corporates. New technology that employees bring into workplaces can be a huge business use, and potential value co-creation is promising for organizations (Burrus, 2013). An increased ability in creating new innovative products and services is one in a series of major business values that organizations can accomplish by aligning cloud services with critical business applications and employee preferences (CXOtoday, 2013). Consumer technology drives employee creativity into business processes by providing them with various ways to use consumer tools to approach, tackle and solve problems (Junglas \& Harris, 2013). A recent survey across Asia, Europe, and the Americas showed that $50 \%$ of full-time employees on average agreed on working more innovatively provided they use their own hardware and software, and this rate rose between $70-78 \%$ for China, India, and Mexico (Junglas \& Harris, 2013). Unisys (2010) claimed that bottom-up initiatives of new ideas and innovation unleashed by consumer technology is driving the fourth wave of today's corporate productivity.

Competitive Advantage and Agility: PCS consumerization can help organizations develop business agility and sustain competitive advantage. Organizations can find competitive advantage through empowering employees with the latest and greatest technologies (Microsoft, 2011). Forrester's 2011 study showed that $83 \%$ of IT decisionmakers regarded the effect of IT consumerization as mostly positive (Microsoft, 2011). Consumer technology is a huge pool of resources in the market where everyone can access; therefore, organizations that do not stay ahead of this trend will not only miss out rare opportunities, but also lose their competitive edge (Andriole, 2012; Blount, 2011). Moreover, it provides corporates with greater business agility (Burrus, 2013); organizational flexibility (Unisys, 2010); IT flexibility (Blount, 2011); and employee enthusiasm (Junglas \& Harris, 2013) as tools to compete and leapfrog competitors in the current ultrafast moving market and technology trend. It is, thus, essential that corporates leverage the advantages, flexibility and innovative functionality that consumer technology like PCS to innovate their business processes for positioning them on a competitive edge.

\subsubsection{Challenges}

Literature in PCS brought up two issues as significant challenges posed by PCS consumerization — cloud service management and integration, and service degradation. 
Cloud Service Management and Integration: CIOs are currently challenged by the dilemma of ease of use versus security. The practice where employees use a variety of PCS services (e.g. Dropbox, GoogleDrive, iCloud, OneDrive, etc.) to handle business data has imposed a real hardship on IT department in managing and integrating both data and services. Although known to be secured, PCS providers are apparently not liable to corporate data confidentiality (Mitchell, 2013). Users interact with a unified layer of cloud services, but the physical data may either be scattering across the globe or be lying under vulnerable security regimes without the knowledge of users (Mitchell, 2013). Employees consuming tools and services from different providers may end up with information fragmentation and unstandardized applications, causing adverse problems in data management (Schaffhauser, 2013). Therefore, in order to ensure that corporate applications interact with cloud services with sound data management, information exchange and integration, it requires IT department's efforts in integrating multiple PCS services to work smoothly in a unified corporate environment (Mitchell, 2013).

Service Degradation: PCS consumerization may create possible service degradation in terms of service delivery problems and network performance degradation. Providers commonly offer a service level agreement (SLA) which ensures robust, reliable and resilient service delivery to users. However, different service providers has different policies and rules (Conley, 2013) and in most cases those SLAs are vague and openended, which fails to hold them liable for quality of service (QoS) (Connor, Corrigan, \& Bagley, 2011). Even prominent providers such as Amazon, Microsoft, Google, Apple, DropBox, CloudFlare, Verizon, and Yahoo also had their cloud services repeatedly experienced with significant outages from several minutes, hours to days; which caused business operation halt, customer frustration, productivity loss, and monetary loss in their client businesses (Raphael, 2013a, 2013b). Furthermore, network performance and availability are another common critical consideration for cloud storage implementation (Mullevey, 2013). Drago et al. (2012)'s technical investigation into well-known DropBox proved possible network performance bottlenecks. Due to its huge bandwidth and Internet traffic consumption, cloud storage may require high-speed dedicated link; otherwise, users may experience considerable transmission latency and network disruption (Connor et al., 2011; Drago et al., 2012). Thus, inclusion of PCS into the corporate network could fail to ensure efficient and effective service delivery and network performance. 


\subsubsection{The Conceptual Model of Consumerization of PCS}

The literature review concluded with the new conceptual model of PCS Consumerization, synthesizing the existing model of IT consumerization with the newly identified components from the literature in PCS. Table 3-5, Table 3-6, and Table 3-7 exhibit all the drivers, benefits and challenges of consumerization of PCS, respectively.

\section{DRIVERS}

\begin{tabular}{|c|c|c|}
\hline HIGH & MEDIUM & Low \\
\hline $\begin{array}{l}\text { Telecommunications-infrastructure } \\
\text { and general affordability }\end{array}$ & $\begin{array}{l}\text { Workplace expectation of } \\
\text { customers and employees are } \\
\text { changing }\end{array}$ & $\begin{array}{l}\text { Employees from younger } \\
\text { generation and digital } \\
\text { natives }\end{array}$ \\
\hline $\begin{array}{l}\text { Consumer devices as disruptive } \\
\text { technology }\end{array}$ & $\begin{array}{l}\text { Externalization of businesses, cloud } \\
\text { computing and partner eco systems }\end{array}$ & $\begin{array}{l}\text { Attractive licensing } \\
\text { models }\end{array}$ \\
\hline $\begin{array}{l}\text { Processing power of consumer } \\
\text { devices }\end{array}$ & Usage factor of consumer devices & \\
\hline Superior application usability & Form factor of consumer devices & \\
\hline $\begin{array}{l}\text { Collaboration and social computing } \\
\text { tools }\end{array}$ & $\begin{array}{l}\text { Ecological factor of consumer } \\
\text { devices }\end{array}$ & \\
\hline Cloud bundle & $\begin{array}{l}\text { Always-on feature of consumer } \\
\text { devices }\end{array}$ & \\
\hline Blurring of work and home & $\begin{array}{l}\text { Increasing mobility of customers } \\
\text { and employees }\end{array}$ & \\
\hline Plurality of devices & Fashion, status and curiosity & \\
\hline Average age of leadership & Network externality & \\
\hline
\end{tabular}

BENEFITS

\begin{tabular}{lll}
\hline \multicolumn{1}{c}{ HIGH } & \multicolumn{1}{c}{ MEDIUM } & \multicolumn{1}{c}{ Low } \\
$\begin{array}{l}\text { Productivity through employees } \\
\text { bringing in consumer behaviour } \\
\text { and skills }\end{array}$ & $\begin{array}{l}\text { Employee productivity through } \\
\text { trust }\end{array}$ & $\begin{array}{l}\text { Productivity through } \\
\text { employees bringing in new } \\
\text { technology }\end{array}$ \\
$\begin{array}{l}\text { Employee engagement and } \\
\text { retention }\end{array}$ & $\begin{array}{l}\text { Standardisation enforced by } \\
\text { consumer vendors }\end{array}$ & $\begin{array}{l}\text { Finding newer skills through } \\
\text { social networking websites } \\
\text { Accelerates business growth }\end{array}$ \\
$\begin{array}{l}\text { Innovation } \\
\text { Competitive advantage and agility }\end{array}$ & & \\
\hline
\end{tabular}

Table 3-6: Benefits identified in PCS Consumerization 


\section{Challenges}

\begin{tabular}{lll}
\hline \multicolumn{1}{c}{ HIGH } & \multicolumn{1}{c}{ MEDIUM } & \multicolumn{1}{c}{ LOW } \\
$\begin{array}{l}\text { Immaturity of consumer } \\
\text { technologies }\end{array}$ & $\begin{array}{l}\text { Cost constraints and uncertain } \\
\text { cost boundaries } \\
\text { Economic downturn }\end{array}$ & $\begin{array}{l}\text { Challenges around evolving } \\
\text { Celations and expectations }\end{array}$ \\
Challenges in support and control & $\begin{array}{l}\text { Cloud service management and } \\
\text { integration }\end{array}$ & \\
Security challenges & & \\
Regulatory obligations & & \\
Service degradation & & \\
\hline
\end{tabular}

Table 3-7: Challenges identified in PCS Consumerization

\section{Methodology}

\subsection{Research Approach}

Many previous researches (Junglas \& Harris, 2013; Seagate, 2013; Stroz Friedberg, 2013; Tejada 2013) adopted a quantitative approach using survey questionnaires to obtain objective responses for their national and global studies in investigating and informing about the PSC trend. A qualitative approach was employed by fewer researchers, e.g. Sen (2012). This study makes use of a mixed-methods approach through combining both quantitative and qualitative strategies. It enables researchers to harness the strengths of both strategies, filling in the gaps of one another (Bryman \& Bell, 2011). On the one hand, such strengths of quantitative research methods can be captured: i) greater objectivity and accuracy of results with the use of scientific quantitative analysis and measurement techniques (Lee, 1992); ii) a broader study involving a larger representative sample, which enhances generalizability of findings (Sekaran \& Bougie, 2010); and iii) reduction on personal biases against intrusion of special characteristics, expectations or values of researchers, which enhances replicability of findings (Bryman \& Bell, 2011). On the other hand, this research approach draws on such key strengths of qualitative research methods as emphasis on contextual understanding and the meaning of action (Bryman \& Bell, 2011); and in-depth exploration into the research subject, especially new subjects like this study (Myers, 2008). More importantly, not only has mixed method research been particularly popular in business and management areas, but it also allows multi-methods 
triangulation which improves research validity (Bryman \& Bell, 2011). This, therefore, is aligned with the objective of this research for basing on prior literature works in both IT consumerization and PCS to explore the state of PCS consumerization in the NZ context.

\subsection{Population and Sample}

The population for the study comprises three participant groups: employees working for NZ businesses, employers and PCS providers. This research employed a convenience sampling, a method for selecting a sample population based on respondents accessible by the researcher, and this technique has been very common and more prominent in the fields of business and management (Bryman \& Bell, 2011). Samples for the surveys were taken from three data sources: the researcher's professional network LinkedIn; the contact database of student alumni of Master of Information Management (MIM); and the contact from Cloud Storage Review (www.top-10-online-backups.com). 400 respondents (MIM alumni and LinkedIn) who are employees in NZ private and public sectors represented the employee sample. The employer sample comprised 150 respondents taken from LinkedIn, who possess managerial positions, namely CIOs, CTOs, CISOs, and IT consultants in NZ corporates. Finally, the cloud provider sample was taken from 30 representative respondents of PCS companies in the Cloud Storage Review contact. The employer group was the target sample for a focus group. This sampling was random in four professional communities in LinkedIn: CIO Forum, Information Security Community, Information Management Group, and Information Technology Forum.

\subsection{Data Collection}

As a mixed-methods approach suggests, this study employed two methods of data collection, namely online anonymous surveys and an online focus group. Triangulation denotes the use of multiple research methods or data sources in examining a research subject (Bryman \& Bell, 2011). At the method level, this study employed Hammersley's (1996) method triangulation approach to mixed-methods research (as cited in Bryman \& Bell, 2011), which collaborates between quantitative (the survey) and qualitative (the focus group) research findings. At a further level, data-source triangulation denotes a cross examination of multiple data sources of the same phenomenon, possibly deriving from one or more of triangulation types: different phases of the fieldwork, different points of time, or different accounts of participants from various settings (Atkinson \& Hammersley, 
2007). Administering separate surveys to the above three sample groups enables cross check of the survey findings from three perspectives: employees, employers and cloud providers. This triangulation is useful for the research since it helps the researcher to be more confident in the results through cross-findings examination, less reliance on a single source, and multiple deviant dimensions of a phenomenon (Yeasmin \& Rahman, 2012).

\subsubsection{Ethical Considerations}

Conforming to the human ethics process of Victoria University of Wellington, the data collection commenced after the approval from the university HEC on $30^{\text {th }}$ January 2014. The surveys and online focus group ran from $11^{\text {th }}$ February to $20^{\text {th }}$ March 2014. Each participant was provided with a participant information sheet attached with the invitation email and at the home page. The participant information sheet described the research's purpose, assured participants of the confidentiality of their responses, and stated participant's right to withdraw from the research in case of the online focus group, before data analysis began. By informing participants at the homepage, electronic consent was implied by taking the survey and joining discussions in the focus group.

\subsubsection{Online Surveys}

Survey Design: The surveys were built using Qualtrics online platform. Respondents accessed the surveys through a URL link within the email invitation. The surveys used a forced four-point Likert scale (None, Low, Medium and High) identified from the literature review, which determines the recognition level on a factor or statement. Respondents were asked to rate each statement based on their recognition level. Multiple-choice questions were also used to investigate other areas. In addition, a freeform question was supplied in each section of the surveys for obtaining clarity and additional information.

Three surveys were prepared separately for the three samples. Each survey contained five sections with minor variation of questions targeting specific issues about each sample. Sections 1 to 4, which correspond to the research questions, inquire respondents about the current state of PCS consumerization, the factors driving its uptake and the benefits and challenges posed to organizations, respectively. Section 5 attempts to identify the respondent demography (position level and organization size). This allows the findings to represent diversity in the respondent organizational hierarchy and business size, which 
better represents the actual population. Appendix 1 illustrates the survey contents, and the mappings of survey questions and the conceptual model is exhibited in Appendix 3.

Response Rate: The survey participation was both anonymous and voluntary. The responses received from the three samples - employees, employers, and cloud providerswere 169, 63 and 17, respectively. To ensure completeness of data, incomplete responses were discarded. As a result, the valid response figures of the three surveys arrived at 150 employees, 53 employers, and 13 providers.

An attempt to increase validity of the research was made as recommended by Bryman and Bell (2011) approach of method triangulation using a focus group.

\subsubsection{Online Focus Group}

This research leveraged the power of social networking technology. This made use of online forum discussion on LinkedIn, which is an instance of Bryman and Bell (2011) asynchronous online focus group. The discussion forum was targeted at a sample of employers, which was an arena for in-depth discussion about the research topic. Three open-ended questions corresponding to the research questions were posted on three subsequent occasions for the topic for each discussion. The forum was administered in the above four LinkedIn communities. Only members in the communities could contribute to the discussions by posting comments either answering directly the topic or replying to each other, whereas the researcher played the moderator role. The moderator used group dynamics principles, as suggested by Cooper and Schindler (2008), in focusing and guiding the group in communicating ideas, feelings, experiences and expertise on the topic. To reduce bias while achieving a high level of dialogue flow and balanced contribution among participants, the moderator maintained a minimum intrusive and structured approach, as prescribed by Bryman and Bell (2011), by occasionally injecting guided questions in either inviting elaboration on particular points or keeping the group on track.

Participation in the discussion was voluntary and mainly based on participants' personal interest on the topic. Consequently, there were a total of 36 participants who have managerial roles and consulting expertise in IT, IS and InfoSec (see Table 4-1). The Focus Group questions are supplied in Appendix 2. 


\begin{tabular}{lc}
\hline Participant Position & Number of Participants \\
\hline Presidents / Vice Presidents & 4 \\
CIOs & 8 \\
CTOs & 5 \\
InfoSec Managers/Consultants & 13 \\
IS Managers & 3 \\
IT Project Managers & 3 \\
\hline
\end{tabular}

Table 4-1 Focus Group Participants

\subsection{Data Analysis}

The data analysis was conducted in light of deductive and inductive strategies. Applying both strategies (the interplay between deductive and inductive analysis) helps the researcher to avoid missing out new processes, explanations and behaviors which have yet neither emerged in the conceptual design nor considered by the researcher (Hennink, Hutter, \& Bailey, 2011).

\subsubsection{Quantitative Analysis of Survey Data}

Analysis of survey data was conducted using two procedures: descriptive statistics on Likert-scale items and multiple-choice questions, and qualitative content analysis on freeform questions. The latter will be described in the next section. Descriptive statistics analysis involved three process components. First, the data was summarized by summing and counting using Qualtrics Statistical Analysis toolsets: tables and graphical charts. Second, the researcher applied inter-group analysis to identify further significant interpretation on the data and inter-group comparison by regrouping and re-summarizing based on several key indicators. Third, comparison and contrast analysis was applied on the datasets of the three samples, which illustrated the holistic view of examination into the research topic. The overall process is deemed to be a deductive strategy based on the conceptual model established in the literature review.

\subsubsection{Qualitative Analysis of Focus Group Data}

A qualitative analysis was carried out on the focus group data and freeform survey responses. This process followed an inductive strategy, where the researcher aimed to mine the data for both concepts previously recognized in the research conceptual model and new emerging concepts, simultaneously. A qualitative content analysis method was used with the aid of Excel spreadsheet in performing analysis. The two datasets were inductively coded following a general inductive coding technique by Thomas (2006). The 
raw responses were organized in a common format. Then, through multiple readings of each response, themes and categories were established by summarizing, sorting, and grouping. The key themes and categories were laid out in a table. This process was carried out iteratively in order to achieve a synthesis of key themes, allowing the researcher to draw conclusions from different themes.

\section{Findings}

This section presents the findings from the data analysis on the four data sources- three surveys and an online focus group. It is outlined into four sub-sections in accordance with the literature review, with a synthesis illustration of significant relationships. All figures are presented in percentages, and percentages may not total $100 \%$ due to rounding. The terms or notes in brackets are used to denote the source of data as follows:

- The Employees or (EMP) denotes the survey data from the employee sample.

- The Employers or (MAN) denotes the survey data from the employer sample.

- The Providers or (PRO) denotes the survey data from the cloud provider sample.

- The Focus Group or (FOC) denotes the online focus group data.

\section{Demography}

The surveys explored two demographic variables - position level and business sizewhich are important to represent a realistic picture of the NZ businesses. The position of respondents in the Employees survey was fairly distributed across a common organizational hierarchy, roughly half of them occupying a lower position than director and the other half in a director level and above. The other two surveys, the Employers and Providers, received respondents with the expected majority of junior and senior managerial positions of $91 \%$ and $76 \%$, respectively. These figures correspond to the above desirable demographic characteristics of the population and sample. Table 5-1 illustrates the figures in detail. 


\begin{tabular}{lcccc}
\hline & Staff & Supervisor & $\begin{array}{c}\text { Director/Business } \\
\text { unit manager }\end{array}$ & Above director \\
\hline The Employees & $31 \%$ & $21 \%$ & $36 \%$ & $12 \%$ \\
The Employers & $8 \%$ & $2 \%$ & $66 \%$ & $25 \%$ \\
The Providers & $8 \%$ & $15 \%$ & $38 \%$ & $38 \%$ \\
\hline
\end{tabular}

Table 5-1: Position demography of respondents in the three surveys

The Employees' respondents worked across various business sizes, $43 \%$ of whom came from large corporates and the rest from small and medium companies. Medium (42\%) and large (36\%) businesses toped the list in the Employers' responses; whereas over half of the Providers' responses were collected from small orgamizations. Overally, the responses in the three surveys achieved a diversity of business sizes as exhibited in Table 5-2.

\begin{tabular}{lcccc}
\hline & Very small & Small & Medium & Large \\
\hline The Employees & $9 \%$ & $21 \%$ & $27 \%$ & $43 \%$ \\
The Employers & $9 \%$ & $13 \%$ & $42 \%$ & $36 \%$ \\
The Providers & $8 \%$ & $54 \%$ & $15 \%$ & $23 \%$ \\
\hline
\end{tabular}

Table 5-2: Demography of business size in the three surveys

\subsection{State of PCS Consumerization in NZ Corporates}

Following the earlier highlight in the literature review about the widespread adoption by individuals (Conley, 2013; Mitchell, 2013; Tejada 2013) and increasing emergence of PCS in the workplace (Seagate, 2013; Stroz Friedberg, 2013), this subsection investigates the use and awareness aspects of PCS consumerization.

In response to the question asking respondents about the use of PCS, 69\% of the Employees admitted using PCS for work purposes indicating a frequency ranging from rarely to always, while $31 \%$ denied the use. This result resembles the Employers' responses, $73 \%$ of whom estimated their employees' usage of PCS at the workplace with indication of some to all of employees. Similarly, $92 \%$ of the Providers claimed that a range of some to all of their consumers used PCS for work purposes. These results (Figure 5-1 to Figure 5-3) clearly indicate a significant prevalence of PCS at the workplace. 


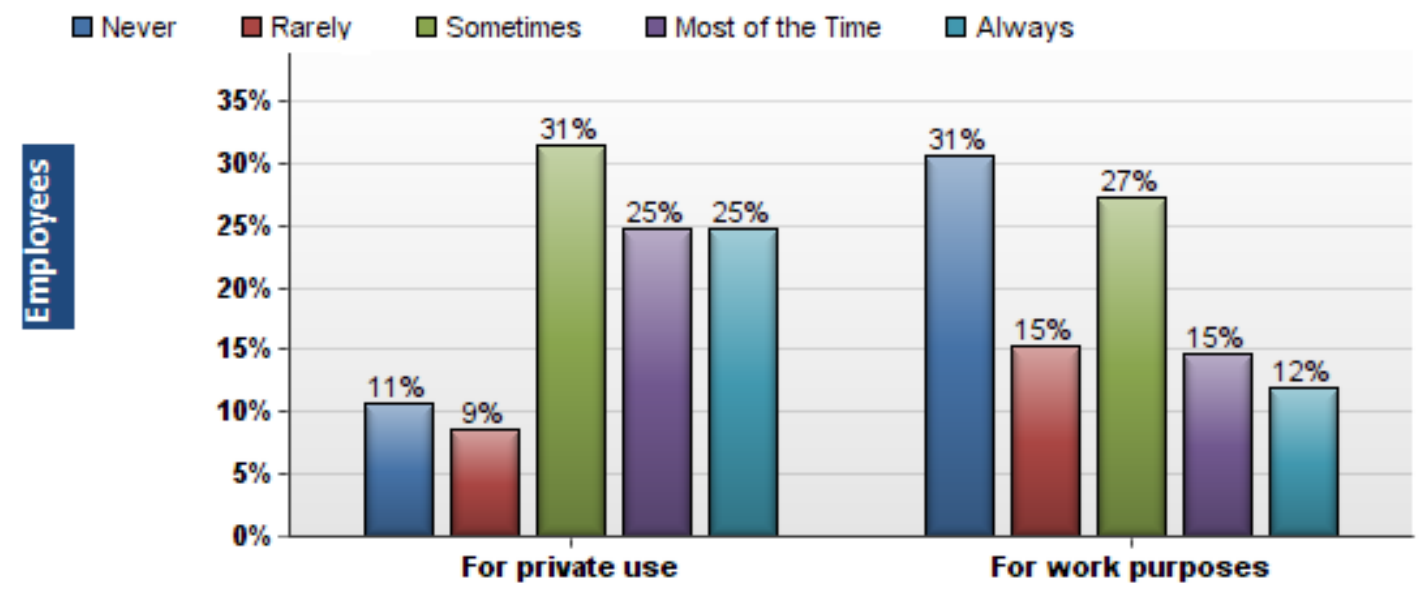

Figure 5-1 Do you use personal cloud storage (e.g. DropBox, iCloud, GoogleDrive, etc.)?

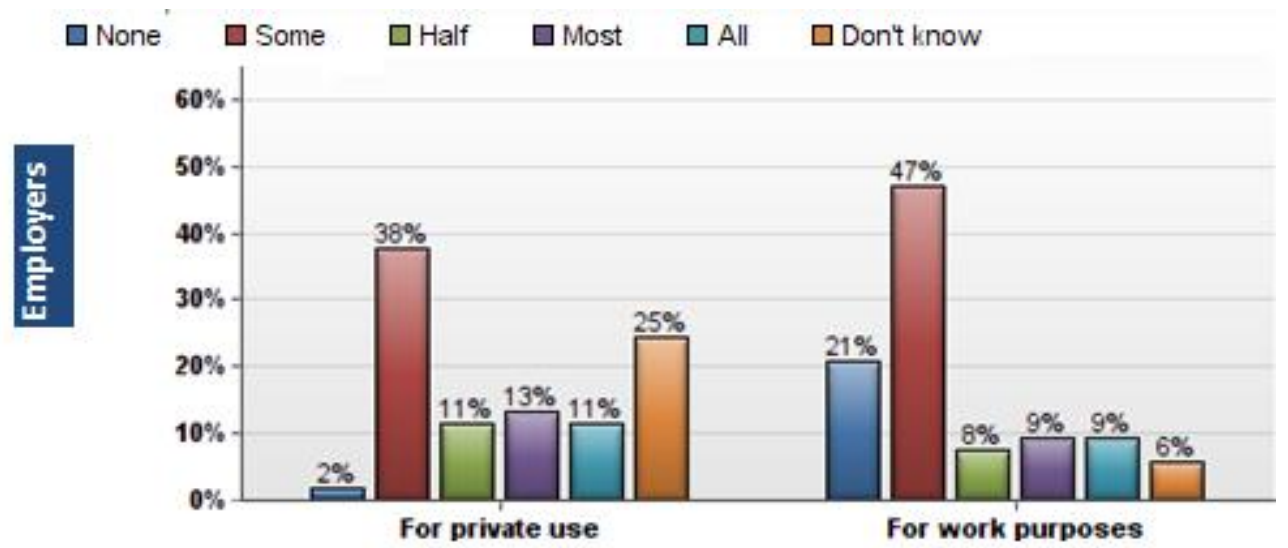

Figure 5-2 How many employees use personal cloud storage (e.g. DropBox, iCloud, GoogleDrive, etc.) in your organization?

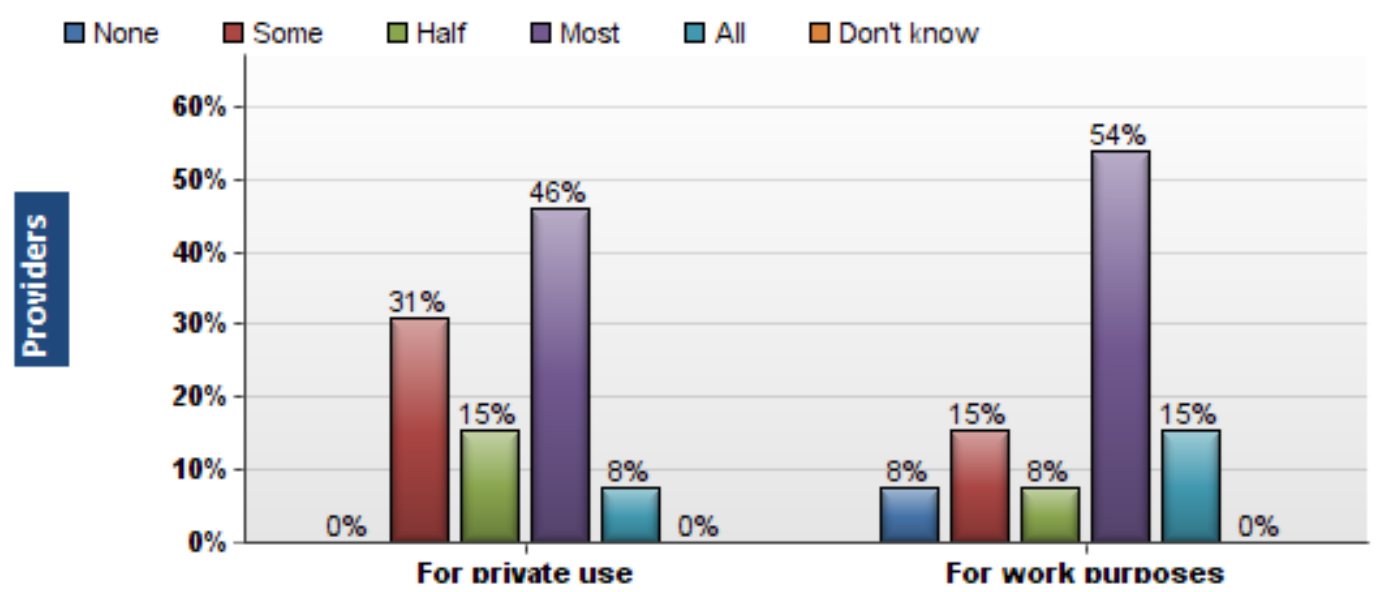

Figure 5-3 What purposes might your consumers use personal cloud storage for?

It is essential to explore the awareness about PCS consumerization trend. Generally, the results show that at least more than $90 \%$ of all respondents have been aware of the trend before reading the research information paper. Word-of-mouth and reading published articles were the two major mediums for getting to know it, accounting between $30 \%$ and 
$42 \%$ of the Employees and Employers. The analysis of free form responses provided further insights. The majority of Providers (31\%) appeared to recognize the trend more through a formal corporate source, whereas this internal source was minor in the case of the Employees (2\%) and the Employers (11\%). Table 5-3 lists in details with other minor mediums: personal experience, personal research interest, and vendor channels.

\begin{tabular}{lccccccc}
\hline & $\begin{array}{c}\text { Word-of- } \\
\text { mouth }\end{array}$ & $\begin{array}{c}\text { Reading } \\
\text { articles }\end{array}$ & $\begin{array}{c}\text { Research } \\
\text { Information } \\
\text { Paper }\end{array}$ & $\begin{array}{c}\text { Personal } \\
\text { experience }\end{array}$ & $\begin{array}{c}\text { Personal } \\
\text { research// } \\
\text { interest }\end{array}$ & $\begin{array}{c}\text { Part of } \\
\text { corporate } \\
\text { policy }\end{array}$ & $\begin{array}{c}\text { Vendor } \\
\text { channel/ } \\
\text { Corporate } \\
\text { source }\end{array}$ \\
\hline The Employees & $40 \%$ & $32 \%$ & $10 \%$ & $6 \%$ & $5 \%$ & $2 \%$ & $2 \%$ \\
The Employers & $42 \%$ & $30 \%$ & $4 \%$ & $11 \%$ & $11 \%$ & $11 \%$ & $2 \%$ \\
\hline The Providers & $23 \%$ & $23 \%$ & $8 \%$ & - & $15 \%$ & - & $31 \%$ \\
\hline
\end{tabular}

Table 5-3 How did you become aware of the trend for employees to use personal cloud storage for both corporate and private data?

There was an absence of policy related to use of PCS at the workplace, as reported by approximately half of the Employees; however, this figure dropped at only $25 \%$ of the Employers' responses. According to the results, many corporates appeared to be cautious about the trend, where 25\% of the Employees and 34\% of the Employers reported a complete ban on PCS in the workplace. However, some businesses (11\% to 23\%) adopted a lenient approach to the use, either by freely allowing PCS or by only prohibiting it for some critical tasks (Figure 5-4). The Focus Group results showed similar variation of approaches to PCS. One organization strictly banned the use of PCS. "My corporate PC is scanned for such apps, and their network ports are blocked" (FOC). Another company has a formal relevant IT policy. "Where I used to work placing much of anything outside the company network would be an IT policy violation" (FOC). However, a flexible on-demand measure to PCS was adopted in another workplace. "At our company, we don't officially allow access to personal cloud based storage for security reasons but common requests are to use the tools for moving large files between companies" (FOC). 


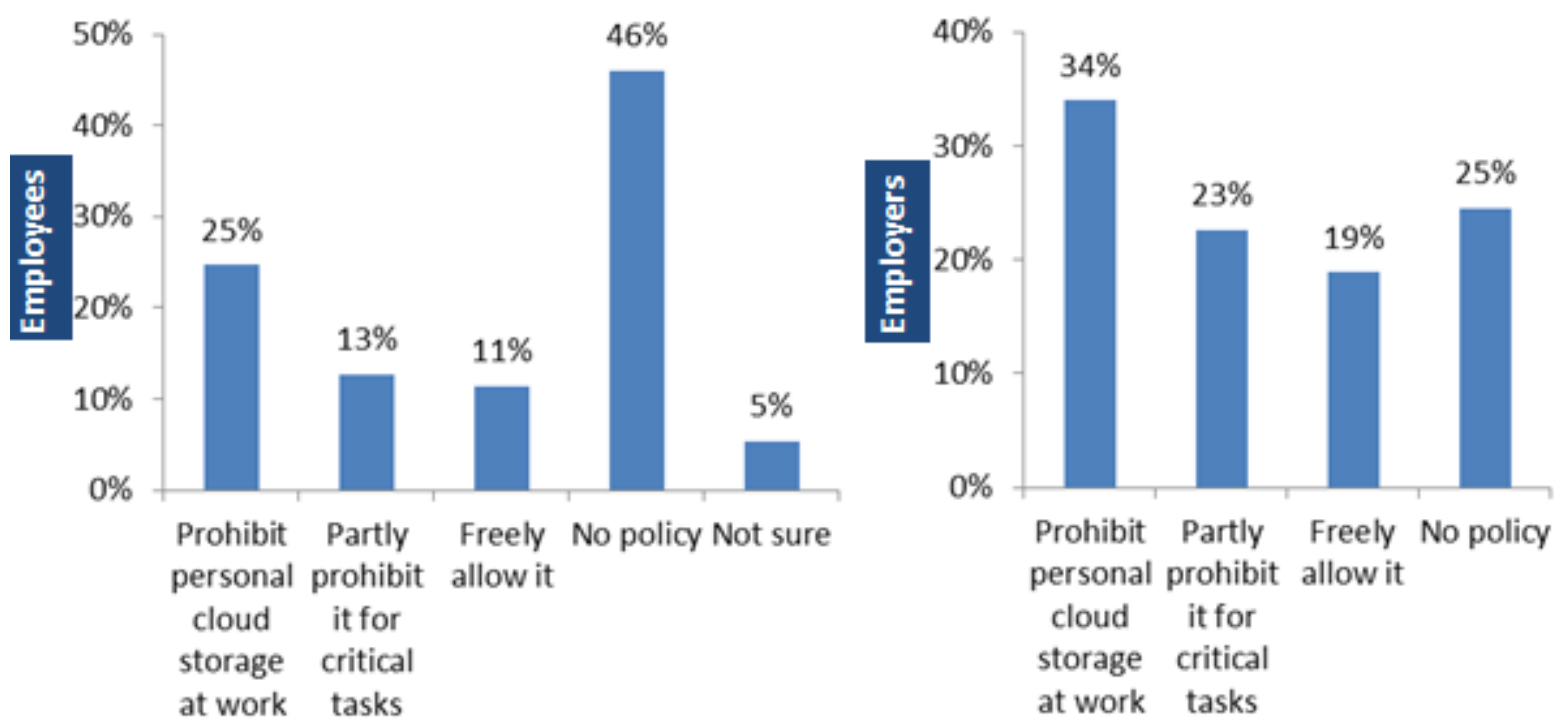

Figure 5-4 Does your organization have a policy related to personal cloud storage?

Regarding to security awareness, the overall results showed that roughly half of organizations have not yet had such programs dealing with PCS (Table 5-4). Only 27\% of the Employees' responses agreed that their organizations have such programs in place, whereas half of the Employers claimed having the programs implemented. An instance of security awareness program manifested in the Focus Group. "At our bi-weekly meetings we would touch on this subject often. And it was published in the IT Policy Hand book as well" (FOC). Some Focus Group participants demanded for such programs in addition to a policy and corporate solution in order to safeguard their organization. "It has to start with policy, but it has to finish with training, auditing, and enforcement so employees understand that this is serious business"; "Before the [corporate solutions], starting point is an awareness campaign about risk and value of the information, it can be associated with the rollout of an IPP: Information Protection Policy" (FOC).

\begin{tabular}{lccc}
\hline & Yes & No & I don't know \\
\hline The Employees & $27 \%$ & $60 \%$ & $13 \%$ \\
The Employers & $51 \%$ & $49 \%$ & - \\
\hline Table 5-4 Does your organization have any security training/awareness program about personal cloud storage?
\end{tabular}

\subsection{Drivers}

This subsection describes the findings about the drivers of PCS consumerization. This is organized into fives factor groups as outlined in the literature review section. Table 5-5 illustrates a synopsis of the drivers identified from the overall findings. More details can be found in Appendix 5. 


\begin{tabular}{|c|c|c|c|c|}
\hline \multicolumn{5}{|c|}{ DRIVERS } \\
\hline Ref. & Drivers Identified & Survey & Focus Group & Group \\
\hline 5.1.1. & $\begin{array}{l}\text { Telecommunications-infrastructure and general } \\
\text { affordability }\end{array}$ & High & Not mentioned & $\begin{array}{l}\text { General } \\
\text { Industry }\end{array}$ \\
\hline 5.1.2. & Data hoarding (New Factor) & High & Recognized & \\
\hline 5.1.3. & Consumer devices as disruptive technology & High & Not mentioned & $\begin{array}{l}\text { Consumer } \\
\text { Devices }\end{array}$ \\
\hline 5.1.4. & Processing power of consumer devices & Medium & Not mentioned & \\
\hline 5.1.5. & Usage factor of consumer devices & Medium & Not mentioned & \\
\hline 5.1.6. & Form factor of consumer devices & Medium & Not mentioned & \\
\hline 5.1.7. & Ecological factor of consumer devices & Low & Not mentioned & \\
\hline 5.1.8. & Always-on feature of consumer devices & High & Not mentioned & \\
\hline 5.1 .9 . & Superior application usability & High & Recognized & Consumer \\
\hline 5.1.10. & Attractive licensing models & High & Recognized & ррасало \\
\hline 5.1 .11$. & Collaboration and social computing tools & Medium & Recognized & \\
\hline 5.1 .12$. & Cloud bundle & High & Recognized & \\
\hline 5.1 .13$. & Blurring of work and home & High & Not mentioned & Consumer \\
\hline 5.1 .14$. & Increasing mobility of customers and employees & High & Recognized & \\
\hline 5.1.15. & $\begin{array}{l}\text { Workplace expectation of customers and } \\
\text { employees are changing }\end{array}$ & Medium & Recognized & \\
\hline 5.1.16. & Fashion, status and curiosity & Low & Not mentioned & \\
\hline 5.1 .17 & Plurality of devices & High & Recognized & \\
\hline 5.1.18. & Network externality & Medium & Not mentioned & \\
\hline 5.1.19. & $\begin{array}{l}\text { Externalization of businesses, cloud computing } \\
\text { and partner eco systems }\end{array}$ & Low & Recognized & $\begin{array}{l}\text { Corporate } \\
\text { Factors }\end{array}$ \\
\hline 5.1.20. & $\begin{array}{l}\text { Employees from younger generation and digital } \\
\text { natives }\end{array}$ & Medium & $\begin{array}{l}\text { Indirectly } \\
\text { mentioned }\end{array}$ & \\
\hline 5.1.21. & Average age of leadership & Low & $\begin{array}{l}\text { Indirectly } \\
\text { mentioned }\end{array}$ & \\
\hline 5.1 .22 & Corporate technology limitations (New Factor) & High & Recognized & \\
\hline 5.1 .23 & Corporate policy limitations (New Factor) & High & Recognized & \\
\hline
\end{tabular}


General Industry Factors (5.1.1 to 5.1.2): Overall survey results indicated the fact that the internet has extensively expanded its footprint and that consumer devices have become more affordable at low cost (5.1.1) is significantly driving the consumerization trend of PCS. Internet broadband and consumer device affordability both gained the majority responses from the Employees, Employers and Providers altogether standing at over 77\% combined percentages of high and medium rates (Figure 5-5). Nonetheless, the Focus Group failed to mention any of the factors.

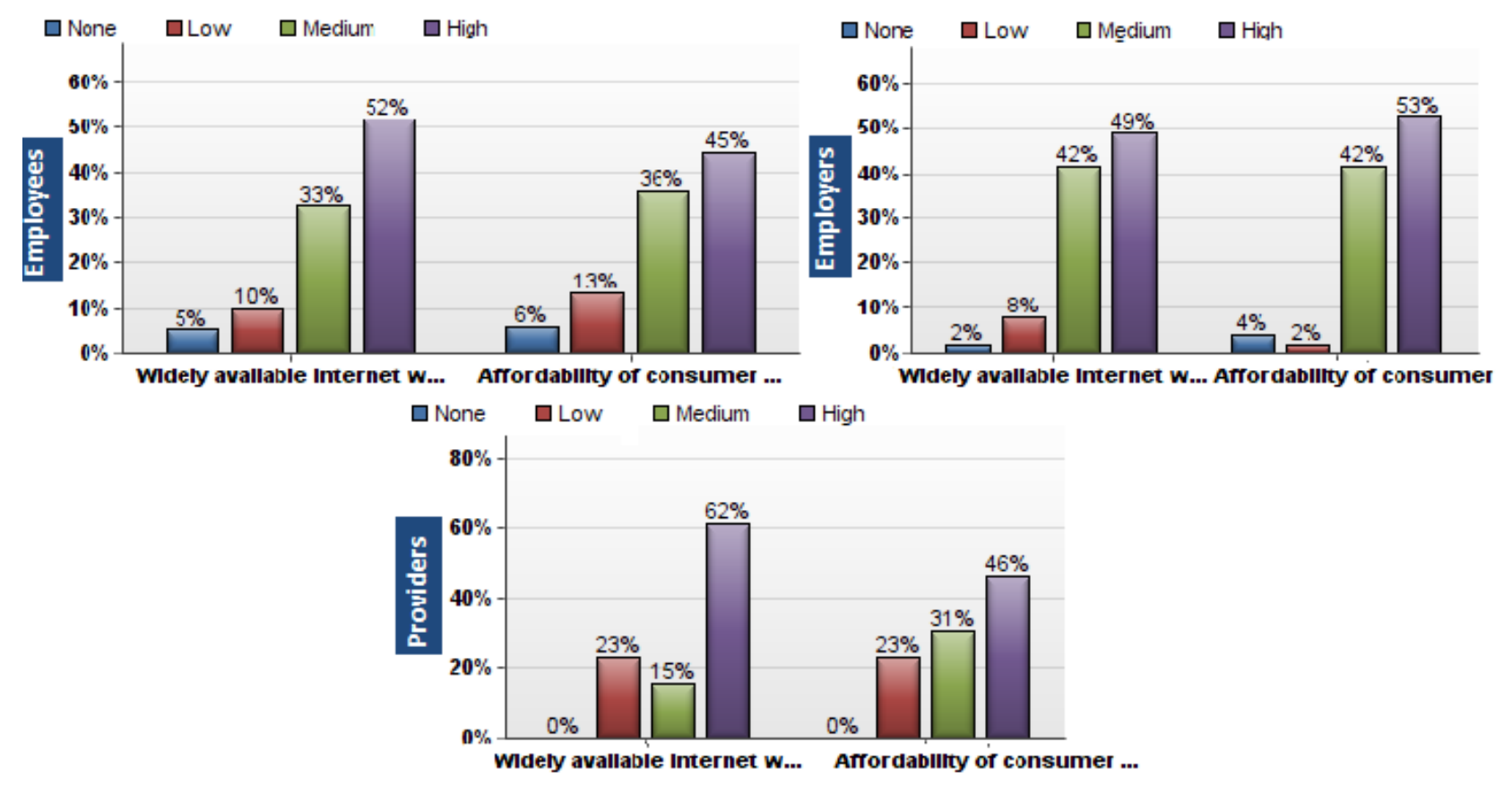

Figure 5-5 What industry-related factors do you think are driving Personal Cloud Storage in the Workplace?

Data hoarding phenomenon (5.1.2), which did not exist in the literature review, appeared as a new factor emerging from the free form question. Both people and organizations trapped in data hoarding are commonplace in this era of big data, where its complexity and increasingly uncontrollable amount drive the need for efficient management (Bertolucci, 2013). IDC (2012) estimated that every person in the world will own approximately $5,247 \mathrm{~GB}$ of data by 2020 . This massive volume of data which humans are accumulating may come from a variety of sources of their digital life, including emails, digital documents, photos, videos, click streams, e-commerce and Internet transactions, instruments, sensors, and all other digital sources available today and in the future (Floridi, 2012).

The two aspects of data hoarding — massive volume of data and huge file size — were raised in the survey responses as an immense driving force of the consumerization. The 
Employees contended that a vast amount of data and large files to transport across organizations necessitated using PCS. “... by using personal cloud storage at work (using a personal account) to easily transmits a large amount of data between a corporate environment and a vendor doing development work on a large project"; "The requirement I have to shift large files that can't be emailed. Which is generally the ONLY reason why I put work files on my own cloud storage" (EMP). The Employers responses also recognized "E-Mail size restrictions" as a factor. Similarly, the Providers pointed out the troublesome large files. "Employees need to email large files, need to collaborate in projects" (PRO).

Data hoarding as a reason of adopting PCS also emerged in the Focus Group discussion. Large volume of cloud storage which allows employees to keep virtually everything appeared to be the case. "Still, consideration should be given to the issue of data hoarding. The availability of large amounts of storage at a rather low cost, quite often free, provides people with the opportunity to keep everything. Whether this is personal or corporate emails, documents or pictures" (FOC). Employees would opt for PCS for moving their huge files around regardless of an offer of conventional corporate solutions which they felt outdated and difficult to use. "When employees contacted service desk asking what to do with their $400 \mathrm{mb}$ movie file, they want to share with customers outside company, we were instructed to offer them an FTP account and access. I believe many employees simply said "thank you" and used Dropbox instead" (FOC).

Consumer Device Factors (5.1.3 to 5.1.8): Consumer device as disruptive technology (5.1.3), always-on feature (5.1.8), processing power (5.1.4), usage capability (5.1.5), convenient form (5.1.6) of consumer devices were significantly rated between medium and high, according to the overall chart trend (Figure 5-6). Consumer devices as disruptive technology, and always-on feature gained the majority rate as high at $51 \%$ and $53 \%$ of the Employers, respectively. However, it is notable that the Providers rated the two factors as medium equally at $62 \%$. At the medium rank stood the processing power, usage capability, and convenient form of consumer devices, each of which was rated by approximately half of the Employees, Employees, and Providers. Only eco-friendliness factor (5.1.7) was notably disregarded as a driver with a low rate by about half of all responses, and with an overall rate between low and none. Nonetheless, the Focus Group did not mention any of the consumer device factors. 


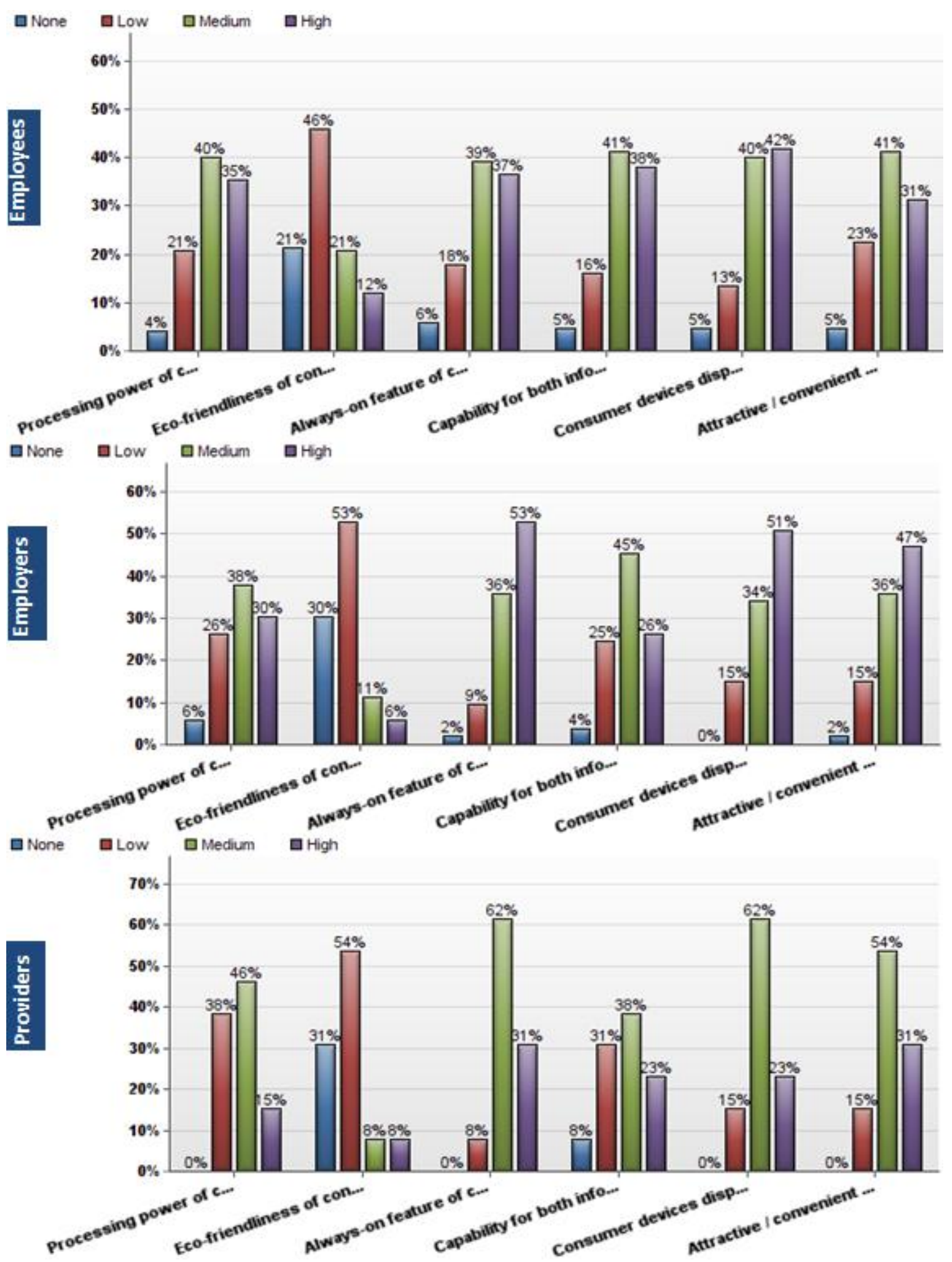

Figure 5-6 What device factors do you think are driving Personal Cloud Storage in the workplace?

Consumer Application Factors (5.1.9 to 5.1.12): The overall trend of the charts (Figure 5-7) showed that cloud bundle (5.1.12), low cost licensing (5.1.10), and application superior usability (5.1.9) were recognized as high, and that a medium rate was assigned to collaboration and social networking tools (5.1.11). At least $40 \%$ of the Employees, 
Employers and Providers altogether rated high on cloud bundle, low cost licensing, and application superior usability (ease of use and rich functionality). It was notable that ease of use topped the list, with high rates between $62 \%$ and $77 \%$. The majority of the Employers rated social collaboration at medium over high, while the Employees and Providers gave roughly equal rate of medium and high.

The Focus Group results supported the significance of the above four application drivers. PCS providers marketing their licensing strategy of a free startup and a low premium fee became a consumer's choice for storage solutions. "But external cloud solutions are gaining ground and for very good reason. Low cost."; "The availability of large amounts of storage at a rather low cost, quite often free, provides people with the opportunity to keep everything" (FOC).

Employees were inspired by the possibility that their collaborative and networking desires for intra-organizations, inter-organizations and external stakeholders were facilitated by PCS features. "In a number of inter-organizational enterprises (think of a prime contractor with a series of subcontractors), it is absolutely natural to share data with one another, sometimes in a cloud space, with the shared data marked by whose it is."; “...especially with the benefits it brings to a collaborative working environment" (FOC).

Similar to the survey findings, the fact that consumer cloud storage is both convenient and useful becomes a main driving force of the adoption. This usability outperforming legacy corporate systems was spurred with the Focus Group comments such as convenience, ease of use, high availability, an abundance of rich functionality, huge storage, sharing, data management, collaboration, and access on the move. "[There're] three main drivers for these types of cloud services, one is to store stuff, another to share, and a third is easy access from any device when mobile."; "Employee can always access the work data and stay in touch"; "Having data on a cloud storage provides various benefits such as mitigation of risk against loss of data, close to $100 \%$ availability and in some services, ability to view versions and track changes" (FOC).

Regarding to cloud service bundle, the Focus Group did not specifically mention PCS as complementary to mobile devices; rather, a participant claimed PCS as a value-added service in a way that free email accounts do. “...I see it eventually becoming a [valueadded] service (like a free email account) to the other cloud services..." (FOC). 


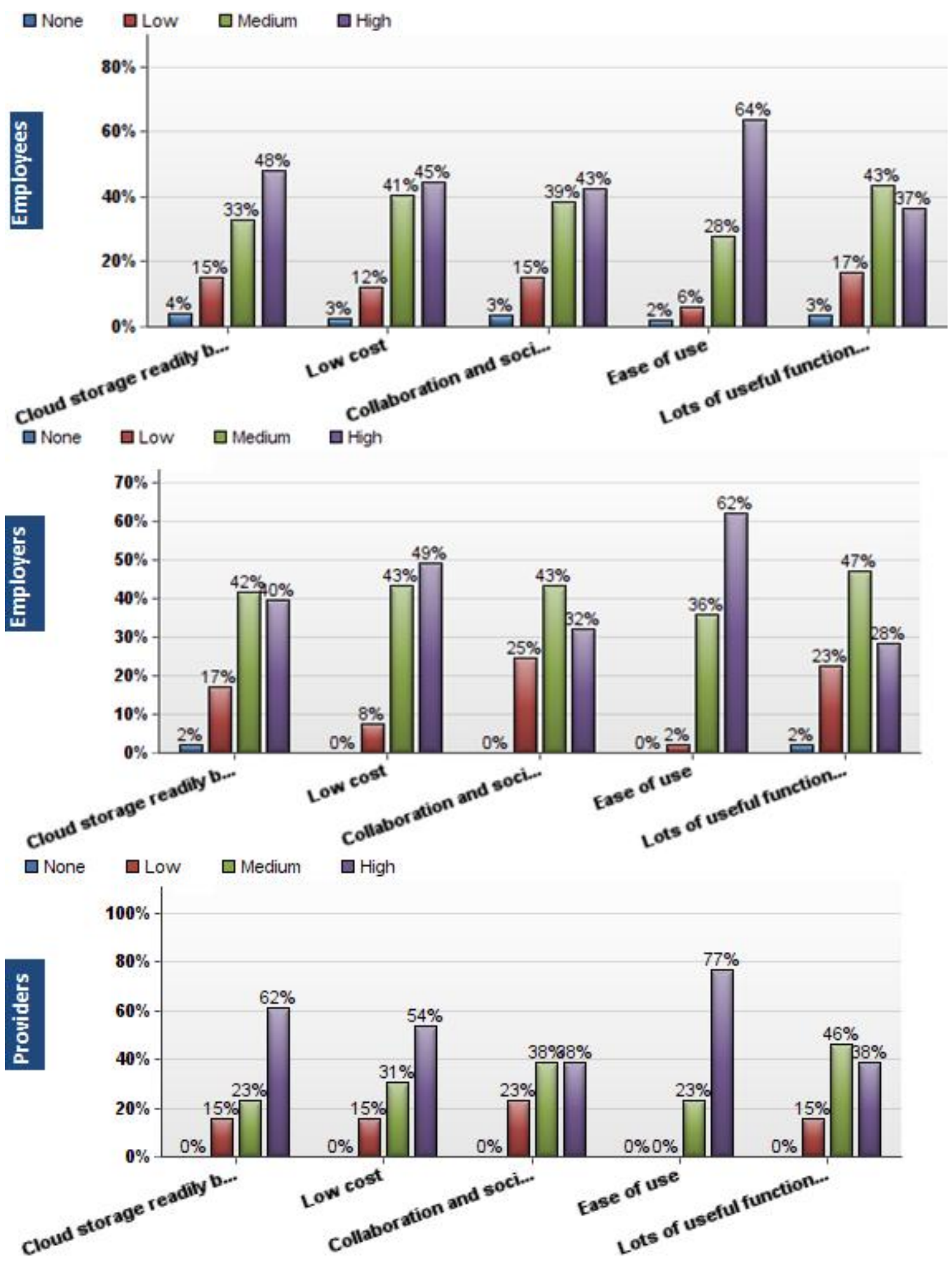

Figure 5-7 What application factors do you think are driving Personal Cloud Storage in the workplace?

Consumer Behavior Factors (5.1.13 to 5.1.18): The overall chart trend (Figure 5-8) showed that device plurality (5.1.17), blurring of work and home (5.1.13), increasing mobility of customers and employees (5.1.14), workplace technology expectations by employees (5.1.15), and network externality (5.1.18) were rated between high and 
medium, except that material symbol (5.1.16) was rated as low. The Employees, Employers, and Providers all recognized device plurality, blurring of work and home, and mobility of customers and employees as high at the majority percentage of above $40 \%$. This percentage is similar to that of the medium recognition on workplace technology expectations and network externality; however, it is noted that more than half of the Providers appeared to disregard the network externality with a low rate.

As the Focus Group findings suggested, mobility of staff and customers gained significant importance. Travelling, remote offices, and access on the move were highlighted as vital demands of today's business. "We utilize cloud storage, which is very helpful since several of our executives are in remote offices and travel quite frequently."; "Most important factor is ease of use and "on the move" need to access social [and] business media" (FOC).

Changing expectations of customers and employees about workplace technology also emerged in the Focus Group dialogue. Nowadays people expect and demand for an equivalent copy of their everyday technology in the corporate environment. "If you use this in your personal lives which most people now do, then there is an expectation for a corporate equivalent service. People most often look outside when the corporate IT doesn't step up.”; “...our workers are now driving demands for flexible answers to their data needs" (FOC).

Tendency to own many personal devices was indeed another driving force which the Focus Group asserted. People preferred to use PCS services to bridge crosscommunication between their devices and platforms. "Tablets are begging for cloud solutions. And consider the multi-device consumer; cell phone, tablet, laptop, desktop, home automation (security, fire, energy)... even our cars are becoming end point devices..."; "BYOD/BYOA both are dynamic since we have 3 4 platforms to support and numerous apps (non-market) which offer similar service" (FOC).

Nevertheless, the Focus Group did not mention three other drivers: symbol of fashion, status, and curiosity; blurring of work and home life; and network externality. 


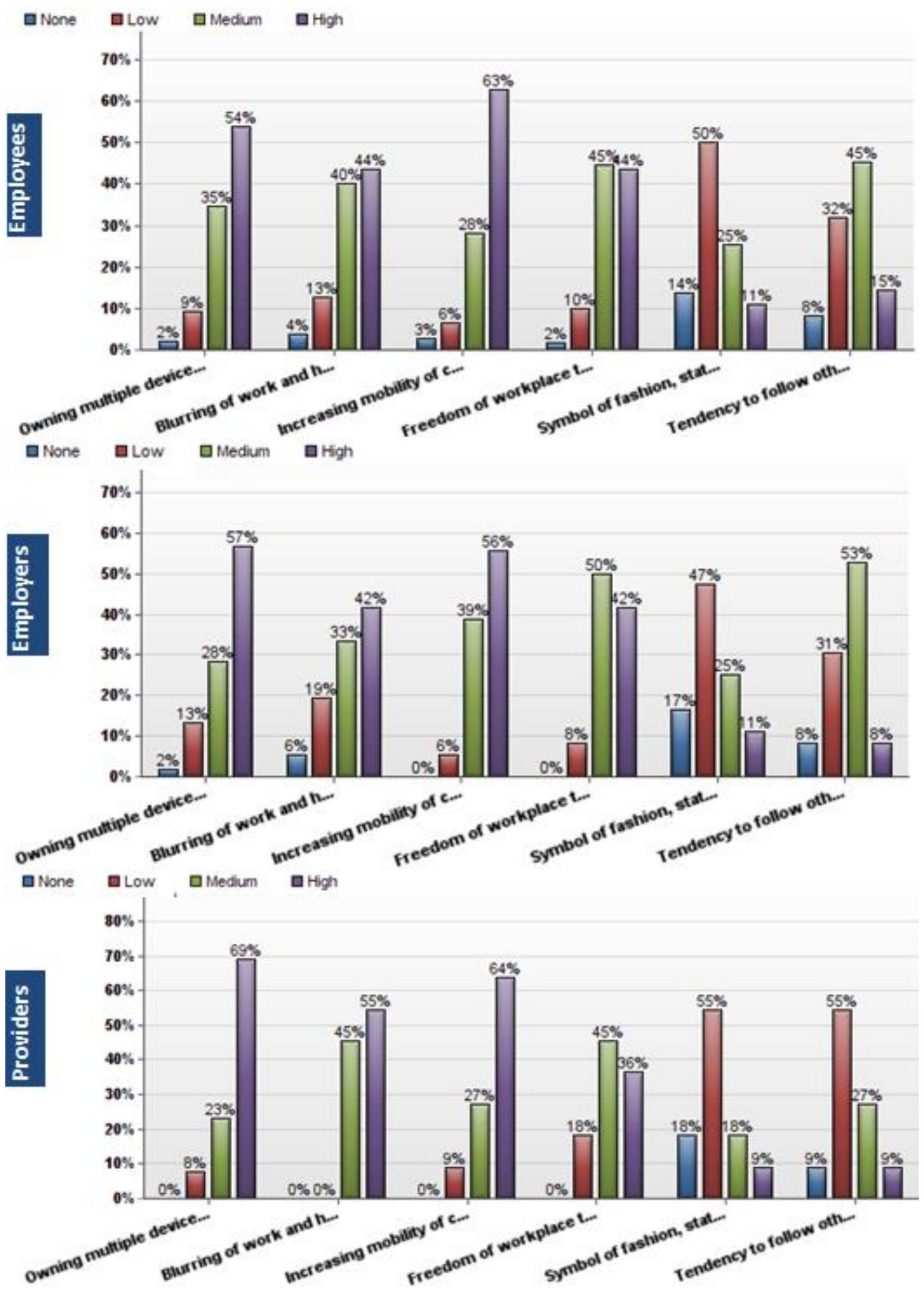

Figure 5-8 What behavioral factors do you think are driving Personal Cloud Storage in the workplace?

Corporate Factors (5.1.19 to 5.1.23): The charts (Figure 5-9) in overall showed that business externalization factor (5.1.19) was recognized by the majority between low and medium. While the Employees rated the demand for business externalization slightly more on medium (35\%) than low (27\%), the response rate from the Employers and Providers was greater on low than medium. 
The general trend of the charts marked a medium rate on young-employee factor (5.1.20) as opposed to a low rate of young-leader factor (5.1.21). With a significant rate between medium and high, 33\% of the Employees responses recognized employees from younger generation as medium, and this rate grew close to half of the Employers and Providers. Young-leader factor was weighted low in the Employees (37\%) and Employers (46\%) responses; on the contrary, it is worth noting that the Providers strongly supported this factor with medium rate (57\%).

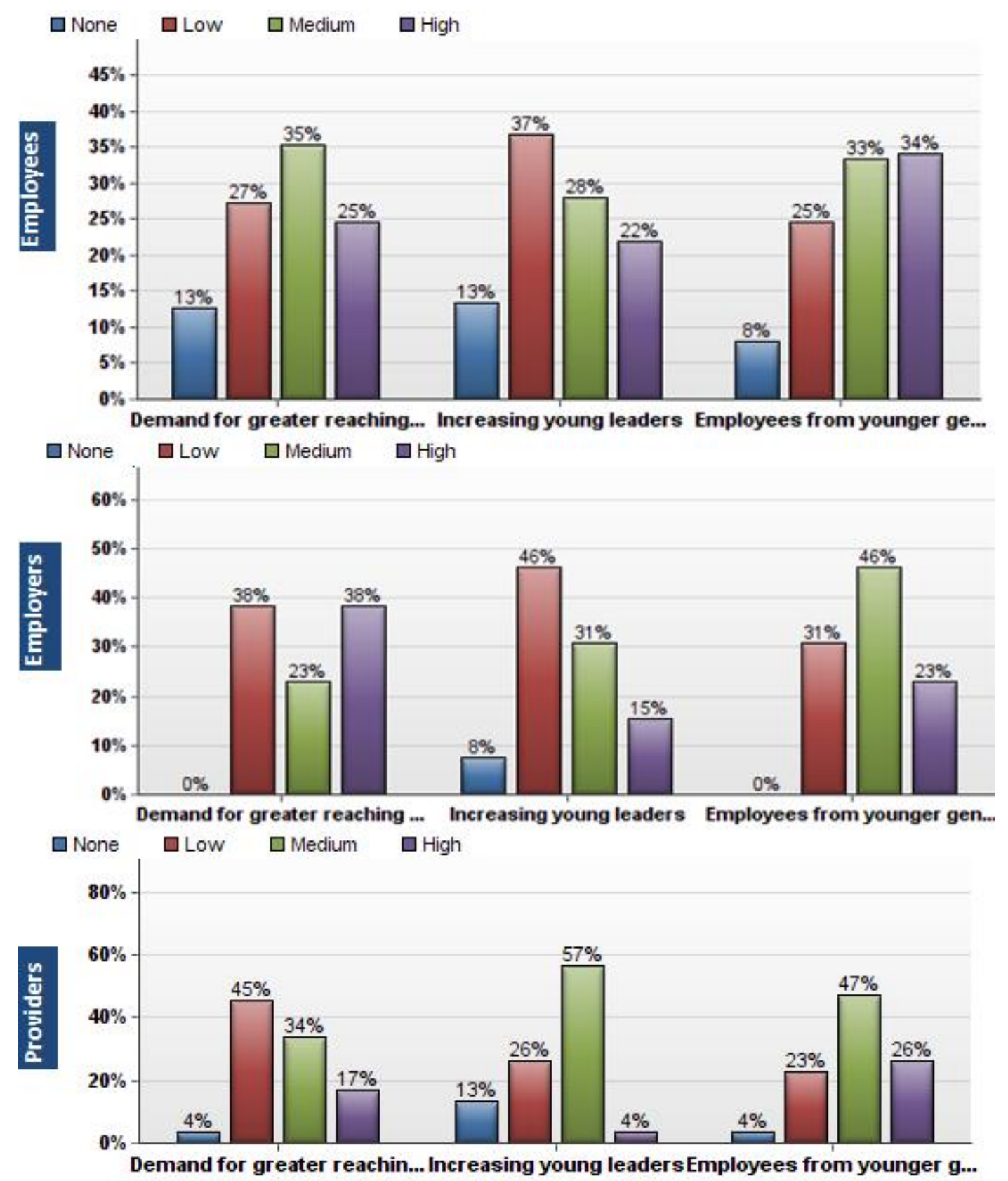

Figure 5-9 What industry-related factors do you think are driving Personal Cloud Storage in the Workplace? 
Business externalization gained its ground for leveraging cloud solutions as mentioned in the Focus Group. The participants maintained that legacy systems became unresponsive while business demanded for increasing flexibility and greater outreach to external stakeholders including customers, partners, suppliers, contractors, etc. "I used to make my outside users connect to VPN and sync with our file server but that does not help outside collaboration."; "As most employees need to share documents with people external to the organization, best solution is hybrid cloud..."; "In a number of inter-organizational enterprises (think of a prime contractor with a series of subcontractors), it is absolutely natural to share data with one another, sometimes in a cloud space..."(FOC).

The Focus Group did not particularly raise anything about young leaders or young employees as a driver. However, a participant indicated a relationship between technology, business requirements and modern workers. “(A) Policy, governance, risk and technological limitations/requirement go head to head with (B) modern workers and flexible business desires. B is happening...make A suitable" (FOC).

Other two new drivers (corporate technology limitations and corporate policy limitations), which emerged from the analysis of free form questions, fall into the corporate factors.

Limitations of corporate technology (5.1.22) significantly contributed to employees' own decision to use their PCS in the workplace. The Employees' responses raised issues around unsupportive infrastructure, poor corporate networks, system complexity and failure to meet their work demands. "We rely upon it, we don't have an internal file storage infrastructure"; "limitations of traditional main frame servers being used for access function and hard drive storage"; "poor corporate networks and remote access policies encourage personal cloud storage"; and "inability of business IT department to adapt to desire of users fast enough" (EMP). The Employers' responses highlighted several issues of corporate infrastructure such as inconvenience and lack of required functionality. "Using cloud storage makes collaboration and document sharing easier when often organization systems don't facilitate this"; "When employees find that the technology provided in the workplace, is not as convenient to use as their own personal cloud storage items - then the 'urge' to use their own cloud devices...” (MAN). Similarly, the Providers' perspective was centered on such limitations of corporate technology as complexity, inefficiency and lack of core functions. “... because their company doesn't provide them with one or more of: enough on-premise storage, ability to share files 
externally with suppliers/vendors/customers, dedicated hard drive backup, or lack of company network access from outside..."; "Most company does not provide efficient tools for this, or too complicated systems with a bad user experience or to complex because of all security access levels..." (PRO). The participants in the Focus Group emphasized several drawbacks of internal infrastructure such as inadequacy of information services, unresponsiveness, low performance, outdated technology, and lack of system integration. "...the organization does not provide adequate information services to its employees..."; “...the infra not being able to meet the business requirements..."; "...the email app is not integrated to an EDMS...”; “... legacy IT is slow and unresponsive to emerging business needs for flexible data access and storage solutions”; “...corporate IT rarely issued latest state of the art IT equipment" (FOC).

Absence or looseness of relevant corporate policies (5.1.23) including guidelines and implementation programs played a crucial role in putting employees at risk using PCS. Pursuing their own temptation, some employees might take the issue for granted, while others might resort into purposefully violating security restrictions. Evidence from the Employee responses asserted that nonexistence of policies, act of deliberate security policy bypass and policy ignorance due to low awareness were driving employees' risky use of PCS. "Lack of awareness regarding security issues, poor or nonexistent policies"; "Wanting to circumvent official work systems as being too 'prescriptive"; "Working around restrictive work place policies with locked down USBs" ; "Problematic corporate restrictions on taking physical information offsite" (EMP). The Employers' responses also highlighted low awareness about risk and intentional policy violation. "Lack of information or understanding of risks... willfully disregarding policy as they know best" (MAN). Intentional policy violation and lack of relevant corporate policies were also stressed in the Providers' responses. "Most corporates don't have a security policy on the use of consumer services for business."; "Employees and teams will find ways to get their work done, regardless of impediments inflicted by corporate IT staff" (PRO). A participant in the Focus Group suggested that BYOD policy leaves a gap for PCS to automatically intrude the corporate. "If you allow BYOD, then by default you have already allowed BYOA" (FOC). 


\subsection{Benefits}

This subsection describes the findings about the benefits brought to corporates by PCS consumerization. Table 5-6 exhibits a synopsis of the corporate benefits identified from the overall findings. Appendix 5 gives further details.

\begin{tabular}{|c|c|c|c|}
\hline \multicolumn{4}{|c|}{ BENEFITS } \\
\hline Ref. & Benefits Identified & Survey & Focus Group \\
\hline 5.2 .1 & Accelerates business growth & Medium & Not mentioned \\
\hline 5.2.2. & $\begin{array}{l}\text { Productivity through employees bringing in } \\
\text { new technology }\end{array}$ & Medium & $\begin{array}{l}\text { Indirectly } \\
\text { mentioned }\end{array}$ \\
\hline 5.2.3. & Employee productivity through trust & Medium & $\begin{array}{l}\text { Indirectly } \\
\text { mentioned }\end{array}$ \\
\hline 5.2.4. & $\begin{array}{l}\text { Productivity through employees bringing in } \\
\text { consumer behaviour and skills }\end{array}$ & Medium & $\begin{array}{l}\text { Indirectly } \\
\text { mentioned }\end{array}$ \\
\hline 5.2 .5 & Standardisation enforced by consumer vendors & Low & Not mentioned \\
\hline 5.2.6. & $\begin{array}{l}\text { Finding newer skills through social } \\
\text { networking websites }\end{array}$ & Low & Not mentioned \\
\hline 5.2 .7 & Cost benefits & Medium & Recognized \\
\hline 5.2 .8 & Employee engagement and retention & Medium & Recognized \\
\hline 5.2.9. & Innovation & Medium & Not mentioned \\
\hline 5.2 .10 & Competitive advantage and agility & Medium & Recognized \\
\hline 5.2 .11 & Data security solution workarounds (New Factor) & $\begin{array}{l}\text { Not } \\
\text { mentioned }\end{array}$ & Recognized \\
\hline
\end{tabular}

Table 5-6 Corporate benefits identified from the findings

Responding to the question about corporate benefits, the overall findings (Figure 5-10) showed that productivity through employees bringing new technology (5.2.2), employee productivity through trust (5.2.3), and employee satisfaction/retention (5.2.8) were rated between medium and high. There were some contrasting views on the other benefits. Having a common majority rate (medium over high) on all other benefits, the Employees gave roughly equal majority responses between low and medium recognitions on three factors-accelerating business growth (5.2.1), standardization enforced by consumer vendors (5.2.5), and newer skills through social networking (5.2.6). Recognition on standardization and newer skills factors got further exacerbated in the Employer and Provider responses with the majority (over 61\%) of low and none ratings combined. On 
the contrary, there was a markedly opposing thought on accelerating business growth, which was highly recognized as medium (54\%) by the Providers as opposed to the low rate from about half of the Employers. Regarding to productivity through employees bringing consumer behavior and skills (5.2.4), there was a sharp contrast between the Employees (45\% at medium) and the Providers (46\% at low), while the Employers gave similar rates of low and medium. Cost benefit factor (5.2.7) received a remarkable different perspective from the Providers who rated high at $46 \%$, as opposed to the majority of medium from the Employees and Employers. While the majority of Employees and Providers rated innovation (5.2.9) and competitive advantage (5.2.10) between medium and high, it is notable that approximately half of the Employers rated the two factors as low and none.

There were many comments in the Focus Group about business productivity as a major benefit. Business productivity was interpreted in terms of improved work efficiency, worker collaboration, and on-demand data access. "These are tools for productivity and collaboration. By definition if the corporate environment restricts their use either through policy or active blocking then it kinda hinders collaboration."; "Employee can always access the work data and stay in touch."; "The mission to collaborate, among employees, customers, vendors, regulator and government, is to enhance the productivity and to reduce the operative cost" (FOC). However, there were no comments on whether the productivity might derive particularly from employees bringing new technology, consumer behaviors and skills, or employee trust.

The Focus Group findings suggested cost benefits as another important benefit. The participants emphasized cost effectiveness in terms of low cost storage solutions, reduced operational costs through such facilities as work collaboration, IT maintenance cost reduction, and long-term cost savings through cloud strategy. "There's a lot of interesting benefit to these builds, low-cost (long term), ..."; "The mission to collaborate ...to reduce the operative cost."; "Can reduce IT costs for small business"; “...you have an optimized, extremely mobile, easily managed network and system that is both cost effective and... highly adaptable."; "But even if you have to store sensitive data onsite (accounting, personnel records, etc.), there is a lot that can be pushed to the cloud - reducing your need for onsite hardware and the techs that will keep it viable. And the upgrades you'll need to do every six months, when an OS changes, or a vendor app requires a new architecture, etc." (FOC). 

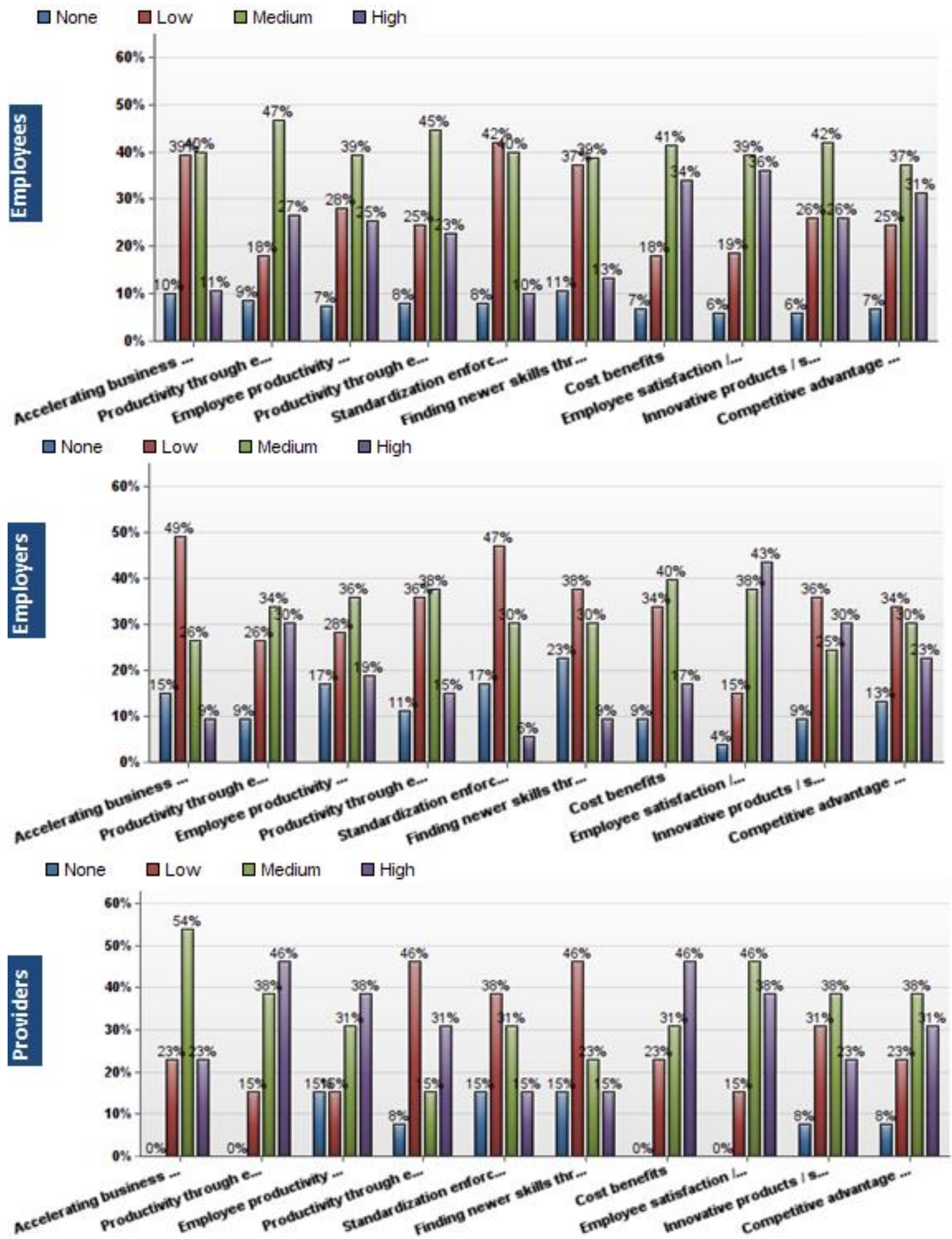

Figure 5-10 What Benefits can Personal Cloud Storage in the workplace bring to organizations?

A couple of factors contributing to greater employee engagement also emerged in the Focus Group. A participant suggested social benefits and employee goodwill as the benefits in addition to business productivity. "There is the business productivity benefit, but what about social benefits, employee goodwill, etc." (FOC). 
Three elements of competitive advantage - mobility, flexible IT, and cloud potentialswere reflected in the Focus Group discussion. The participants suggested staff mobility, agile IT architecture, and development potential of cloud strategy as the benefits of PCS. "But on the plus side, you have an optimized, extremely mobile, easily managed network and system that is both cost effective and (with consideration for some future [development]) highly adaptable."; "But external cloud solutions are gaining ground and for very good reason. Low cost. Flexible architecture. Development potential ... by the third, I mean to say that we are still creating ways to capitalize on the cloud share strategy" (FOC).

Such benefits as accelerating business growth, standardization enforced by consumer vendors, finding new skills through networking websites, and innovation were not mentioned in the Focus Group. Nonetheless, there emerged a new benefit-Data Security Solution Workarounds (5.2.11). Despite numerous data security issues identified in the literature review, the Focus Group suggested that PCS provides a certain level of data security to the extent that it can help achieve high service availability and mitigate data loss and leakage due to device loss or file damage. "If the employee uploads the data to a personal cloud (Dropbox or something similar), then we have at least eliminated the possibility of losing a physical flash drive."; "Having data on a cloud storage provides various benefits such as mitigation of risk against loss of data, close to $100 \%$ availability and in some services, ability to view versions and track changes" (FOC).

\subsection{Challenges}

This subsection presents the findings about the corporate challenges posed by PCS consumerization. Table 5-7 illustrates a synopsis of the corporate challenges identified from the overall findings. Appendix 5 illustrates it in detail.

\section{Challenges}

\begin{tabular}{clcc}
\hline Ref. & Challenges Identified & Survey & Focus Group \\
5.3.1. & Immaturity of consumer technologies & Medium & Not Mentioned \\
5.3.2. & Cost constraints and uncertain cost boundaries & Medium & Not Mentioned \\
5.3.3. & Economic downturn & Low & Not Mentioned \\
5.3.4. & Security challenges & High & Recognized \\
5.3.5. & Challenges in support and control & High & Not Mentioned
\end{tabular}


5.3.6. Challenges around evolving relations and expectations $\quad$ High $\quad$ Partially Mentioned

5.3.7. Changing policy needs

High Recognized

5.3.8. Regulatory obligations

High Recognized

5.3.9. Cloud service management and integration

Medium Recognized

5.3.10. Service degradation

Low Recognized

5.3.11. Data governance challenges (New Factor)

High Recognized

5.3.12. Consideration on corporate solution (New Factor)

High Recognized

Table 5-7 Corporate challenges identified from the findings

The overall survey findings (Figure 5-11) showed the top five challenges-security challenges (5.3.4), support/control challenges (5.3.5), regulatory liability on organizations (5.3.8), challenges around evolving relations and expectations (5.3.6), and changing policy needs (5.3.7) — with majority high rating ranges at 85-100\%, 63-69\%, 54-60\%, 31-47\%, and $31-43 \%$, respectively. In overall, immaturity of consumer technology (5.3.1), cost constraints (5.3.2), and cloud service management (5.3.9) were regarded as medium with a majority rating at least $38 \%$; however, the Providers appeared to consider consumer technology as highly immature, and cloud service management as highly challenging. Economic downturn hindering consumerization initiatives (5.3.3) and service degradation (5.3.10) (combination of service delivery and network performance) were generally disregarded with the majority of low ratings at a minimum of $36 \%$; nonetheless, the Employees perceived the service degradation more moderately with equal rating (37\%) on low and medium.

The Focus Group findings suggested numerous security challenges inherent in PCS consumerization. Those security issues were ranged from security risks, compliance, implementation and enforcement. The participants suggested several instances of security risks including data leakage, security bypass, and security policy violation. "This tends to create an environment where data leakage is the norm."; "Sensitive data can be stolen using social engineering"; "While you can put policies in place to say don't use the services this will just drive the users deeper underground."; "Hence it's not so surprising many teams would finds ways to bypass policy to do their job better" (FOC). Inclusion of external cloud storage services into the corporate could be challenging in terms of service enrollment into corporate security frameworks and compliance with industry security standards. "Difficulties enrolling such services with company's security framework and 
policies..."; "I thought you were looking at the corporate framework and how the cloud might fit into that architecture."; "One thing that [may] help is that if you are PCI compliant and have data classifications, you could have a rule that only documents that fall in classes $x$ and $y$ can be put in cloud storage" (FOC).
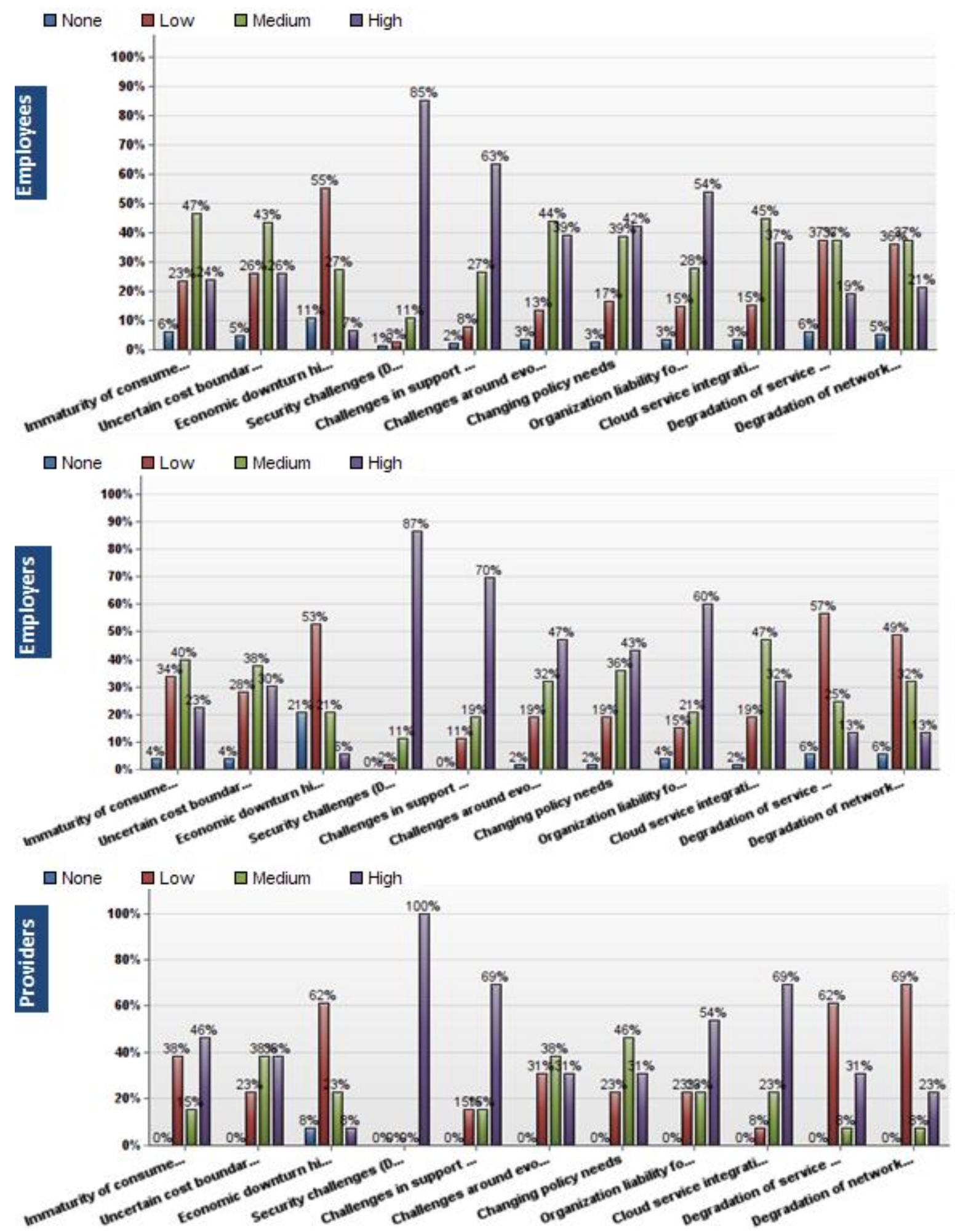

Figure 5-11 What Challenges can Personal Cloud Storage in the workplace pose to organizations? 
Furthermore, greater effort was necessary for implementing security awareness programs and education regarding to the value of data and the associated risks. "Before the tools, starting point is an awareness campaign about risk and value of the information."; "It has to start with policy, but it has to finish with training, auditing, and enforcement so employees understand that this is serious business" (FOC). Additional threats also lay on the security vulnerabilities of external cloud providers. "But, I am not all too convinced about the security offered by the major players (Dropbox, Google, etc.)."; "This is a big concern of mine especially with the many security breaches at Dropbox" (FOC).

The need for corporate policy change was strongly desirable for a formal adoption of PCS, according to the Focus Group. It was demanded for a relevant policy, particularly for the uptake. "It is important to have the proper policies in place" (FOC). Moreover, this also required reviewing, redefining, or establishing other related policies, e.g. information policy. “...an information policy will [define] this and a product/technology chosen to meet those requirements to separate out personal vs. organizational information”; “...due diligence, service and security level management and internal IT policies should all be reviewed or created (if [it's] not yet in existence) by the corporations before even consider using it" (FOC). Effective policies should be both strong and flexible, which ensures a robust security regime while meeting rapid business demands and fostering innovation simultaneously. "I think CIOs need to adopt a strategy... where they identify requirements with the staff, and jointly pick one system that everyone uses that meets both their needs for universal access, and your needs for security."; "Having policies which consider different types of data, and having an effective approach to the identification and application of metadata, can create an environment which controls sensitive data but does not stymie opportunities to innovate" (FOC).

In certain cases, organizations were legally bound to risks associated with handling data. The Focus Group pointed out critical legal obligations and liability imposed on organizations, especially some industries such as finance, health care, aerospace, and defense. "Of course, in a select few situations, the management of data is strictly regulated by law or policy. Financial services, health care, aerospace [and] defense, and other industries have clear policies which prevent specific types of data from any exposure outside the enterprise."; "Biopharmaceuticals are just one with heavy constraints. 
Financials are another. Your consumer may want zero hassle flexibility in accessing documents, but you are required to provide both safety and retention of the IP in those documents" (FOC).

Challenges in cloud service management were also another concern from the Focus Group. The participants described the need for ascertaining third party service management such as service and security level management, due diligence, and other vendor practices. "So essentially [it's] an Outsourced DMZ. So... same as in any other third party service management; due diligence, service and security level management..."; "Challenging your assumptions on partner security is a must, and understanding all of your partner's practices and procedures can uncover problems before they happen."; "Like many things in the enterprise, the proverbial sword can cut both ways. It's my view that the differentials in most cases are clearly defined, well enforced policy, and transparent, verifiable partner security" (FOC). Vendor liability for the corporate data being held was another point of careful consideration raised by the participants.

Regarding to degradation of service, the Focus Group suggested consideration over service and security level management in order to ensure satisfying delivery of storage services in supporting business operations. “...due diligence, service and security level management and internal IT policies should all be reviewed or created (if [it's] not yet in existence) by the corporations before even consider using it" (FOC). Nonetheless, there was no comment about network degradation.

About challenges around evolving relations and expectations, the Focus Group suggested increasing business desires were driving IT solutions. “...our workers are now driving demands for flexible answers to their data needs" (FOC).

There was no comment found in the Focus Group about other challenges, namely immaturity of consumer technologies, cost constraints and uncertain cost boundaries, economic downturn, or challenges in support and control.

In addition, two new challenges arose from the findings, namely data governance challenge, and corporate solution consideration. Data governance establishes policies overarching the implementation of data stewardship and data ownership, which is "a system of decision rights and accountabilities for information-related processes, executed according to agreed-upon models which describe who can take what actions with what 
information, and when, under what circumstances, using what methods" (Data Governance Institute, n.d.).

The survey findings suggested several instances of data governance challenges (5.3.11) such as risking corporate information assets or intellectual properties (IP) outside the corporate, loss of control over data, missing well-defined responsibility over data, and concerns over data ownership and stewardship. "Ownership of data especially when/if employees leave and the ability for organizations to remotely delete or control access, especially once the employment relationship has ended."; "Risks around loss of control of data once in cloud storage. Employee may leave and take IP with them" (EMP). "Personally and professionally, I consider that personal cloud storage has to be very carefully monitored in the workplace - where it is allowed at all - as there is too much to [lose] (security, privacy, data protection, Intellectual Property, etc.) for the business, merely for 'ease of use' of its employees."; "responsibility and ownership" (MAN). "This is actually a major issue for most business! having corporate IP exist outside the firewall in a consumer based free service stored offshore is risky at best" (PRO).

The Focus Group also raised several concerns about data ownership and stewardship including data safety, IP retention, IP loss with employee leaves, and corporate espionage. "Your questions brings up questions about Data Ownership and Data Stewardship and how they apply to different categories of data within an enterprise..."; "The downside is, the information may be essential IP, and cannot be accessed once an employee leaves the company"; "but you are required to provide both safety and retention of the IP in those documents."; "Internal threats are by far the biggest risk to a data and security as Edward Snowden proved" (FOC).

Consumerization of PCS was perceived as a short-term workaround, requiring for a longterm viable corporate solution (5.3.12). An employee commented that it was being "used as a secondary temporary backup in specific cases" (EMP). The Focus Group participants regarded the adoption as a temporary stop-gap arrangement to be replaced with a corporate solution in the future. "But, as a stop gap arrangement, with proper SOP's [Standard Operating Procedure] in place (as to what can be put on public drives, password protecting them and so on), it can be given the go ahead till the in-house infra or a dedicated vendor host box is in place" (FOC). 
In the long term, a formal corporate-level solution would be a viable measure. The overall findings from the surveys and the Focus Group suggested a new challenge in considering about offering a formal corporate solution in two approaches - pure equivalent corporate cloud systems, and commercial cloud solutions. The Employers recommended an effort for implementing a corporate-wide solution, e.g. private corporate cloud. "Find a corporate-wide solution which offers the same (or very similar) ease of use for employees, for placing corporate information safely in a cloud-based mature and secure storage area, which is a private corporate cloud. And preferably a cloud which is within that company's national boundaries" (MAN). The Providers also suggested an upgrade to a commercial cloud solution, e.g. corporate Dropbox. "Consumers will take the shortest path to solving their problem. Corporate Dropbox is a good way to give staff what they need whilst maintaining control" (PRO).

Similarly, the Focus Group recommended both corporate-built solutions and commercial cloud solution as a good approach for fulfilling the demands of employees and business operations. "My thoughts are that if you want to stop staff using Dropbox/Skydrive/Google Drive for work related storage then you should provide a solution that is just as good or better (i.e. private cloud)."; "best solution is not to try to fight against this usage but offer the same corporate level of service."; "The only valid route to take here, is to offer your employees a better solution ...than private Onedrive/Dropbox etc." (FOC).

\section{Discussion}

This section presents discussion and comparison analysis of the results addressed in the finding section and the literature review by focusing on the top important drivers, benefits and challenges inherent in PCS consumerization. Less significant factors are illustrated in the detailed and summary comparison tables in Appendices 5 and 6, respectively.

\subsection{A Glance at Consumerization of PCS in NZ Corporates}

Empirical evidences from this study show that consumerization of PCS is notably prevalent within NZ corporates from small companies to large enterprises. At the ratio of 7 in 10 of the Employees surveyed admitted using PCS at work with a certain frequency. This ratio is also true for the Employers agreeing with the trend, while the Cloud Providers appeared absolutely optimistic about their PCS consumers importing these tools into the workplace. This result found in the NZ context goes in line with the literature exploring at 
a national and global level, where approximately 3 of 5 global business leaders (Seagate, 2013) and 3 of 4 US workers (Stroz Friedberg, 2013) consumerized PCS.

The Kiwi workers surveyed seemed to be highly aware of the consumerization trend as proven by less than $10 \%$ of them getting aware of the trend only once reading the research information paper. This estimation might not fully represent general NZ employees, since the survey participants were likely those who had known about this trend while the majority of those who had not might have opted out of the surveys. Nonetheless, this outcome is parallel with what suggested in the literature about the 2013 wave of consumerization for PCS (Mitchell, 2013) and prior popular research publications by Gartner (2012), Conley (2013), Mullevey (2013) and so forth.

An IDC report (Burrus, 2013) depicted merely a quarter of corporate executives began coping with IT consumerization issues. How do Kiwi executives react with PCS consumerization? NZ corporates appear better than the IDC figure in that only about half of the Employees and a quarter of the Employers reported no policy about it. Approximately half of them (Employees and Employers) also conceded lack of security awareness programs or training related to the issue. Both the surveys and Focus Group revealed various measures used by NZ corporates dealing with PCS, including complete ban, partial prohibition for critical tasks or sensitive data, unrestricted use, and implementation of security awareness programs. Thus, NZ corporates appeared to have already dealt with the consumerization at a greater extent compared to the global trend.

\subsection{The Drivers}

Of all the drivers being investigated, 15 drivers are of significant importance, about which business executives should be well-informed. The surveys and the Focus Group findings strongly supported the profound impact of those drivers, despite the fact that many drivers get higher recognition than previously in the literature review and that three new drivers emerged purely from the data analysis. Those top 15 drivers are grounded in both the external environment (general industry, consumer devices and applications) and internal environment (employee behavior and corporate factors) of the business.

General Industry: The role of telecommunication infrastructure and consumer endpoint devices (6.1.1) is undeniably facilitating the growing adoption of PCS at workplaces. All the three surveys' results strongly supported the factors, although it was not directly 
mentioned in the Focus Group. The reason behind could be that the Internet and consumer devices have become part of everyday life. A Provider remarked on the Internet era and its enabling role. "In the internet era employees are expected to be mobile and effective every day and around the clock, and internet tools enable this" (PRO). With the presence of consumer devices, e.g. smartphones, and mobile Internet access ( $3 G$ and $4 G$ ) anywhere even in workplaces, there left a backdoor where employees could get personal cloud storage through to the corporate realm. An Employee gave her own experience about accessing cloud storage on personal Internet and devices at the workplace. "However I have to use my own personal device connected to an external Wi-Fi to do it. But the nature of my work means that I need to shift large files - so you find a way" (EMP). This ubiquity of Internet and consumer devices was also emphasized by Bless et al. (2010).

Data hoarding (6.1.2) is another push for PCS consumerization. This new factor was strongly supported by the survey respondents and Focus Group, although it was not present in the literature review as a driver. IDC (2014) projected an annual increase of $40 \%$ of the digital universe, whilst consumers and workers created two-thirds of the digital universe bits in 2013. This contributed to the currently escalating issues of data hoarding, which became a grave concern for organizations as their employees got flooded with massive volume of digital content and resorted to storing their work data outside the corporate firewall (Bertolucci, 2013). Moreover, this goes in line with a prediction by Gartner (2012) that a third of consumer data will go into cloud by 2016. In overall, this confirms a causal link between data hoarding and PCS consumerization.

Consumer Devices: There was a consensus between the survey results and the literature on two distinct characteristics of consumer devices-being disruptive technology (6.1.3) and its always-one feature (6.1.4) — making them a relevant platform for fostering PCS consumerization. The rapid uptake of smartphones and tablets, which can substitute the use of traditional PCs to a greater extent, made these consumer devices a disruptive technology (Clevengar, 2011). These devices capitalize on its instant access or always-on nature, becoming a perfect match with the on-demand access of cloud computing. Although the Focus Group generally did not mention any consumer device factor, this was highlighted in several additional comments from the Employees addressing the need for instant access; for example, "Always available access when required"; and "instant access to information" (EMP). 
Consumer Applications: Four major application-related factors were attributed to PCS consumerization. First, application usability of PCS (6.1.5) is one of the top drivers highly regarded in both the literature and the findings. The findings indicated that PCS is much more convenient to use and has more useful functionalities than proprietary enterprise systems. Ease of use and usefulness are key determinants for technology adoption, according to TAM (Venkatesh \& Bala, 2008). The literature illustrated several key functionalities of PCS including infinite access, document management and collaboration, secured backup, and unrestricted usability. These functionalities were also highlighted in the surveys and Focus Group; for instance ability to access anytime, anywhere and any devices; online backup; large file transport; fast speed; effective data control; document collaboration; synchronization; etc.

Second, PCS is generally available at very low cost, mostly free of charge. This Freemium licensing model (6.1.7) became another major driver of the consumerization. This factor relates to the third driver-cloud storage bundle with consumer devices (6.1.6). The literature pointed out a popular marketing strategy by several mobile device vendors, which provided cloud storage readily and freely embedded with those devices. These practices apparently encouraged the uptake of PCS. In recognizing the relationship between consumer devices and such consumer applications as PCS, a Focus Group participant argued that "If you allow BYOD, then by default you have already allowed BYOA" (FOC). These two factors were strongly supported by the surveys and Focus Group findings, whereas the literature initially recognized the licensing factor as low. For example, storage solutions at low cost, and its comparison to free email accounts were reflected in the Focus Group.

Finally, desires for collaborative work and necessity of social computing tools (6.1.8) in making collaboration possible in virtual communities became another driving force that moderately pushed for PCS consumerization. Although the Employees highly recognized this factor, there was a small decline on its recognition from the overall findings (Medium) as compared to the literature $(\mathrm{High})$. Nonetheless, the collaboration and social networking factor should not be overlooked as there emerged a new trend of Collaboration 2.0, which Gohring (2014) described as a convergence of web, cloud, and new kinds of collaboration centered around task management, chat, social networking and document sharing. Thus, cloud and social network are the cornerstones of Collaboration 2.0, and disregarding them 
would simply mean not following the Collaboration 2.0 trend. Accordingly, an Employee insisted, "Collaboration! Key use-case for me" (EMP).

Consumer Behavior: Other four important factors about consumer behavior are worth considering when dealing with the consumerization. Firstly, the possibility that PCS helps sort out bridging and synchronization problems as a result of consumers' ownership of multiple devices, either private or enterprise devices, encouraged the consumerization. Empirical evidences showed that all the parties (Employees, Employers and Providers) including the Focus Group strongly supported this device plurality factor (6.1.9). They highlighted the burden of working and moving data across device platforms, especially data synchronization. "Synchronization makes cloud storage compelling" (PRO). The literature also critically stressed the fact that cloud applications are key to solve the multiple device problem (Douglas \& Katz, 2013). Thus, there concluded an absolute agreement on the factor of multiple devices.

Secondly, mobility of customers and employees (6.1.10) necessitated the use of PCS. This mobility demand could be coupled with the third driver-work/home permeability (6.1.12). The survey findings strongly supported this mobility and blurring work/home boundary, aligned with the literature at an increase of high recognition of mobility. Although the Focus Group merely mentioned staff and work mobility, yet failed to highlight work/home permeability, it is apparent that the two concepts are highly intertwined. There has been a great demand for flexible work environments, for instance home working, remote workplace, mobile work, telework and virtual office. This has been made possible by technology such as portable computers, smartphones, the Internet, and secure communication infrastructure, so that people are no longer confined in a particular physical location to do their job (Currie \& Eveline, 2011; Hill, Miller, Weiner, \& Colihan, 1998). A similar case was also found in a recent study in the government sector (Hutchins, 2014), claiming that cloud-based file storage, being an anytime and anywhere computing enabler, helped organizations achieve collaboration, mobility, and operational continuity.

Lastly, changing expectations of customers and employees about workplace technology (6.1.11) remained a moderate driver as identified earlier in the literature review. While the surveys rated this factor with medium recognition, the expectation of equivalent corporate technology and employee-driven technology initiatives were emphasized in the Focus Group. These employee assumptions presumably drove their actions into PCS 
consumerization. Moreover, this consumerization could also have been facilitated by the changing corporate IT role from a resource controller to a resource enabler and service provider (Babcock, 2011).

Corporate Factors: Three factors born within enterprises stood out as significant drivers, two of which did not surface in the literature review. Firstly, poor corporate technology (6.1.13) was an undeniable cause of PCS consumerization, according to overall findings. This is a new driver which purely emerged from the data analysis. The Employees, Employers, Providers, and Focus Group altogether indicated several limitations of corporate legacy technology, including complexity, poor network infrastructure, outdated systems, disintegrated systems, and IT services' responsiveness to business requirements. As they suggested, employees found PCS better fulfilling their corporate technology gaps. Secondly, PCS intruded into the corporate realm was also found to be caused by not having relevant corporate policies in place (6.1.14), which was another emerging driver from the overall findings. Each party raised various cases, making a huge gap of policy problems. Employee using PCS at work with or without a deliberate attempt against security policy was a result of loose or missing relevant guidelines and policy-related programs, according to the Employees. While the Employees mentioned security bypass, ignorance about policy, and low awareness about risks, the Employers and the Providers criticized about intentional policy violation and insufficient relevant policies. Another notable point about one policy (e.g. BYOD) leaving a space for consumer applications (e.g. PCS) was made in the Focus Group. Thus, these corporate technology and policy matters were outstanding and might attract potential concerns regarding to PCS consumerization.

Thirdly, employees of the younger generation (6.1.15), in other words, tech-savvy workers or digital natives, rose in its importance from low recognition in the literature review to a medium driver in the findings. The Employees, Employers, and Providers altogether acknowledged medium recognition for this factor. Similar to Bernnat et al. (2011) claiming that digital-native employees are early adopters of new consumer technology in the market, the Focus Group also highlighted the interrelationship between modern workers, business requirements, and technology requirements. It implied that desires of contemporary employees and business needs drove new technology requirements. 
Table 6-1 depicts the top drivers' changes in recognition between the literature and the findings.
Literature $\star$ Consensus Finding (surveys $\star$ Finding (only surveys) + Finding (only focus $\&$ focus group) group)

REF. DRIVERS

RECOGNITION

Low Medium High

General Industry

6.1.1 Telecommunications-infrastructure and general

$\Delta \star$ Affordability

6.1.2 Data hoarding

\section{Consumer Devices}

6.1.3 Consumer devices as disruptive technology

6.1.4 Always-on feature of consumer devices

\section{Consumer Applications}

6.1.5 Superior application usability

6.1.6 Cloud bundle

6.1.7 Attractive licensing models

6.1.8 Collaboration and social computing tools

$\theta$

**

\section{Consumer Behaviour}

6.1.9 Plurality of devices

6.1.10 Increasing mobility of customers and employees

6.1.11 Workplace expectation of customers and employees are changing

6.1.12 Blurring of work and home

\section{Corporate Factors}

6.1.13 Corporate technology limitations

6.1.14 Corporate policy limitations

6.1.15 Employees from younger generation and digital natives

Table 6-1 Significant Drivers: Comparison of the findings with literature

\subsection{The Benefits}

Of all the benefits in the study findings, there exist seven outstanding benefits that PCS consumerization may bring to corporates. The survey findings showed merely moderate benefits with gain and loss in recognition compared to the literature, and a new benefit 
purely emerged from the Focus Group. Although there are no substantial benefits, it is worthwhile to consider those seven major benefits.

The practice of PCS consumerization found its moderate importance in employee engagement and talent retention (6.2.1). As suggested in the literature review, employee satisfaction with easier ways in getting their job done (Burrus, 2013), and their feeling of empowerment through their demands and initiatives on technology use (Conley, 2013) determined constant engagement with their job and contributed to retaining talents. The Employees, Employers, and Providers altogether regarded this benefit as medium down from the high recognition in the literature, while the Focus Group stressed on employees' goodwill and social benefits, making them happier and more satisfied employees. More evidences were discovered in many additional comments emphasizing easier jobs, convenient tools and valuable technology. "Greater flexibility for employees who find it easier to work from home" (EMP). "People tend to seek simple things that just get the job done" (PRO). "I immediately saw the benefit - having access to my documents anytime, anywhere, on any device was enormously valuable" (FOC).

Business agility and competitive advantage (6.2.2) is another important benefit. The overall findings suggested that staff mobility, agile IT architecture, and cloud strategic potential were the benefits of PCS consumerization. The Employees, Employers and Providers altogether regarded the benefit as medium, lower compared to the high recognition in the literature,. Moreover, business agility, responsiveness, and always catching up with technology were remarked by a Provider. "Enterprises adapting consumer technology get the job done faster, and is more likely to be experienced as an agile, responsive, and up-to-date organization that is more fun to work with for customers and suppliers" (PRO). These findings go parallel with those indicated in the literature, including greater business agility (Burrus, 2013); organizational flexibility (Unisys, 2010); IT flexibility (Blount, 2011); and employees' enthusiasm for consumer IT (Junglas \& Harris, 2013). It also demonstrated the open opportunities of consumer cloud storage which organizations should never miss while everyone else can always leverage (Andriole, 2012; Blount, 2011).

Cost benefit (6.2.3) was another crucial outcome. The surveys showed medium recognition on this benefit, higher compared to the literature review regarding it as only a cost reduction from employees using their own devices and tools. However, there were 
several other sources of cost savings found in the Focus Group, including low-cost storage solutions due to new consumer licensing model; operational cost reduction through innovative and collaborative tools; IT maintenance cost reduction via cloud infrastructure; and long-term cost savings of cloud strategies. Thus, there appeared many channels of cost benefits, other than the saving from not investing on employees' private devices and tools.

Another benefit is the increase in business productivity derived from three sources-new technology (6.2.5), consumer behavior and skills (6.2.6), and employee trusted relationship (6.2.4), according to the literature. These three sources of work productivity gained moderate support in the Employee, Employer and Provider surveys. Indicators of business productivity, revealed in the Focus Group, fall under the operational perspective, including enhanced work efficiency, team collaboration, and greater corporate data access. Although the Focus Group did not specifically mention the three productivity sources, it became obvious that organizations gained certain business productivity through PCS consumerization. This result is in line with a recent global survey (Junglas \& Harris, 2013) showing employee perspectives that such consumer technology is deemed as a productivity enhancer making employees work more effectively and efficiently.

The last important, yet brand-new benefit is data security solution workaround (6.2.7). Purely emerging from the Focus Group, this benefit was considered to a temporary solution, which could be a vital step prior to a full-fledged corporate solution. Despite its off-the-firewall drawback, PCS actually offers a certain level of data security including high availability of services and mitigation against data loss and leakage due to such incidents as device loss, hardware failure and file damage. This could be a choice for data storage solution when data confidentiality and privacy were not the case. An Employee suggested that PCS was "used as a secondary temporary backup in specific cases" (EMP). In the case of a larger scale deployment at a corporate level, having an accompanying policy is necessary for an enterprise-managed cloud storage version. "For larger organizations especially, provide an enterprise-managed version or alternative where the organization retains control of the service (e.g. Citrix ShareFile or WatchDox). This needs to be paired with explicit business conduct training delivered annually" (MAN).

Table 6-2 exhibits the outstanding benefits, showing changes in the recognition between the literature and findings. 
Literature * Consensus Finding (surveys \& focus group) + Finding (only focus group)

\begin{tabular}{lll} 
REF. & BENEFITS & RECOGNITION \\
\hline $\mathbf{6 . 2 . 1}$ & Employee engagement and retention & LOW \\
$\mathbf{6 . 2 . 2}$ & Competitive advantage and agility \\
$\mathbf{6 . 2 . 3}$ & Cost benefits \\
$\mathbf{6 . 2 . 4}$ & Employee productivity through trust \\
$\mathbf{6 . 2 . 5}$ & $\begin{array}{l}\text { Productivity through employees bringing in new } \\
\text { technology }\end{array}$ \\
$\mathbf{6 . 2 . 6}$ & $\begin{array}{l}\text { Productivity through employees bringing in } \\
\text { consumer behaviour and skills }\end{array}$ \\
$\mathbf{6 . 2 . 7}$ & Data security solution workarounds
\end{tabular}

Table 6-2 Significant benefits: Comparison of the findings with literature

\subsection{The Challenges}

Eight challenges of high significance stood out from the list of challenges of PCS consumerization under investigation. Security, support/control, and regulatory obligations were the top three issues highly recognized in the surveys, while data governance and corporate solution emerged as new challenges from open responses of the surveys and Focus Group.

Security challenge (6.3.1) was among the top concerns for corporates. As indicated in the literature review, data leaks, compliance with data and security standards, privacy, system hack, and virus spread are critical to corporate security (Sen, 2012). These issues were evident in the Focus Group, namely security risks, compliance, implementation and enforcement. For instance, sensitive data leakage, security bypass by employees, and security policy violation were serious security risks. Compliance was challenging in terms of enrolling external cloud services into corporate security frameworks, compliance with industry security standards, and ensuring third-party security compliance. Security implementation and enforcement required a great deal of efforts in conducting security awareness programs and education regarding to the value of data and the associated risks. A Provider raised a dilemma between imposing security restrictions and provisioning of alternative solutions. "Employees and teams will find ways to get their work done, regardless of impediments inflicted by corporate IT staff... Corporations would be better served from a data security and confidentiality standpoint if they implemented easy-to-use 
cloud file sharing products for their employees, while ensuring a degree of control, security and data integrity" (PRO).

Another enormous challenge was a burden on corporate IT in shouldering support and control (6.3.2) inherent in accommodating PCS use. As Blount (2011) and D'Archy (2011) raised critical concerns over managing and supporting consumer devices, the survey results also highly regarded the control and support challenges. Though none was mentioned in the Focus Group, additional comments in the surveys shed more light on the issue. In addition to controlling and supporting consumer devices through which employees commonly accessed cloud storage, as far as corporate data management was concerned it is essential that data repositories be effectively managed so that there would be no partial data residing off the central data repository. "Make data available in the cloud instead, using shared storage rather than individual storage. ...Enable, authorize and support employee use of mobile and personal devices, because they will use them anyway, leading to bootleg, DYI solutions causing spread of corporate data" (PRO). "In the public sector it is mainly a risk as cannot readily capture information as required under legislation, yet more repositories to manage and support discovery" (EMP).

Regulatory obligations on organizations (6.3.3) were another huge challenge.

Organizations, particularly finance, health care, aerospace, and defense, are confronted with legal obligations on risks in handling corporate data, specifically sensitive client data, according to the Focus Group. The literature review also suggested legal liability on organizations for employee violation of copyrights and licenses. Copyrights and IP also became serious concerns of an Employee. “...but with data security, copyrights, and IP concerns on the rise, organizations may want to consider alternatives that can offer better control" (EMP). Moreover, according to another Employee's view, organizations might be constrained by the government regulations, for example privacy act and data protection law. "Understanding of legal commitments—privacy, data protection laws, etc., some countries, including NZ, do not permit certain types of personal info to be stored offshore" (EMP).

The need for change in corporate policies (6.3.4) is another highly recognized challenge, rising from medium recognition of the literature review. According to the Focus Group, it might require to establish specific policies for PCS consumerization, or existing related policies to be reviewed or redefined, e.g. information policy. However, there was a need 
for effective, flexible policies that would achieve a robust security regime and meeting rapid business demands simultaneously. An Employer added that once participating in cloud services, organizations needed to "implement good policies to manage security and authenticity of information" (MAN).

Challenges around evolving relations and expectations (6.3.5) were found strongly critical, rising from low recognition in the literature review. The literature indicated organization-wide relations and expectations: business expecting IT as enablers rather than gatekeeper (Blount, 2011); virtuous cycle of consumer search and vendor publishing (van Zant, 2009); transformation to more customer-centric attitude of business (Moschella, 2011); technology adoption pattern between industries (Moschella, 2011); and employee needs and talent retention necessitating the workplace effort in technology advancement (Blount, 2011; D'Archy, 2011). Of these challenges, only the pressure on IT department in switching from controlling to empowering the business was reported in the Focus Group. Feldman (2013) supported that it is better off for IT department to build its credibility by engaging with employees and creating welcoming atmosphere where employees will always seek IT's opinion before using new technology. A view by executive panelists at 2014 CITE Conference and Expo encouraged an internal consultant role of IT department, which act as a kind of cloud services broker in advising business leaders and supporting the business in adopting cloud services while still maintaining compliance and security (Kaneshige, 2014). The matters of employee satisfaction and talent retention were reflected in the above benefits of the consumerization. Nevertheless, the overall survey results recognized this challenge as high.

Another moderate challenge is cloud service management and integration (6.3.6). As indicated in the literature, there were difficulties in ensuring that PCS services are secure, reliable, and well-integrated with other enterprise services. While the surveys generally recognized this challenge as medium, there were some important points to note in the Focus Group. Service and security level management, due diligence, and vendor practices were critical concerns in managing the third-party services. More importantly, careful consideration should be put into how cloud providers would be liable for the corporate data they hold.

Data governance (6.3.7) became a formidable challenge, emerging from the open responses of the surveys and the Focus Group. Data governance deals with decision rights 
and accountability over information processes (Data Governance Institute, n.d.). The Employees, Employers, and Providers raised several instances of data governance challenges, namely risking corporate information assets or IP outside the corporate, loss of control over data, lack of well-defined responsibility over data, and concerns over data ownership and stewardship. Many concerns about data ownership and stewardship including data safety, IP retention, IP loss with employee leaves, and corporate espionage were also stressed by the Focus Group. When dealing with cloud computing, risks and liabilities should be evaluated, making data governance policies necessary for organizations (Vizard, 2010). As corporate data resided off corporate firewall, Chen (2011) suggested that data governance should be considered as a key part in the corporate cloud strategy, especially its four sub-disciplines: data definition, lifecycle, quality, and security.

Another newly emerged challenge is consideration for a proper corporate solution (6.3.8). This challenge was also highly regarded in numerous open comments of the surveys and the Focus Group. Since PCS consumerization was considered as temporary, there was a need for a viable solution for the long term. A formal corporate-level solution was highly considered in two approaches - equivalent corporate cloud solutions, and commercial corporate-graded cloud solution-according to the overall findings from the surveys and the Focus Group. While the Employers recommended a private corporate cloud such as commercial version cloud storage, the Focus Group suggested either corporate-built solutions or commercial cloud solutions as a choice. Regardless of which option to choose, it became challenging for organizations to consider many issues, for instance self-readiness assessment for cloud, data classification for going to the cloud (Staimer, 2013), and criteria for cloud system selection (Sullivan, 2014).

Many of those top challenges rose higher in recognition than previously noted in the literature review. Table 6-3 illustrates the comparison changes. 


\begin{tabular}{|c|c|c|c|c|}
\hline \multicolumn{2}{|r|}{ * Consensus Finding (surveys \& fo } & group) & \multicolumn{2}{|c|}{$\star$ Finding (only surveys) } \\
\hline \multirow{2}{*}{ REF. } & \multirow{2}{*}{ Challenges } & \multicolumn{3}{|c|}{ RECOGNITION } \\
\hline & & Low & MEDIUM & HIGH \\
\hline 6.3 .1 & Security challenges & & & $\theta *$ \\
\hline 6.3 .2 & Challenges in support and control & & & $\theta \star$ \\
\hline 6.3 .3 & Regulatory obligations & & & $* *$ \\
\hline 6.3 .4 & Changing policy needs & & $\theta$ & $*$ \\
\hline 6.3 .5 & $\begin{array}{l}\text { Challenges around evolving relations and } \\
\text { expectations }\end{array}$ & 8 & & $\star$ \\
\hline 6.3.6 & Cloud service management and integration & & $\theta *$ & \\
\hline 6.3 .7 & Data governance challenges & & & $*$ \\
\hline 6.3 .8 & Consideration on corporate solution & & & $*$ \\
\hline
\end{tabular}

Table 6-3 Significant challenges: Comparison of the findings with literature

\section{Limitations and Implications for Future Research}

There are three main limitations of this research found to be challenging. Firstly, this research was based on a small sample of data. A total of 216 complete responses, and 36 participants in the online focus group were collected, while the short time frame of six months appeared to constrain the scope and in-depth of the study. Secondly, the data sources could be also challenged since participants were mainly based on LinkedIn, and the researcher's academic and social networks. Third, bias on data analysis and interpretation could be potentially high due to the issue of a single researcher, which failed to meet "investigator triangulation" (Yeasmin \& Rahman, 2012). Moreover, this could be influenced by the researcher's IT professional background.

Consumerization of PCS is a relatively new phenomenon, having drawn increasing attention of NZ executives as well as global business leaders over the recent years. The literature showed quite little academic research investigating this issue, especially in the NZ context. More research needs to be done in a larger scale which involves deeper investigation into the issue, more variety of qualitative and quantitative research methods, and greater participation not only from employees, employers, and service providers, but also from other likely impacted stakeholders e.g. customers, suppliers, partners, regulators, etc. Furthermore, relationship between the consumerization and other technological and 
business phenomena should be thoroughly investigated in order that future research promises to shed greater light on the consumerization issues and other related areas. In addition, seeking for more expert recommendations for harnessing greater benefits yet lowering risks from the consumerization trend would be worthwhile.

\section{Conclusion}

The objective of the study was to investigate the state of PCS consumerization in NZ corporates by identifying the drivers, corporate benefits and challenges inherent in the trend. In light of prior literature works in IT consumerization, particularly Sen (2012), and recent publications in PCS, this study concludes that many drivers, benefits and challenges, which existed in predecessor IT consumerization trend and previous market researches in PCS along with those newly found in this study, remain prevalent in PCS consumerization in the NZ context. The analysis on the survey responses and focus group data illustrates the pervasiveness of PCS adoption by employees in NZ corporates. Publications and word-of-mouth are two major mediums of getting informed about the trend. Unfortunately, there are considerable concerns over lack of policies and security awareness programs in corporates regarding to the consumerization.

The study also provides new insights into the consumerization trend, offering richer understanding in addition to the literature. The driving forces of the consumerization are rooted in the industry-wide development, consumer devices and applications, behavior of consumers, and the issues within the organizations themselves. Some drivers identified in the literature review lose the recognition, while many gain high significance; moreover, attention should also be drawn on such newfound drivers as limitations of corporate technology, corporate policy limitations, and data hoarding phenomenon. Several driving forces identified as a result of this study go along with a global study by Transparency Market Research (2013) indicating that five major factors-1) demand for efficient storage, 2) increased frequency of data access, 3) data sharing, 3) usage of portable devices, 4) cost effective storage, and 5) safety against data loss — will be driving the personal cloud market over a six-year period (2013-2019) .

In overall, the challenges considerably outweigh the benefits which the consumerization might bring to businesses. The majority of challenges identified in the literature are highly recognized. Serious concerns are among security challenges, control and support, 
regulatory obligations imposed on organizations, and the need for policy changes.

Organizations might be confronted with other two emerging challenges: data governance and consideration for introducing corporate storage solutions. Interestingly, three of those challenges of this study (security, data governance, and corporate storage solutions) are also closely related to those top challenges (security concerns, low awareness, cost constraints, and affordable safe data storage) of Transparency Market Research (2013) projection.

Apart from the challenges, the majority of benefits recognized in the literature either lower or higher are considered as medium. Nevertheless, corporates might also realize several major benefits including enhanced work productivity, better employee engagement and retention, certain degree of competitive advantage, and cost efficiency on operation and technology investment. Accordingly, not only does this study outcome provide a glance at the trend of PCS in the workplace, but also it reflects the cause and effect view on the PCS consumerization, which current NZ corporates may take into account. 


\section{References}

Andriole, S. J. (2012). Managing technology in a 2.0 world. IT Professional Magazine, 14(1), 50-57.

Atkinson, P., \& Hammersley, M. (2007). Ethnography: Principles in practice (3rd ed.). New York: Routledge.

Babcock, C. (2011). Consumerization and cloud: IT isn't keeping up. InformationWeek. Retrieved November 28, 2013, from

http://www.informationweek.com/cloud/software-as-a-service/consumerization-andcloud-it-isnt-keeping-up

Bernnat, R., Acker, O., Bieber, N., \& Johnson, M. (2011). Friendly takeover, The consumerization of corporate IT. Booz\&Co. http://www.booz.com/media/uploads/Friendly_Takeover.pdf

Bertolucci, J. (2013). Data hoarding: How to stop. InformationWeek. Retrieved April 6, 2014, from http://www.informationweek.com/software/data-hoarding-how-to-stop

Bless, E., Alanson, M., \& Noble, C. (2010). Consumerization: What is in store for IT? Intel-Maritz [IMR Position Paper].

http://i.dell.com/sites/content/business/solutions/whitepapers/en/Documents/intel-imrconsumerization-wp.pdf.

Blount, S. (2011). The consumerization of IT: Security challenges of the new world order. CA Technologies. http://www.ca.com/us/ /media/Files/TechnologyBriefs/Consumerization-of-IT-TechBrief.pdf

Bryman, A., \& Bell, E. (2011). Business research methods (3 ed.). New York: Oxford University Press.

Burrus, D. (2013, July 15). Four ways to transform the consumerization of IT into competitive avantage [blog]. Retrieved from http://www.linkedin.com/influencers/20130715155920-48342529-four-ways-totransform-the-consumerization-of-it-into-competitive-advantage

Buyya, R., Yeoa, C. S., Venugopala, S., Broberg, J., \& Brandic, I. (2009). Cloud computing and emerging IT platforms: Vision, hype, and reality for delivering computing as the 5th utility. Future Generation Computer Systems, 25(6), 599-616.

Caldwell, C., Zeltmann, S., \& Griffin, K. (2012). BYOD (Bring Your Own Device). Competition Forum, 10(2), 117-121.

Chen, W. (2011, Arpil 5). Data governance should be a key part of your cloud strategy. Kalido. Retrieved April 24, 2014, from http://blog.kalido.com/data-governance-keypart-cloud-strategy/

Cheston, R. W. (2012). BYOD and consumerization: Why the cloud is key to a viable implemenation. Lenovo White Paper. http://www.partnerinfo.lenovo.com/partners/us/resources/downloads/toolkit/BYODWhite-Paper-Cheston.pdf

Clevengar, N. (2011). IPad in the enterprise: Developing and deploying business applications. Indianapolis, IN: Wiley.

Cobb, M. (2007). Are USB storage devices a serious enterprise risk? TechTarget. Retrieved December 29, 2013, from http://searchsecurity.techtarget.com/answer/AreUSB-storage-devices-a-serious-enterprise-risk

Conley, A. (2013). Privacy, security and control: The consumerization of the personal cloud. The Server Side. Retrieved November 27, 2013, from 
http://www.theserverside.com/feature/BYOC-Beyond-the-consumerization-of-thepersonal-cloud

Connor, D., Corrigan, P. H., \& Bagley, J. E. (2011). Cloud storage: Adoption, practice and deployment An Outlook Report from Storage Strategies NOW. Austin, TX: Storage Strategies NOW.

Cooper, D. R., \& Schindler, P. S. (2008). Business research methods (10th ed.). New York: McGraw-Hill Irwin.

Currie, J., \& Eveline, J. (2011). E-technology and work/life balance for academics with young children. Higher Education, 62(4), 533-550.

CXOtoday. (2013). IT consumerization to drive cloud adoption: Study. CXO Today. Retrieved November 29, 2013, from http://www.cxotoday.com/story/itconsumerization-to-drive-cloud-adoption-study/

D'Archy, P. (2011). CIO strategies for consumerization: The future of enterprise mobile computing. Dell CIO Insight Series. http://marketing.dell.com/Global/FileLib/hp_microsite/dell-consumerization.pdf

Data Governance Institute. (n.d.). Data governance: The basic information. Retrieved April 11, 2014, from http://www.datagovernance.com/adg_data_governance_basics.html

Douglas, \& Katz, D. (2013). Embrace the BYOD future with mobile cloud computing applications. Dynamic Digital Advertising. Retrieved December 9, 2013, from http://www.zeroonezero.com/blog/index.php/iphoneipad-applicationdevelopment/embrace-the-byod-future-with-mobile-cloud-computing-applications/

Drago, I., Mellia, M., Munafò, M. M., Sperotto, A., Sadre, R., \& Pras, A. (2012, November). Inside Dropbox: Understanding personal cloud storage services. Paper presented at the Proceedings of the 2012 ACM Conference on Internet Measurement Conference, 14-16 November 2012, Boston, MA: ACM.

Egnyte. (n.d.). Complete feature list: HybridCloud access and storage Egnyte. Retrieved January 6, 2014, from http://www.egnyte.com/file-server/online-file-serverfeatures.html

Engebretson, J. (2011). SMB Study: Mobile workers drive demand for bundled cloud storage services. Connected Planet Online Business Services. Retrieved December 9, 2013, from http://connectedplanetonline.com/business_services/news/SMB-StudyMobile-workers-drive-demand-for-bundled-cloud-storage-services-0705/

ENISA. (2012). Consumerization of IT: Top risks and opportunities. Heraklion, Greece: European Network and Information Security Agency.

Faas, R. (2012). In weighing data security risks, don't forget the ubiquity of USB flash drives. CITEworld. Retrieved December 29, 2013, from http://www.citeworld.com/security/20585/weighing-data-security-risks-dont-forgetubiquity-usb-flash-drives

Feldman, J. (2013, December 26). Is personal cloud as disruptive as personal computer? InformationWeek. Retrieved April 29, 2014, from http://www.informationweek.com/is-personal-cloud-as-disruptive-as-personalcomputer

FileTrek. (2012). FileTrek survey: 90\% of American adults believe people share company confidential information outside the company. https://filetrek.com/press/2012/03/filetrek-survey-90-percent-of-adults-believepeople-share-company-confidential-information-outside-the-company

Floridi, L. (2012). Big data and their epistemological challenge. Philosophy \& Technology, 25(4), 435-437. 
Gallup. (2010). Employee engagement: What's your engagement ratio? http://www.gallup.com/file/strategicconsulting/121535/Employee_Engagement_Over view_Brochure.pdf

Gartner. (2012). Gartner says that consumers will store more than a third of their digital content in the cloud by 2016. Retrieved November 27, 2013, from http://www.gartner.com/newsroom/id/2060215

Gens, F., Levitas, D., \& Segal, R. (Producer). (2011). 2011 consumerization of IT study: Closing the "Consumerization Gap". IDC-IView Content [Sponsored by Unisys]. Retrieved from http://www.unisys.com/iview

Gohring, N. (2014, April 10). Collaboration 2.0: Old meets new. Computerworld. Retrieved April 19, 2014, from http://www.computerworld.com/s/article/9247338/Collaboration_2.0_Old_meets_new

Golden, B. (2011). What 'consumerization of IT' really means to CIOs. IT World Canada. Retrieved November 30, 2013, from http://www.itworldcanada.com/article/whatconsumerization-of-it-really-means-to-cios/44748

Grajek, S., \& Pirani, J. A. (2012). Top-ten IT issues, 2012. EDUCAUSE Review, 47(3), 36.

Hennink, M. M., Hutter, I., \& Bailey, A. (2011). Qualitative research methods: Sage.

Hill, E. J., Miller, B. C., Weiner, S. P., \& Colihan, J. (1998). Influences of the virtual office on aspects of work and work/life balance. Personnel Psychology, 51(3), 667683.

Hutchins, D. (2014, April 17). The Benefits and dangers of choosing cloud-based file sharing. StateTech. Retrieved April 21, 2014, from http://www.statetechmagazine.com/article/2014/04/benefits-and-dangers-choosingcloud-based-file-sharing

IDC. (2012). The Digital Universe in 2020. Retrieved April 6, 2014, from http://www.emc.com/leadership/digital-universe/index.htm

IDC. (2014, April). The digital universe of opportunities: Rich data and the increasing value of the internet of things. Retrieved April 18, 2014, from http://www.emc.com/leadership/digital-universe/2014iview/executive-summary.htm

Junglas, I., \& Harris, J. (2013). The promise of consumer technologies in emerging markets. Association for Computing Machinery. Communications of the ACM, 56(5), 84.

Kaneshige, T. (2014, April 30). Why CIOs shouldn't block rogue cloud apps. CIO. Retrieved May 6, 2014, from http://www.cio.com/article/752188/Why_CIOs_Shouldn_t_Block_Rogue_Cloud_App $\mathrm{s}$

Kaplan, J. (2012, July 17). The next enterprise wave is Consumerization of cloud storage [Expert blog]. Retrieved from http://www.symform.com/blog/consumerization-ofcloud-storage/

Kennada, A. (2013, November 14). Cloud computing, consumerization and mobility are blurring the boundaries between work and life [Symantec official blog]. Retrieved from http://www.symantec.com/connect/blogs/cloud-computing-consumerizationand-mobility-are-blurring-boundaries-between-work-and-life

Lee, S. K. J. (1992). Quantitative versus qualitative research methods - two approaches to organisation studies. Asia Pacific Journal of Management, 9(1).

Leinwand, A. (2007). The portable risk of high capacity USB drives. Gigaom. Retrieved December 29, 2013, from http://gigaom.com/2007/12/05/the-portable-risk-of-highcapacity-usb-drives/ 
Lelii, S. R. (2011). The cloud washing game: Key functions of a private storage cloud. TechTarget. Retrieved January 6, 2014, from http://searchcloudstorage.techtarget.com/feature/The-cloud-washing-game-Keyfunctions-of-a-private-storage-cloud

Madden, B. (2011, June 2). The consumerization of IT: Why most vendors get it wrong, and why it's a real challenge today (Part 1) [Web Log]. Retrieved from http://www.brianmadden.com/blogs/brianmadden/archive/2011/06/02/theconsumerization-of-it-why-most-vendors-get-it-wrong-and-why-it-s-a-real-challengetoday-part-1.aspx

Martini, B., \& Choo, K.-K. R. (2013). Cloud storage forensics: ownCloud as a case study. Digital Investigation, 10(4), 287-299.

McGrath, C., \& Freed, E. (2012). Social intranet \& employee engagement: An HR solution for meaningful morale building. http://www.thoughtfarmer.com/engagement/

Mell, P., \& Grance, T. (2011). The NIST definition of Cloud Computing:

Recommendations of the National Institute of Standards and Technology, NIST Special Publication 800-145. http://csrc.nist.gov/publications/drafts/800-145/DraftSP-800-145_cloud-definition.pdf

Microsoft. (2011). Strategies for embracing consumerization. Microsoft Corporation. http://download.microsoft.com/download/E/F/5/EF5F8B95-5E27-4CDB-860FF982E5B714B0/Strategies\%20for\%20Embracing\%20Consumerization.pdf

Mitchell, R. L. (2013). Bring your own cloud. Computerworld, 47(9), 26-30.

Mokros, I. (2013, March 11). Personal clouds, consumerization and the post-PC era [Blog]. Ottawa Business Journal. Retrieved November 29, 2013, from http://www.obj.ca/Blog-Article/b/23882/Personal-Clouds-Consumerization-and-thePostPC-era

Moschella, D. (2011, June 23). What the consumerization of IT means to your business, ten messages for CXOs [Bog]. Retrieved from http://lef.csc.com/blog/post/2011/06/what-the-emconsumerization-of-item-means-toyour-business-ten-messages-for-cxos

Mullevey, P. (2013). Consumerization is revolutionizing "File Sync And Share" services. CloudTweaks RSS. Retrieved November 29, 2013, from http://www.cloudtweaks.com/2013/10/consumerization-is-revolutionizing-file-syncand-share-services/

Myers, M. D. (2008). Qualitative research in business \& management: Sage Publications Ltd.

Norman, G. (2011). Apple Bundle: iCloud, iOS 5, Mac OS X Lion, MacShield. Retrieved December 9, 2013, from http://www.findmysoft.com/news/Apple-BundleiCloud-iOS-5-Mac-OS-X-Lion-MacShield/

Prete, C. D., Levitas, D., Grieser, T., Turner, M. J., Pucciarelli, J., \& Hudson, S. (2011). IT consumers transform the enterprise: Are you ready? An IDC White Paper sponsored by CA Technologies. http://www.ca.com/ /media/Files/whitepapers/signatureresearch-idc-whitepaper-final.pdf

Raphael, J. (2013a). The worst cloud outages of 2013 (part 2). Computerworld. Retrieved December 31, 2013, from http://www.computerworld.com/slideshow/detail/133448/The-worst-cloud-outagesof-2013--part-2-

Raphael, J. (2013b). The worst cloud outages of 2013 (so far). InfoWorld. Retrieved December 31, 2013, from http://www.infoworld.com/slideshow/107783/the-worstcloud-outages-of-2013-so-far-221831 
Rigsby, J. (2011, April 1). The personal cloud floats into the enterprise [Blog]. Green Data Center Blog RSS. Retrieved November 29, 2013, from http://greendatacenterconference.com/blog/the-personal-cloud-floats-into-theenterprise/

Rodrigues, T. (2012). The importance of network effects for cloud computing. TechRepublic. Retrieved December 9, 2013, from http://www.techrepublic.com/blog/the-enterprise-cloud/the-importance-of-networkeffects-for-cloud-computing

Rodrigues, T. (2013, February 7). How the cloud has enabled the consumerization of applications. TechRepublic. November 27, 2013, from http://www.techrepublic.com/blog/the-enterprise-cloud/how-the-cloud-has-enabledthe-consumerization-of-applications/

Schaffhauser, D. (2013). Going behind IT's back. Campus Technology, 26(6), 7-10.

Seagate. (2013). Personal cloud storage use creates challenge for IT. Seagate Cloud News. Retrieved December 12, 2013, from http://cloud.media.seagate.com/2013/10/07/personal-cloud-storage-use-createschallenge-for-it/

Sekaran, U., \& Bougie, R. (2010). Research methods for business: A skill-building approach (5th ed.). New York: Wiley.

Sen, P. K. (2012). Consumerization of information technology: Drivers, benefits and challenges for New Zealand corporates. Victoria University of Wellington, Wellington, New Zealand. Retrieved from http://researcharchive.vuw.ac.nz/handle/10063/2095

Sheldon, R. (2011). Risk vs. reward: Personal cloud storage services in the enterprise. TechTarget. Retrieved November 27, 2013, from http://searchconsumerization.techtarget.com/tip/-Risk-vs-reward-Personal-cloudstorage-services-in-the-enterprise

Shelke, R., Kulkarni, G., Belsare, S., Palwe, R., \& Shinde, D. (2013, December). Cloud storage as service. Paper presented at the 2013 International Conference on Machine Intelligence Research and Advancement, 21-13 December 2013, Katra, Jammu and Kashmir, India: IEEE Computer Society.

Sosa-Sosa, V. J., \& Hernandez-Ramirez, E. M. (2012). A file storage service on a cloud computing environment for digital libraries. Information Technology and Libraries (Online), 31(4), 34-45.

Staimer, M. (2013, September). What to consider when storing data in the cloud. TechTarget. Retrieved April 24, 2014, from http://searchcloudstorage.techtarget.com/feature/What-to-consider-when-storing-datain-the-cloud

Stanley, C. (2013). Cloud storage options being bundled with Moto X and Lumia. Cloud Storage Us. Retrieved December 9, 2013, from http://cloudstorage.us/cloud-storageoptions-being-bundled-with-moto-X-and-lumia/1546/

Steger, H. (2012). The cloud storage services battle: What every mobile provider should know. Wireless Week. Retrieved December 9, 2013, from http://www.wirelessweek.com/articles/2012/05/cloud-storage-services-battle-whatevery-mobile-provider-should-know

Stroz Friedberg. (2013). On the pulse: Information security risk in American business. New York, NY: Stroz Friedberg.

Sullivan, D. (2014, March). What should I consider when selecting a cloud storage system? TechTarget. Retrieved April 24, 2014, from 
http://searchcloudcomputing.techtarget.com/answer/What-should-I-consider-whenselecting-a-cloud-storage-system

Swarnalatha, C., \& Prasanna, T. S. (2013). Employee engagement: An overview. International Journal of Management Research and Development, 3(1), 52-61.

Tejada , M. (2013). Study: Personal cloud computing on the rise. Midsize Insider. Retrieved November 27, 2013, from http://midsizeinsider.com/en-us/article/studypersonal-cloud-computing-on-the-r

Thomas, D. R. (2006). A general inductive approach for analyzing qualitative evaluation data. American Journal of Evaluation,, 27(2), 237-246.

Transparency Market Research. (2013). Personal cloud market - Global industry analysis, size, share, growth, trends and forecast, 2013 - 2019. Retrieved December 12, 2013, from http://www.transparencymarketresearch.com/personal-cloud-market.html

Unisys. (2010). Unisys consumerization of IT benchmark study. http://blogs.unisys.com/disruptiveittrends/files/2010/08/10-0190-CITSUMMARY_web.pdf

van Zant, K. (2009, October 29). Consumerization of IT, Part One. Solarwinds Corporate Blog. Retrieved November 29, 2013, from http://whiteboard.solarwinds.com/2009/10/29/consumerization-of-it-part-one.aspx

Venkatesh, V., \& Bala, H. (2008). Technology Acceptance Model 3 and a research agenda on interventions. Decision Sciences, 39(2), 273-315.

Vizard, M. (2010, March 9). Cloud computing forces data governance issue. IT Business Edge. Retrieved April 24, 2014, from http://www.itbusinessedge.com/cm/blogs/vizard/cloud-computing-forces-datagovernance-issue/?cs $=39920$

Wattal, S., Rachera, P., \& Mandviwalla, M. (2010). Network externalities and technology use: A quantitative analysis of intraorganizational blogs. Journal of Management Information Systems, 27(1), 145-173.

Weiß, F., \& Leimeister, J. M. (2012). Consumerization. Business \& Information Systems Engineering, 4(6), 363-366.

Wladawsky-Berger, I. (2009, April 27). Cloud - the emergence of a new model of computing. Retrieved from http://blog.irvingwb.com/blog/2009/04/cloud-theemergence-of-a-new-model-of-computing.html

Woodward, A. (2011). The consumerization of IT: A major opportunity for collaboration applications. IDC \#LT53T, Volume: 1, European Business Analytics and Social Platforms. Software and Services: Insight.

Yeasmin, S., \& Rahman, K. F. (2012). 'Triangulation' research method as the tool of social science research. BUP Journal, 1(1), 154-163. 


\section{Appendices}

\subsection{Appendix 1: Survey Questions}

\section{Questionnaires for Employees}

\section{“Managing Consumerization of Personal Cloud Storage in New Zealand Corporates"}

Q1.1 Do you use personal cloud storage (e.g. DropBox, iCloud, GoogleDrive, etc.)?

\begin{tabular}{|l|c|c|c|c|c|}
\hline & Never & Rarely & Sometimes & $\begin{array}{c}\text { Most of the } \\
\text { Time }\end{array}$ & Always \\
\hline For private use & 0 & 0 & 0 & 0 & 0 \\
For work purposes & 0 & 0 & 0 & 0 & 0 \\
\hline
\end{tabular}

Q1.2 How did you become aware of the trend for employees to use personal cloud storage for both corporate and private data?

O Reading articles

O Word-of-mouth

O This research information sheet

Other, please specify

Q1.3 Does your organization have a policy related to personal cloud storage?

O Prohibit personal cloud storage at work

O Partly prohibit it for critical tasks

O Freely allow it

O No policy

Other, please specify

Q1.4 Does your organization have any security training/awareness program about personal cloud storage?

O Yes

O No

I I don't know

Q1.5 WHAT ELSE would you like to add about your use of personal cloud storage at work? 
Q2.1 What INDUSTRY-RELATED FACTORS do you think are driving Personal Cloud Storage in the Workplace?

\begin{tabular}{|c|c|c|c|c|}
\hline & None & Low & Medium & High \\
\hline Widely available Internet with broadband and $3 \mathrm{G}$ & $\mathrm{O}$ & O & O & $\mathrm{O}$ \\
\hline Affordability of consumer devices & $\mathrm{O}$ & $\mathrm{O}$ & $\mathrm{O}$ & $\mathrm{O}$ \\
\hline $\begin{array}{l}\text { Demand for greater reaching external } \\
\text { stakeholders }\end{array}$ & $\mathrm{O}$ & $\mathrm{O}$ & $\mathrm{O}$ & $\mathrm{O}$ \\
\hline Increasing young leaders & O & O & $\mathrm{O}$ & O \\
\hline Employees from younger generation & $\mathrm{O}$ & O & 0 & O \\
\hline
\end{tabular}

Q2.2 What DEVICE / APPLICATION FACTORS do you think are driving Personal Cloud Storage in the Workplace?

\begin{tabular}{|c|c|c|c|c|}
\hline & None & Low & Medium & High \\
\hline Cloud storage readily bundled with devices & O & $\mathrm{O}$ & $\mathrm{O}$ & O \\
\hline Low cost & O & O & O & $\mathrm{O}$ \\
\hline Collaboration and social computing tools & $\mathrm{O}$ & O & O & $\mathrm{O}$ \\
\hline Processing power of consumer devices & $\mathrm{O}$ & $\mathrm{O}$ & O & $\mathrm{O}$ \\
\hline Eco-friendliness of consumer devices & $\mathrm{O}$ & $\mathrm{O}$ & O & $\mathrm{O}$ \\
\hline Always-on feature of consumer devices & $\mathrm{O}$ & O & O & O \\
\hline Capability for both information consumption and creation & $\mathrm{O}$ & O & $\mathrm{O}$ & $\mathrm{O}$ \\
\hline Ease of use & $\mathrm{O}$ & O & O & O \\
\hline Consumer devices displacing earlier technology & $\mathrm{O}$ & $\mathrm{O}$ & $\mathrm{O}$ & $\mathrm{O}$ \\
\hline Attractive / convenient form of consumer devices & $\mathrm{O}$ & O & O & $\mathrm{O}$ \\
\hline Lots of useful functionalities & $\mathrm{O}$ & $\mathrm{O}$ & $\mathrm{O}$ & $\mathrm{O}$ \\
\hline
\end{tabular}

Q2.3 What BEHAVIOURAL FACTORS do you think are driving Personal Cloud Storage in the Workplace?

\begin{tabular}{|c|c|c|c|c|}
\hline & None & Low & Medium & High \\
\hline Owning multiple devices & O & $\mathrm{O}$ & O & $\mathrm{O}$ \\
\hline Blurring of work and home & O & $\mathrm{O}$ & O & $\mathrm{O}$ \\
\hline Increasing mobility of customers and employees & O & $\mathrm{O}$ & O & $\mathrm{O}$ \\
\hline $\begin{array}{l}\text { Freedom of workplace technology expected by } \\
\text { employees and customers }\end{array}$ & 0 & 0 & O & O \\
\hline Symbol of fashion, status and curiosity & O & $\mathrm{O}$ & O & O \\
\hline Tendency to follow others in using technology & O & O & O & O \\
\hline
\end{tabular}

Q2.4 What other factors might drive Personal Cloud Storage in the Workplace? 
Q3.1 What BENEFITS can Personal Cloud Storage in the Workplace bring to organizations?

\begin{tabular}{|c|c|c|c|c|}
\hline & None & Low & Medium & High \\
\hline Accelerating business growth & O & O & O & $\mathrm{O}$ \\
\hline $\begin{array}{l}\text { Productivity through employees bringing in new } \\
\text { technology }\end{array}$ & O & O & O & O \\
\hline Employee productivity through trust & $\mathrm{O}$ & $\mathrm{O}$ & O & O \\
\hline $\begin{array}{l}\text { Productivity through employees bringing in consumer } \\
\text { behaviour / skills }\end{array}$ & O & O & O & O \\
\hline Standardization enforced by consumer vendors & O & O & O & O \\
\hline Finding newer skills through social networking websites & $\mathrm{O}$ & $\mathrm{O}$ & O & O \\
\hline Cost benefits & O & O & O & O \\
\hline Employee satisfaction / engagement & O & O & 0 & 0 \\
\hline $\begin{array}{l}\text { Innovative products / services through employee } \\
\text { innovation }\end{array}$ & 0 & 0 & 0 & 0 \\
\hline $\begin{array}{l}\text { Competitive advantage and agility with the market and } \\
\text { technology trends }\end{array}$ & 0 & 0 & 0 & 0 \\
\hline
\end{tabular}

Q3.2 What other benefits can Personal Cloud Storage in the Workplace bring to organizations?

Q4.1 What CHALLENGES can Personal Cloud Storage in the Workplace pose to organizations?

\begin{tabular}{|c|c|c|c|c|}
\hline & None & Low & Medium & High \\
\hline Immaturity of consumer technologies & O & $\mathrm{O}$ & O & $\mathrm{O}$ \\
\hline Uncertain cost boundaries/constraints & $\mathrm{O}$ & $\mathrm{O}$ & $\mathrm{O}$ & O \\
\hline Economic downturn hindering consumerization initiatives & $\mathrm{O}$ & $\mathrm{O}$ & $\mathrm{O}$ & O \\
\hline $\begin{array}{l}\text { Security challenges (Data, compliance, privacy, viruses, } \\
\text { hacks) }\end{array}$ & O & O & O & $\mathrm{O}$ \\
\hline Challenges in support and control & $\mathrm{O}$ & O & O & $\mathrm{O}$ \\
\hline $\begin{array}{l}\text { Challenges around evolving organization-wide relations } \\
\text { and expectations }\end{array}$ & O & O & $\mathrm{O}$ & $\mathrm{O}$ \\
\hline Changing policy needs & O & O & $\mathrm{O}$ & $\mathrm{O}$ \\
\hline $\begin{array}{l}\text { Organization liability for licensing breaches by } \\
\text { employees }\end{array}$ & O & $\mathrm{O}$ & $\mathrm{O}$ & $\mathrm{O}$ \\
\hline Cloud service integration and management & $\mathrm{O}$ & $\mathrm{O}$ & $\mathrm{O}$ & $\mathrm{O}$ \\
\hline Degradation of service delivery & $\mathrm{O}$ & $\mathrm{O}$ & O & $\mathrm{O}$ \\
\hline Degradation of network performance & $\mathrm{O}$ & $\mathrm{O}$ & $\mathrm{O}$ & O \\
\hline
\end{tabular}


Q4.2 What other challenges can Personal Cloud Storage in the Workplace bring to organizations?

Demography The following information is for gathering demography of participants only.

D1 What is your position level?

O Staff

O Supervisor

O Director / Business unit manager

Above director

D2 What is your organization size?

O Very small

O Small

O Medium

O Large 


\section{Questionnaires for Employers}

\section{“Managing Consumerization of Personal Cloud Storage in New Zealand Corporates"}

Q1.1 How many employees use personal cloud storage (e.g. DropBox, iCloud, GoogleDrive, etc.) in your organization?

\begin{tabular}{|l|c|c|c|c|c|c|}
\hline & None & Some & Half & Most & All & Don't know \\
\hline For private use & 0 & 0 & 0 & 0 & 0 & 0 \\
For work purposes & 0 & 0 & 0 & 0 & 0 & 0 \\
\hline
\end{tabular}

Q1.2 How did you become aware of the trend for employees to use personal cloud storage for both corporate and private data?

Reading articles

O Word-of-mouth

O This research information sheet

Other, please specify

Q1.3 Does your organization have a policy related to personal cloud storage?

Prohibit personal cloud storage at work

Partly prohibit it for critical tasks

O Freely allow it

O No policy

Other, please specify

Q1.4 Does your organization have any security training/awareness program about personal cloud storage?

O Yes

O No

O I don't know

Q1.5 WHAT ELSE would you like to add about your use of personal cloud storage at work? 
Q2.1 What INDUSTRY-RELATED FACTORS do you think are driving Personal Cloud Storage in the Workplace?

\begin{tabular}{|c|c|c|c|c|}
\hline & None & Low & Medium & High \\
\hline Widely available Internet with broadband and $3 \mathrm{G}$ & $\mathrm{O}$ & O & O & $\mathrm{O}$ \\
\hline Affordability of consumer devices & $\mathrm{O}$ & $\mathrm{O}$ & $\mathrm{O}$ & $\mathrm{O}$ \\
\hline $\begin{array}{l}\text { Demand for greater reaching external } \\
\text { stakeholders }\end{array}$ & $\mathrm{O}$ & $\mathrm{O}$ & $\mathrm{O}$ & $\mathrm{O}$ \\
\hline Increasing young leaders & O & O & $\mathrm{O}$ & O \\
\hline Employees from younger generation & $\mathrm{O}$ & $\mathrm{O}$ & O & $\mathrm{O}$ \\
\hline
\end{tabular}

Q2.2 What DEVICE / APPLICATION FACTORS do you think are driving Personal Cloud Storage in the Workplace?

\begin{tabular}{|c|c|c|c|c|}
\hline & None & Low & Medium & High \\
\hline Cloud storage readily bundled with devices & O & $\mathrm{O}$ & $\mathrm{O}$ & $\mathrm{O}$ \\
\hline Low cost & O & $\mathrm{O}$ & $\mathrm{O}$ & $\mathrm{O}$ \\
\hline Collaboration and social computing tools & $\mathrm{O}$ & $\mathrm{O}$ & $\mathrm{O}$ & $\mathrm{O}$ \\
\hline Processing power of consumer devices & $\mathrm{O}$ & O & $\mathrm{O}$ & $\mathrm{O}$ \\
\hline Eco-friendliness of consumer devices & $\mathrm{O}$ & O & $\mathrm{O}$ & $\mathrm{O}$ \\
\hline Always-on feature of consumer devices & $\mathrm{O}$ & $\mathrm{O}$ & $\mathrm{O}$ & $\mathrm{O}$ \\
\hline Capability for both information consumption and creation & $\mathrm{O}$ & O & $\mathrm{O}$ & O \\
\hline Ease of use & O & O & O & O \\
\hline Consumer devices displacing earlier technology & 0 & O & O & $\mathrm{O}$ \\
\hline Attractive / convenient form of consumer devices & $\mathrm{O}$ & $\mathrm{O}$ & $\mathrm{O}$ & O \\
\hline Lots of useful functionalities & O & O & O & O \\
\hline
\end{tabular}

Q2.3 What BEHAVIOURAL FACTORS do you think are driving Personal Cloud Storage in the Workplace?

\begin{tabular}{|c|c|c|c|c|}
\hline & None & Low & Medium & High \\
\hline Owning multiple devices & $\mathrm{O}$ & $\mathrm{O}$ & $\mathrm{O}$ & $\mathrm{O}$ \\
\hline Blurring of work and home & O & O & O & O \\
\hline Increasing mobility of customers and employees & O & O & O & O \\
\hline $\begin{array}{l}\text { Freedom of workplace technology expected by } \\
\text { employees and customers }\end{array}$ & $\mathrm{O}$ & $\mathrm{O}$ & $\mathrm{O}$ & O \\
\hline Symbol of fashion, status and curiosity & $\mathrm{O}$ & $\mathrm{O}$ & O & $\mathrm{O}$ \\
\hline Tendency to follow others in using technology & $\mathrm{O}$ & $\mathrm{O}$ & O & $\mathrm{O}$ \\
\hline
\end{tabular}

Q2.4 What other factors might drive Personal Cloud Storage in the Workplace? 
Q3.1 What BENEFITS can Personal Cloud Storage in the Workplace bring to organizations?

\begin{tabular}{|l|c|c|c|c|}
\hline Accelerating business growth & None & Low & Medium & High \\
Productivity through employees bringing in new & 0 & $O$ & 0 & 0 \\
technology & 0 & 0 & 0 & 0 \\
Employee productivity through trust & 0 & 0 & 0 & 0 \\
Productivity through employees bringing in consumer & 0 & 0 & 0 & 0 \\
behaviour / skills & 0 & 0 & 0 & 0 \\
Standardization enforced by consumer vendors & 0 & 0 & 0 & 0 \\
Finding newer skills through social networking websites & 0 & 0 & 0 & 0 \\
Cost benefits & 0 & 0 & 0 & 0 \\
Employee satisfaction / engagement & 0 & 0 & 0 & 0 \\
Innovative products / services through employee & & & & \\
innovation & 0 & 0 & 0 & 0 \\
Competitive advantage and agility with the market and & & & \\
technology trends & & 0
\end{tabular}

Q3.2 What other benefits can Personal Cloud Storage in the Workplace bring to organizations?

Q4.1 What CHALLENGES can Personal Cloud Storage in the Workplace pose to organizations?

\begin{tabular}{|c|c|c|c|c|}
\hline & None & Low & Medium & High \\
\hline Immaturity of consumer technologies & $\mathrm{O}$ & O & $\mathrm{O}$ & $\mathrm{O}$ \\
\hline Uncertain cost boundaries/constraints & O & O & O & O \\
\hline Economic downturn hindering consumerization initiatives & $\mathrm{O}$ & $\mathrm{O}$ & $\mathrm{O}$ & O \\
\hline $\begin{array}{l}\text { Security challenges (Data, compliance, privacy, viruses, } \\
\text { hacks) }\end{array}$ & O & $\mathrm{O}$ & O & $\mathrm{O}$ \\
\hline Challenges in support and control & $\mathrm{O}$ & $\mathrm{O}$ & O & $\mathrm{O}$ \\
\hline $\begin{array}{l}\text { Challenges around evolving organization-wide relations } \\
\text { and expectations }\end{array}$ & O & O & O & O \\
\hline Changing policy needs & $\mathrm{O}$ & $\mathrm{O}$ & $\mathrm{O}$ & $\mathrm{O}$ \\
\hline $\begin{array}{l}\text { Organization liability for licensing breaches by } \\
\text { employees }\end{array}$ & $\mathrm{O}$ & O & O & O \\
\hline Cloud service integration and management & $\mathrm{O}$ & $\mathrm{O}$ & $\mathrm{O}$ & $\mathrm{O}$ \\
\hline Degradation of service delivery & O & $\mathrm{O}$ & O & $\mathrm{O}$ \\
\hline Degradation of network performance & $\mathrm{O}$ & $\mathrm{O}$ & O & O \\
\hline
\end{tabular}


Q4.2 What other challenges can Personal Cloud Storage in the Workplace bring to organizations?

Q5 What would you recommend to corporates for getting the most opportunities, while reducing the risks, from the consumerization of personal cloud storage?

Demography The following information is for gathering demography of participants only.

D1 What is your position level?

O Staff

O Supervisor

O Director / Business unit manager

Above director

D2 What is your organization size?

O Very small

O Small

O Medium

O Large 


\section{Questionnaires for Cloud Service Providers}

\section{“Managing Consumerization of Personal Cloud Storage in New Zealand Corporates"}

Q1.1 What purpose might your consumers use personal cloud storage for?

\begin{tabular}{|l|c|c|c|c|c|c|}
\hline & None & Some & Half & Most & All & Don't know \\
\hline For private use & 0 & 0 & 0 & $O$ & 0 & 0 \\
For work purposes & 0 & 0 & 0 & 0 & 0 & 0 \\
\hline
\end{tabular}

Q1.2 How did you become aware of the trend for employees to use personal cloud storage for both corporate and private data?
O Reading articles
O Word-of-mouth
O This research information sheet
Other, please specify

Q1.3 Why do you think that employees might upload work files into their personal cloud storage?

\begin{tabular}{|c|c|c|c|c|}
\hline & None & Low & Medium & High \\
\hline Too much work to bring home & $\mathrm{O}$ & O & $\mathrm{O}$ & $\mathrm{O}$ \\
\hline Preference using personal devices & O & 0 & 0 & O \\
\hline Corporate policy & $\mathrm{O}$ & $\mathrm{O}$ & $\mathrm{O}$ & $\mathrm{O}$ \\
\hline Personal concern about security risks & O & O & O & 0 \\
\hline Degree of data confidentiality & O & O & O & O \\
\hline
\end{tabular}

Q1.4 WHAT ELSE would you like to add about employees using of personal cloud storage at work?

Q2.1 What INDUSTRY-RELATED FACTORS do you think are driving Personal Cloud Storage in the Workplace?

\begin{tabular}{|l|c|c|c|c|}
\hline Widely available Internet with broadband and 3G & None & Low & Medium & High \\
\hline Affordability of consumer devices & 0 & 0 & 0 & 0 \\
Demand for greater reaching external & 0 & 0 & 0 \\
stakeholders & 0 & 0 & 0 & 0 \\
Increasing young leaders & 0 & 0 & 0 & 0 \\
Employees from younger generation & 0 & 0 & 0 & 0 \\
\hline
\end{tabular}


Q2.2 What DEVICE / APPLICATION FACTORS do you think are driving Personal Cloud Storage in the Workplace?

\begin{tabular}{|c|c|c|c|c|}
\hline & None & Low & Medium & High \\
\hline Cloud storage readily bundled with devices & $\mathrm{O}$ & $\mathrm{O}$ & O & $\mathrm{O}$ \\
\hline Low cost & $\mathrm{O}$ & $\mathrm{O}$ & $\mathrm{O}$ & $\mathrm{O}$ \\
\hline Collaboration and social computing tools & O & O & O & O \\
\hline Processing power of consumer devices & O & O & O & O \\
\hline Eco-friendliness of consumer devices & $\mathrm{O}$ & $\mathrm{O}$ & $\mathrm{O}$ & O \\
\hline Always-on feature of consumer devices & $\mathrm{O}$ & $\mathrm{O}$ & $\mathrm{O}$ & O \\
\hline Capability for both information consumption and creation & $\mathrm{O}$ & $\mathrm{O}$ & $\mathrm{O}$ & O \\
\hline Ease of use & $\mathrm{O}$ & $\mathrm{O}$ & $\mathrm{O}$ & $\mathrm{O}$ \\
\hline Consumer devices displacing earlier technology & $\mathrm{O}$ & $\mathrm{O}$ & $\mathrm{O}$ & $\mathrm{O}$ \\
\hline Attractive / convenient form of consumer devices & $\mathrm{O}$ & $\mathrm{O}$ & $\mathrm{O}$ & $\mathrm{O}$ \\
\hline Lots of useful functionalities & O & O & O & O \\
\hline
\end{tabular}

Q2.3 What BEHAVIOURAL FACTORS do you think are driving Personal Cloud Storage in the Workplace?

\begin{tabular}{|c|c|c|c|c|}
\hline & None & Low & Medium & High \\
\hline Owning multiple devices & $\mathrm{O}$ & $\mathrm{O}$ & O & $\mathrm{O}$ \\
\hline Blurring of work and home & $\mathrm{O}$ & $\mathrm{O}$ & $\mathrm{O}$ & $\mathrm{O}$ \\
\hline Increasing mobility of customers and employees & O & $\mathrm{O}$ & $\mathrm{O}$ & O \\
\hline $\begin{array}{l}\text { Freedom of workplace technology expected by } \\
\text { employees and customers }\end{array}$ & O & O & O & O \\
\hline Symbol of fashion, status and curiosity & $\mathrm{O}$ & $\mathrm{O}$ & $\mathrm{O}$ & O \\
\hline Tendency to follow others in using technology & $\mathrm{O}$ & $\mathrm{O}$ & $\mathrm{O}$ & O \\
\hline
\end{tabular}

Q2.4 What other factors might drive Personal Cloud Storage in the Workplace? 
Q3.1 What BENEFITS can Personal Cloud Storage in the Workplace bring to organizations?

\begin{tabular}{|c|c|c|c|c|}
\hline & None & Low & Medium & High \\
\hline Accelerating business growth & O & O & O & $\mathrm{O}$ \\
\hline $\begin{array}{l}\text { Productivity through employees bringing in new } \\
\text { technology }\end{array}$ & O & O & O & O \\
\hline Employee productivity through trust & $\mathrm{O}$ & $\mathrm{O}$ & O & O \\
\hline $\begin{array}{l}\text { Productivity through employees bringing in consumer } \\
\text { behaviour / skills }\end{array}$ & O & O & O & O \\
\hline Standardization enforced by consumer vendors & O & O & O & O \\
\hline Finding newer skills through social networking websites & $\mathrm{O}$ & $\mathrm{O}$ & O & O \\
\hline Cost benefits & O & O & O & O \\
\hline Employee satisfaction / engagement & O & O & 0 & 0 \\
\hline $\begin{array}{l}\text { Innovative products / services through employee } \\
\text { innovation }\end{array}$ & 0 & 0 & 0 & 0 \\
\hline $\begin{array}{l}\text { Competitive advantage and agility with the market and } \\
\text { technology trends }\end{array}$ & 0 & 0 & 0 & 0 \\
\hline
\end{tabular}

Q3.2 What other benefits can Personal Cloud Storage in the Workplace bring to organizations?

Q4.1 What CHALLENGES can Personal Cloud Storage in the Workplace pose to organizations?

\begin{tabular}{|c|c|c|c|c|}
\hline & None & Low & Medium & High \\
\hline Immaturity of consumer technologies & $\mathrm{O}$ & O & $\mathrm{O}$ & $\mathrm{O}$ \\
\hline Uncertain cost boundaries/constraints & O & O & O & O \\
\hline Economic downturn hindering consumerization initiatives & $\mathrm{O}$ & $\mathrm{O}$ & $\mathrm{O}$ & O \\
\hline $\begin{array}{l}\text { Security challenges (Data, compliance, privacy, viruses, } \\
\text { hacks) }\end{array}$ & O & $\mathrm{O}$ & O & $\mathrm{O}$ \\
\hline Challenges in support and control & O & O & O & $\mathrm{O}$ \\
\hline $\begin{array}{l}\text { Challenges around evolving organization-wide relations } \\
\text { and expectations }\end{array}$ & O & O & O & O \\
\hline Changing policy needs & O & O & O & $\mathrm{O}$ \\
\hline $\begin{array}{l}\text { Organization liability for licensing breaches by } \\
\text { employees }\end{array}$ & O & O & O & O \\
\hline Cloud service integration and management & $\mathrm{O}$ & $\mathrm{O}$ & $\mathrm{O}$ & $\mathrm{O}$ \\
\hline Degradation of service delivery & O & $\mathrm{O}$ & O & $\mathrm{O}$ \\
\hline Degradation of network performance & $\mathrm{O}$ & $\mathrm{O}$ & O & O \\
\hline
\end{tabular}


Q4.2 What other challenges can Personal Cloud Storage in the Workplace bring to organizations?

Q5 What would you recommend to corporates for getting the most opportunities, while reducing the risks, from the consumerization of personal cloud storage?

Demography The following information is for gathering demography of participants only.

D1 What is your position level?

Staff

O Supervisor

O Director / Business unit manager

Above director

D2 What is your organization size?

O Very small

O Small

O Medium

O Large

\subsection{Appendix 2: Online Focus Group Questions}

1) How would CIOs or technology managers respond to this popular yet risky trend which employees use their personal cloud storage for both corporate and private data?

2) What factors might drive employees to use personal cloud storage (e.g. DropBox, GoogleDrive, iCloud, etc.) at the workplace?

3) What could be Benefits and Challenges that corporates can get from "employees using Personal Cloud Storage e.g. DropBox, iCloud at the workplace"? 


\subsection{Appendix 3: Mappings of the Conceptual Model and Survey Questions}

\begin{tabular}{lll}
\hline No & Survey Questions & Identified Drivers \\
\hline
\end{tabular}

Q2.1 Widely available Internet with broadband and $3 \mathrm{G}$

Affordability of consumer devices

Telecommunications-Infrastructure and General Affordability

Demand for greater reaching external

Externalization of businesses, cloud stakeholders

Increasing young leaders computing and partner eco systems

Average age of Leadership

Employees from younger generation

Employees from younger generation and digital natives

Q2.2 Cloud storage readily bundled with devices

Cloud bundle

Low cost

Attractive Licensing models

Collaboration and social computing tools

Processing power of consumer devices

Eco-friendliness of consumer devices

Always-on feature of consumer devices

Capability for both information consumption and creation

Ease of use

Consumer devices displacing earlier technology

Attractive / convenient form of consumer devices

Lots of useful functionalities

Collaboration and Social Computing Tools

Processing Power of Consumer Devices

Ecological Factor of Consumer Devices

Always-on feature of Consumer Devices

Usage Factor of Consumer Devices

Superior application usability

Consumer Devices as Disruptive

Technology

Form Factor of Consumer Devices

Superior application usability

Q2.3 Owning multiple devices

Plurality of Devices

Blurring of work and home

Blurring of work and home

Increasing mobility of customers and employees

Increasing mobility of customers and employees

Freedom of workplace technology expected by employees and customers

Workplace expectation of customers and employees are changing

Symbol of fashion, status and curiosity

Fashion, Status and Curiosity

Tendency to follow others in using technology

Network Externality 
Q3.1 Accelerating business growth

Productivity through employees bringing in new technology

Employee productivity through trust

Productivity through employees bringing in consumer behaviour / skills

Standardization enforced by consumer vendors

Finding newer skills through social networking websites

Cost benefits

Employee satisfaction / engagement

Innovative products / services through

employee innovation

Competitive advantage and agility with the market and technology trends
Accelerates Business Growth

Productivity through Employees bringing in New Technology

Employee Productivity through Trust

Productivity through Employees bringing in Consumer Behaviour and Skills

Standardization Enforced by Consumer Vendors

Finding Newer Skills through Social Networking Websites

Cost Benefits

Employee Engagement and Retention

Innovation

Competitive advantage and agility

\section{No Survey Questions}

Q4.1 Immaturity of consumer technologies

Uncertain cost boundaries/constraints

Economic downturn hindering

consumerization initiatives

Security challenges (Data, compliance, privacy, viruses, hacks)

Challenges in support and control

Challenges around evolving organization-wide relations and expectations

Changing policy needs

Organization liability for licensing breaches by employees

Cloud service integration and management

Degradation of service delivery

Degradation of network performance

\section{Identified Challenges}

Immaturity of Consumer Technologies

Cost Constraints and Uncertain Cost

Boundaries

Economic Downturn

Security Challenges

Challenges in Support and Control

Challenges around Evolving Relations and Expectations

Changing Policy Needs

Regulatory Obligations

Cloud service management \& integration

Service Degradation 


\section{Information Sheet for Survey Participants}

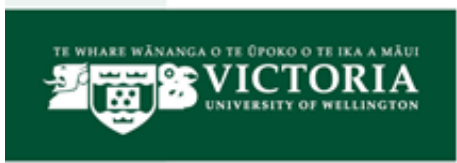

SCHOOL OF INFORMATION MANAGEMENT

TE KURA TIAKI, WHAKAWHITI KÓRERO

LEVEL 5, RUTHERFORD HOUSE, PIPITEA CAMPUS, 23 LAMBTON QUAY, WELLINGTON

PO Box 600 , Welington 6140 , New Zealand

Phone +64-4-4635103 Fax +64-4.4635446 Email sim@vww.ac.nz Website www.victoria.ac.nz/sim

\section{Information Sheet for Survey Participants}

\section{Research Project Title: Managing Consumerization of Personal Cloud Storage in New Zealand Corporates}

\section{Researcher: Soklay Ky, School of Information Management, Victoria University of Wellington}

As part of the completion of my master of information management, this study is designed to identify the drivers, corporate benefits and challenges brought by the consumerization of personal cloud storage. It investigates the current trend for employees to use personal cloud storage, originally intended for personal use, at work to manage both private and corporate data. This consumerization of personal clouds has become one of the top worldwide issues in 2013 following past years' consumerization of consumer devices. This research project will contribute to:

1 Identifying the drivers, corporate benefits and challenges brought by the consumerization;

2 Informing individuals and corporate executives about the causes and benefits of the consumerization; and

3 Being a recommendation for formulation of corporate IT policies with regard to consumerization of personal cloud storage.

In as part of this project students will conduct survey questionnaires with participants.

\section{Please note the following points:}

1. In the reporting no individuals or organizations will be identifiable. Only the student and the lecturer will have access to the raw data. All data relating to this research will be stored securely and destroyed after two years.

2. Participants can receive a copy of the student's final report on request.

3. Students are required to obtain electronic consent from each person before commencing the survey.

4. The combined data may be presented at a conference or used in a journal article. These may be stored in a Victoria University repository and be available online. All data will be aggregated so that no individual or organisation could be identified.

5. This research has been approved by the Ethics Committee of the School of Information Management.

Any questions about this research can be directed to the researcher, Soklay Ky at kysok11@myvuw.ac.nz, or the project supervisor, Dr. David Mason at xxx-xxxx or david.mason@vuw.ac.nz. 


\section{Information Sheet for Online Focus Group Participants}

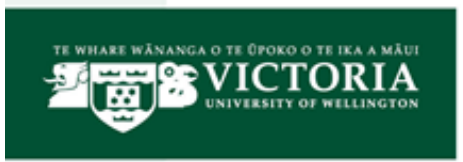

SCHOOL OF INFORMATION MANAGEMENT

TE KURA TIAKI, WHAKAWHITI KÖRERO

LEVEL 5, RUTHERFORD HOUSE, PIPITEA CAMPUS, 23 LAMBTON QUAY, WELUNGTON

PO Box 600 , Welington 6140 , New Zealand

Phone +64-4.4635103 Fax +64-4.4635446 Email sim@vuw.ac.nz Website www.victoria.ac.nz/sim

\section{Participant Information Sheet}

Research Project Title: Managing Consumerization of Personal Cloud Storage in New Zealand Corporates

\section{Researcher: Soklay Ky, School of Information Management, Victoria University of Wellington}

As part of the completion of my master of information management, this study is designed to identify the drivers, corporate benefits and challenges brought by the consumerization of personal cloud storage. It investigates the current trend for employees to use personal cloud storage, originally intended for personal use, at work to manage both private and corporate data. This consumerization of personal clouds has become one of the top worldwide issues in 2013 following past years' consumerization of consumer devices. This research project will contribute to:

1 Identifying the drivers, corporate benefits and challenges brought by the consumerization;

2 Informing individuals and corporate executives about the causes and benefits of the consumerization; and

3 Being a recommendation for formulation of corporate IT policies with regard to consumerization of personal cloud storage.

In as part of this project students will conduct online discussion forum with participants.

\section{Please note the following points:}

1. In the reporting no individuals or organizations will be identifiable. Only the student and the lecturer will have access to the raw data. All data relating to this research will be stored securely and destroyed after two years.

2. Participants can receive a copy of the student's final report on request.

3. Students are required to obtain electronic consent from each person before commencing the forum. The consent is implied by participating in the discussion forum.

4. The combined data may be presented at a conference or used in a journal article. These may be stored in a Victoria University repository and be available online. All data will be aggregated so that no individual or organisation could be identified.

5. This research has been approved by the Ethics Committee of the School of Information Management.

Any questions about this research can be directed to the researcher, Soklay Ky at kysok11@myvuw.ac.nz, or the project supervisor, Dr. David Mason at xxx-xxxx or david.mason@vuw.ac.nz. 


\subsection{Appendix 5: Detailed Table of Comparison of Findings and the Literature}

The tables below give detailed comparison of the findings from individual data sources and the literature. The elements are arranged in order of match with the literature, the top elements being the most similar and the bottom being the most different. The terms (High, Medium, Low, and None) were used to identify each recognition level. Where two of the terms with joined with a hyphen, it denotes that the left recognition status was slightly higher than that on the right.

\begin{tabular}{|c|c|c|c|c|c|c|c|c|}
\hline \multicolumn{2}{|c|}{ IDENTIFIED DRIVERS } & \multirow{3}{*}{$\begin{array}{l}\text { LITERATURE } \\
\text { Recognition }\end{array}$} & \multicolumn{4}{|c|}{ SURVEY RESPONDENTS } & \multicolumn{2}{|l|}{$\begin{array}{l}\text { FOCUS GROUP } \\
\text { PARTICIPANTS }\end{array}$} \\
\hline Ref & Drivers & & Employee & Employer & Provider & Overall & Recognition & \\
\hline & & & & & & Recognition & & \\
\hline 7.1.1 & Superior application usability & High & High & $\begin{array}{l}\text { High- } \\
\text { medium }\end{array}$ & High & High & Recognized & $\hat{\imath}$ \\
\hline 7.1.2 & Plurality of devices & High & High & High & High & High & Recognized & $\wedge$ \\
\hline 7.1.3 & Cloud bundle & High & High & $\begin{array}{l}\text { Medium- } \\
\text { high }\end{array}$ & High & High & Recognized & 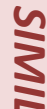 \\
\hline 7.1.4 & $\begin{array}{l}\text { Workplace expectation of customers and } \\
\text { employees are changing }\end{array}$ & Medium & $\begin{array}{l}\text { Medium- } \\
\text { high }\end{array}$ & $\begin{array}{l}\text { High- } \\
\text { medium }\end{array}$ & Medium & Medium & Recognized & $\begin{array}{l}\Delta \\
1\end{array}$ \\
\hline 7.1.5 & $\begin{array}{l}\text { Telecommunications-infrastructure and } \\
\text { general affordability }\end{array}$ & High & High & High & High & High & Not mentioned & $\hat{\wedge}$ \\
\hline 7.1.6 & $\begin{array}{l}\text { Consumer devices as disruptive } \\
\text { technology }\end{array}$ & High & $\begin{array}{l}\text { High- } \\
\text { medium }\end{array}$ & High & Medium & High & Not mentioned & $\hat{\imath}$ \\
\hline
\end{tabular}




\begin{tabular}{|c|c|c|c|c|c|c|c|}
\hline 7.1.7 & Blurring of work and home & High & $\begin{array}{l}\text { High- } \\
\text { medium }\end{array}$ & High & High & High & Not mentioned \\
\hline 7.1.8 & Usage factor of consumer devices & Medium & $\begin{array}{l}\text { Medium- } \\
\text { high }\end{array}$ & Medium & Medium & Medium & Not mentioned \\
\hline 7.1.9 & Form factor of consumer devices & Medium & Medium & High & Medium & Medium & Not mentioned \\
\hline 7.1.10 & Network externality & Medium & Medium & Medium & Low & Medium & Not mentioned \\
\hline 7.1.11 & Data hoarding & New Factor & High & High & Medium & High & Recognized \\
\hline 7.1.12 & Corporate technology limitations & New Factor & High & High & High & High & Recognized \\
\hline 7.1.13 & Corporate policy limitations & New Factor & High & Medium & High & High & Recognized \\
\hline 7.1.14 & Attractive licensing models & Low & $\begin{array}{l}\text { High- } \\
\text { medium }\end{array}$ & $\begin{array}{l}\text { High- } \\
\text { medium }\end{array}$ & High & High & Recognized \\
\hline 7.1.15 & Collaboration and social computing tools & High & $\begin{array}{l}\text { High- } \\
\text { medium }\end{array}$ & Medium & $\begin{array}{l}\text { Medium- } \\
\text { high }\end{array}$ & Medium & Recognized \\
\hline 7.1.16 & $\begin{array}{l}\text { Increasing mobility of customers and } \\
\text { employees }\end{array}$ & Medium & High & High & High & High & Recognized \\
\hline 7.1.17 & $\begin{array}{l}\text { Externalization of businesses, cloud } \\
\text { computing and partner eco systems }\end{array}$ & Medium & $\begin{array}{l}\text { Medium- } \\
\text { low }\end{array}$ & Low-high & $\begin{array}{l}\text { Low- } \\
\text { medium }\end{array}$ & Low & Recognized \\
\hline 7.1.18 & $\begin{array}{l}\text { Employees from younger generation and } \\
\text { digital natives }\end{array}$ & Low & $\begin{array}{l}\text { Medium- } \\
\text { high }\end{array}$ & Medium & Medium & Medium & Indirectly mentioned \\
\hline 7.1.19 & Average age of leadership & High & Low & Low & Medium & Low & Indirectly mentioned \\
\hline
\end{tabular}




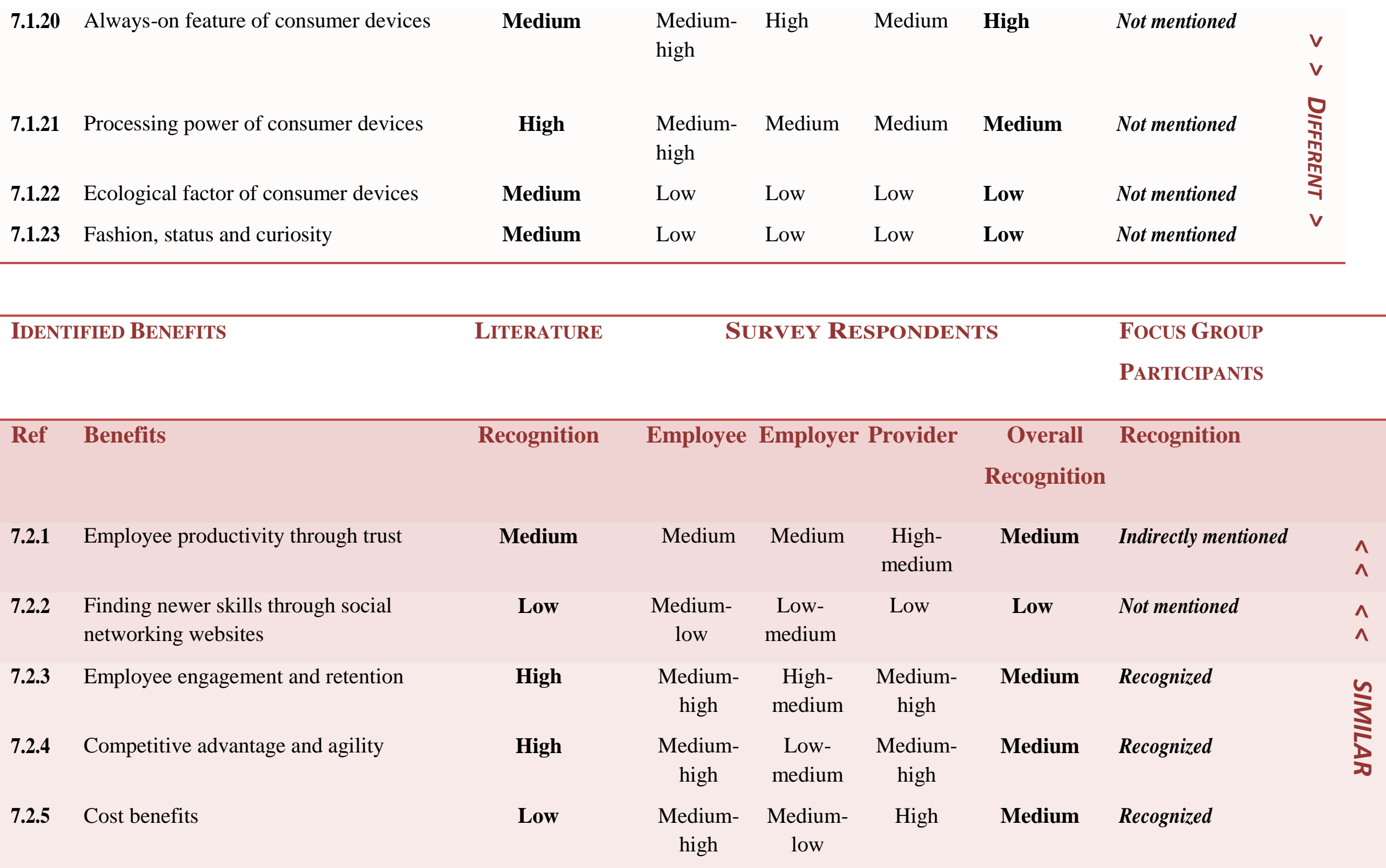


7.2.6 Productivity through employees bringing in new technology

7.2.7 Productivity through employees bringing in consumer behaviour and skills

7.2.8 Accelerates business growth

7.2.9 Innovation

7.2.10 Standardisation enforced by consumer vendors

7.2.11 Data security solution workarounds
Low

High

High

High

Medium

New Factor
Medium

Medium-

high

Medium

Medium-

low

Medium-

low

Medium

Low

Low-high

Medium

Medium-

low

Low-

medium

Low

NA

$$
\begin{aligned}
& \text { High- } \\
& \text { medium }
\end{aligned}
$$

Low

Low-

medium

NA
Medium Indirectly mentioned

Medium

Indirectly mentioned

Medium Not mentioned

Medium Not mentioned

Low Not mentioned

\section{Recognized}

Not

mentioned

\begin{tabular}{|c|c|c|c|c|c|c|c|c|}
\hline \multicolumn{2}{|c|}{ IDENTIFIED CHALLENGES } & \multirow{2}{*}{$\begin{array}{l}\text { LITERATURE } \\
\text { Recognition }\end{array}$} & \multicolumn{4}{|c|}{ SURVEY RESPONDENTS } & \multicolumn{2}{|l|}{ FOCUS GROUP } \\
\hline Ref & Challenges & & Employee & Employer & rovider & Overall & Recognition & \\
\hline & & & & \multicolumn{5}{|c|}{ Recognition } \\
\hline 7.3.1 & Security challenges & High & High & High & High & High & Recognized & $\wedge$ \\
\hline 7.3.2 & Regulatory obligations & High & High & High & High & High & Recognized & $\hat{\tilde{n}}$ \\
\hline 7.3.3 & Cloud service management and integration & Medium & $\begin{array}{l}\text { Medium- } \\
\text { high }\end{array}$ & Medium & High & Medium & Recognized & $\sum_{30}$ \\
\hline
\end{tabular}

mentioned




\begin{tabular}{|c|c|c|c|c|c|c|c|c|}
\hline 7.3.4 & Challenges in support and control & High & High & High & High & High & Not mentioned & $\hat{\Lambda}$ \\
\hline 7.3.5 & $\begin{array}{l}\text { Cost constraints and uncertain cost } \\
\text { boundaries }\end{array}$ & Medium & Medium & $\begin{array}{l}\text { Medium- } \\
\text { high }\end{array}$ & $\begin{array}{l}\text { Medium- } \\
\text { high }\end{array}$ & Medium & Not mentioned & $\hat{\hat{\Lambda}}$ \\
\hline 7.3.6 & Data governance challenges & New Factor & High & High & Medium & High & Recognized & $\hat{\Lambda}$ \\
\hline 7.3.7 & Consideration on corporate solution & New Factor & Medium & High & High & High & Recognized & $\wedge$ \\
\hline 7.3.8 & Changing policy needs & Medium & $\begin{array}{l}\text { High- } \\
\text { medium }\end{array}$ & $\begin{array}{l}\text { High- } \\
\text { medium }\end{array}$ & Medium & High & Recognized & $\begin{array}{l}\mathbf{v} \\
\mathbf{v}\end{array}$ \\
\hline 7.3.9 & $\begin{array}{l}\text { Challenges around evolving relations and } \\
\text { expectations }\end{array}$ & Low & $\begin{array}{l}\text { Medium- } \\
\text { high }\end{array}$ & High & $\begin{array}{l}\text { Medium- } \\
\text { high }\end{array}$ & High & Partially mentioned & v \\
\hline 7.3.10 & Service degradation & High & $\begin{array}{l}\text { Medium- } \\
\text { low }\end{array}$ & Low & Low & Low & Recognized & 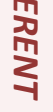 \\
\hline 7.3.11 & Immaturity of consumer technologies & High & Medium & $\begin{array}{l}\text { Medium- } \\
\text { low }\end{array}$ & High-low & Medium & Not mentioned & $\begin{array}{l}\mathbf{v} \\
\mathbf{v}\end{array}$ \\
\hline 7.3.12 & Economic downturn & High & Low & Low & Low & Low & Not mentioned & v \\
\hline
\end{tabular}


10.6 Appendix 6: Summary Table of Comparison of Findings and the Literature
Literature
* Consensus Finding (surveys \& focus group)
$\star$ Finding (only surveys)
+ Finding (only focus group)

\begin{tabular}{|c|c|c|c|c|c|c|c|c|c|}
\hline \multirow{2}{*}{ REF. } & \multirow{2}{*}{ DRIVERS } & \multicolumn{3}{|c|}{ RECOGNITION } & \multirow[b]{2}{*}{ REF. } & \multirow[b]{2}{*}{ DRIVERS } & \multicolumn{3}{|c|}{ RECOGNITION } \\
\hline & & Low & MEDIUM & HIGH & & & Low & Medium & HIGH \\
\hline \multicolumn{5}{|c|}{ General Industry } & \multicolumn{5}{|c|}{ Consumer Behaviour } \\
\hline 8.1.1 & $\begin{array}{l}\text { Telecommunications-infrastructure and } \\
\text { general affordability }\end{array}$ & & & $\theta \star$ & 8.1.13 & Plurality of devices & & & $\theta *$ \\
\hline 8.1.2 & Data hoarding & & & * & 8.1.14 & Increasing mobility of customer and employees & & $\theta$ & * \\
\hline \multicolumn{2}{|c|}{ Consumer Devices } & & & & 8.1.15 & $\begin{array}{l}\text { Workplace expectation of customers and } \\
\text { employees are changing }\end{array}$ & & $* *$ & \\
\hline 8.1.3 & Consumer devices as disruptive technology & & & $\theta \star$ & 8.1.16 & Blurring of work and home & & & $\theta \star$ \\
\hline 8.1.4 & Always-on feature of consumer devices & & $\theta$ & $\star$ & 8.1.17 & Network externality & & $\theta \star$ & \\
\hline 8.1.5 & Processing power of consumer devices & & $\star$ & $\theta$ & 8.1.18 & Fashion, status and curiosity & $\star$ & $\theta$ & \\
\hline 8.1.6 & Usage factor of consumer devices & & $\theta \star$ & & Corpol & ate Factors & & & \\
\hline 8.1.7 & Form factor of consumer devices & & $\theta \star$ & & 8.1.19 & Corporate technology limitations & & & * \\
\hline 8.1.8 & Ecological factor of consumer devices & $\star$ & $\theta$ & & 8.1.20 & Corporate policy limitations & & & * \\
\hline \multicolumn{2}{|c|}{ Consumer Applications } & & & & 8.1.21 & Employees from younger generation... & $\theta$ & $\star$ & \\
\hline 8.1.9 & Superior application usability & & & $\theta *$ & 8.1.22 & Average age of leadership & $\star$ & & $\theta$ \\
\hline 8.1.10 & Cloud bundle & & & $\theta *$ & 8.1.23 & Externalization of businesses, cloud & $\star$ & $\theta$ & \\
\hline 8.1.11 & Attractive licensing models & $\theta$ & & * & & computing and partner eco systems & & & \\
\hline 8.1.12 & Collaboration and social computing tools & & $*$ & $\theta$ & & & & & \\
\hline
\end{tabular}




\begin{tabular}{|c|c|c|c|c|c|c|c|c|c|}
\hline \multirow{2}{*}{ REF. } & \multirow{2}{*}{ BENEFITS } & \multicolumn{3}{|c|}{ RECOGNITION } & \multirow{2}{*}{ REF. } & \multirow[b]{2}{*}{ Challenges } & \multicolumn{3}{|c|}{ RECOGNITION } \\
\hline & & Low & MEDIUM & HIGH & & & Low & MEDIUM & HIGH \\
\hline 8.2 .1 & Employee engagement and retention & & * & $\theta$ & 8.3.1 & Security challenges & & & $\theta *$ \\
\hline 8.2 .2 & Competitive advantage and agility & & * & $\theta$ & 8.3.2 & Challenges in support and control & & & $\theta \star$ \\
\hline 8.2 .3 & Cost benefits & $\theta$ & $\star$ & & 8.3.3 & Regulatory obligations & & & $\theta *$ \\
\hline 8.2 .4 & Employee productivity through trust & & $* *$ & & 8.3 .4 & Changing policy needs & & $\theta$ & * \\
\hline 8.2 .5 & $\begin{array}{l}\text { Productivity through employees } \\
\text { bringing in new technology }\end{array}$ & $\theta$ & * & & 8.3.5 & $\begin{array}{l}\text { Challenges around evolving relations } \\
\text { and expectations }\end{array}$ & 0 & & * \\
\hline 8.2 .6 & $\begin{array}{l}\text { Productivity through employees bring- } \\
\text { ing in consumer behaviour and skills }\end{array}$ & & * & $\theta$ & 8.3.6 & $\begin{array}{l}\text { Cloud service management and } \\
\text { integration }\end{array}$ & & $\theta *$ & \\
\hline 8.2.7 & Data security solution workarounds & & + & & 8.3.7 & Data governance challenges & & & $\star$ \\
\hline 8.2.8 & Accelerates business growth & & $\star$ & $\theta$ & 8.3.8 & Consideration on corporate solution & & & $\star$ \\
\hline 8.2 .9 & Innovation & & $\star$ & $\theta$ & 8.3.9 & Immaturity of consumer technologies & & $\star$ & $\theta$ \\
\hline 8.2.10 & $\begin{array}{l}\text { Finding newer skills through social } \\
\text { networking websites }\end{array}$ & $\theta \star$ & & & 8.3.10 & $\begin{array}{l}\text { Cost constraints and uncertain cost } \\
\text { boundaries }\end{array}$ & & $\theta \star$ & \\
\hline \multirow[t]{2}{*}{ 8.2.11 } & $\begin{array}{l}\text { Standardisation enforced by consumer } \\
\text { vendors }\end{array}$ & $\star$ & $\theta$ & & 8.3.11 & Service degradation & * & & $\theta$ \\
\hline & & & & & 8.3.12 & Economic downturn & $\theta \star$ & & \\
\hline
\end{tabular}

Content word count: 18,498 words (excluding the title page, abstract, references, and appendices)

\section{END OF DOCUMENT}

